Florida International University FIU Digital Commons

3-29-2006

\title{
Customer relationship management : a content analysis of issues and best practices
}

Samit Chakravorti

Florida International University

DOI: $10.25148 /$ etd.FI14060135

Follow this and additional works at: https://digitalcommons.fiu.edu/etd

Part of the Business Administration, Management, and Operations Commons

\section{Recommended Citation}

Chakravorti, Samit, "Customer relationship management : a content analysis of issues and best practices" (2006). FIU Electronic Theses and Dissertations. 2103.

https://digitalcommons.fiu.edu/etd/2103 
FLORIDA INTERNATIONAL UNIVERSITY

Miami, Florida

CUSTOMER RELATIONSHIP MANAGEMENT:

A CONTENT ANALYSIS OF ISSUES AND BEST PRACTICES

A dissertation submitted in partial fulfillment of the

requirements for the degree of

DOCTOR OF PHILOSOPHY

in

BUSINESS ADMINISTRATION

by

Samit Chakravorti

2006 
To: Dean Joyce Elam

College of Business Administration

This dissertation, written by Samit Chakravorti, and entitled Customer Relationship Management: A Content Analysis of Issues and Best Practices, having been approved in respect to style and intellectual content, is referred to you for judgment.

We have read this dissertation and recommend that it be approved.

Barnett Greenberg

Kimberly Taylor

Christos Koulamas

Peter R. Dickson, Major Professor

Date of Defense: March 29, 2006

The dissertation of Samit Chakravorti is approved.

\begin{tabular}{r} 
Dean Joyce Elam \\
College of Business Administration \\
\hline Interim Dean Stephan L. Mintz \\
University Graduate School
\end{tabular}

Florida International University, 2006 


\section{DEDICATION}

I dedicate this dissertation to all positive human endeavors 


\section{ACKNOWLEDGMENTS}

Acknowledgments are due to a number of people. First and foremost I would like to specially thank my chair Dr. Peter Dickson without whose active mentoring and help it would not have been possible for me to successfully complete the program. I learned a lot from him.

I would also like to thank my committee members, Dr. Kimberly Taylor, Dr. Barnett Greenberg, and Dr. Christos Koulamas for their timely and instructive feedback.

I thank my colleagues Cecelia and Shazad for their support through the program, the faculty for the experience and knowledge I gained in the seminars, and the department secretaries Hilda and Anna for their help. I also thank Ruth Chapman who helped me edit my document.

Last but not least I thank my family for believing in me and my friends for motivating me. 


\section{ABSTRACT OF THE DISSERTATION \\ CUSTOMER RELATIONSHIP MANAGEMENT:}

A CONTENT ANALYSIS OF ISSUES AND BEST PRACTICES

by

Samit Chakravorti

Florida International University, 2006

Miami, Florida

Professor Peter R. Dickson, Major Professor

This dissertation is a study of customer relationship management theory and practice. Customer Relationship Management (CRM) is a business strategy whereby companies build strong relationships with existing and prospective customers with the goal of increasing organizational profitability. It is also a learning process involving managing change in processes, people, and technology. CRM implementation and its ramifications are also not completely understood as evidenced by the high number of failures in CRM implementation in organizations and the resulting disappointments.

The goal of this dissertation is to study emerging issues and trends in CRM, including the effect of computer software and the accompanying new management processes on organizations, and the dynamics of the alignment of marketing, sales and services, and all other functions responsible for delivering customers a satisfying experience.

In order to understand CRM better a content analysis of more than a hundred articles and documents from academic and industry sources was undertaken using a new methodological twist to the traditional method. An Internet domain name 
(http://crm.fiu.edu) was created for the purpose of this research by uploading an initial one hundred plus abstracts of articles and documents onto it to form a knowledge database. Once the database was formed a search engine was developed to enable the search of abstracts using relevant CRM keywords to reveal emergent dominant CRM topics. The ultimate aim of this website is to serve as an information hub for CRM research, as well as a search engine where interested parties can enter CRM-relevant keywords or phrases to access abstracts, as well as submit abstracts to enrich the knowledge hub.

Research questions were investigated and answered by content analyzing the interpretation and discussion of dominant CRM topics and then amalgamating the findings. This was supported by comparisons within and across individual, paired, and sets-of-three occurrences of CRM keywords in the article abstracts.

Results show that there is a lack of holistic thinking and discussion of CRM in both academics and industry which is required to understand how the people, process, and technology in CRM impact each other to affect successful implementation. Industry has to get their heads around CRM and holistically understand how these important dimensions affect each other. Only then will organizational learning occur, and overtime result in superior processes leading to strong profitable customer relationships and a hard to imitate competitive advantage. 
INTRODUCTION

Overview

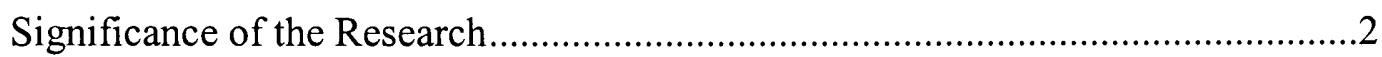

Objectives and Purpose of the Research ...............................................................6

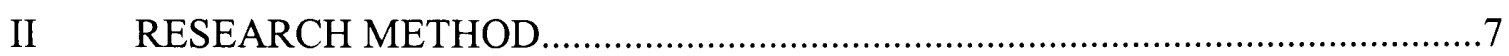

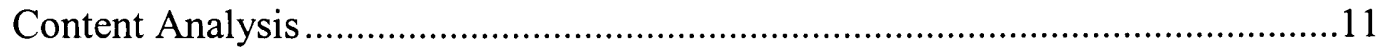

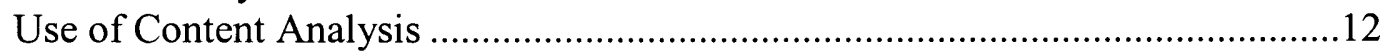

Planning the Content Analysis.........................................................................14

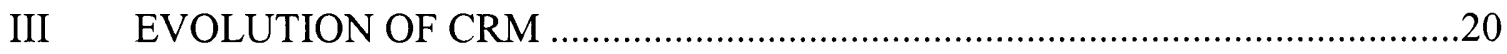

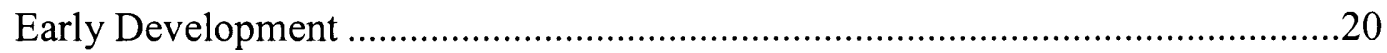

Rise of Relationship Marketing …...................................................................21

Advancement of Marketing Information Technology .......................................23

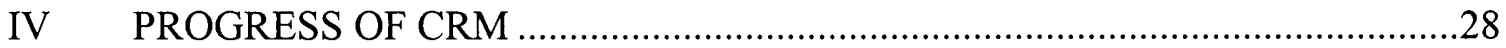

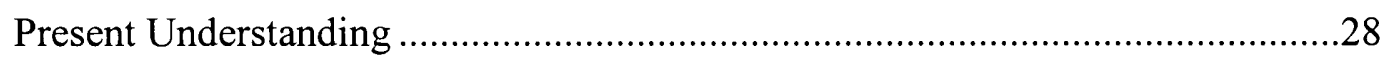

Definitions of Customer Relationship Management...........................................29

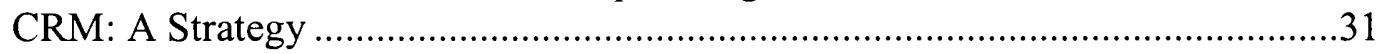

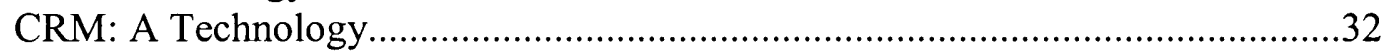

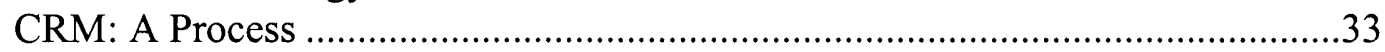

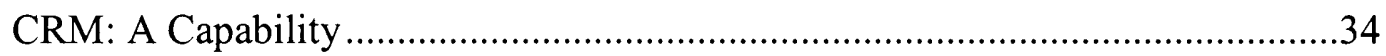

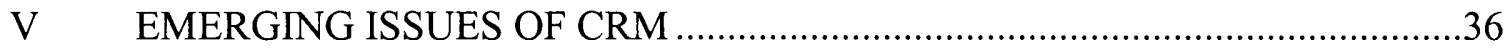

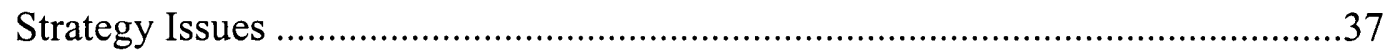

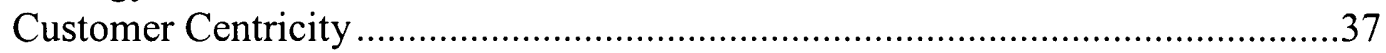

Shared Customer Vision and Goals ..................................................................42

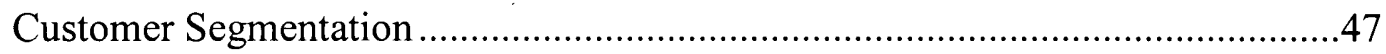

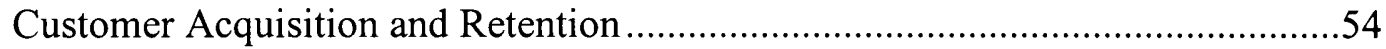

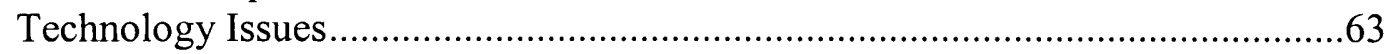

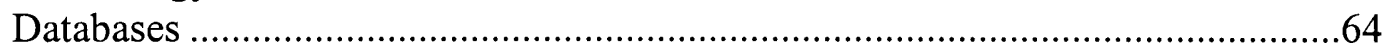

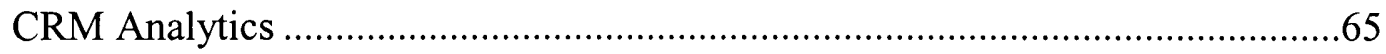

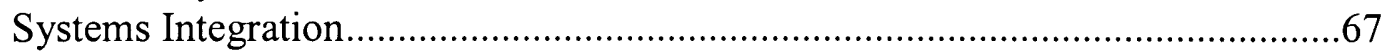

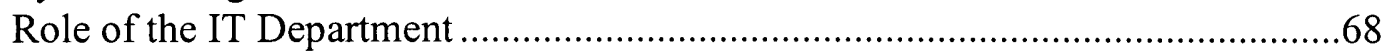

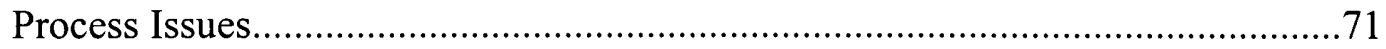

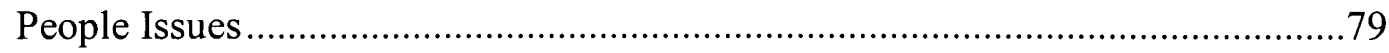

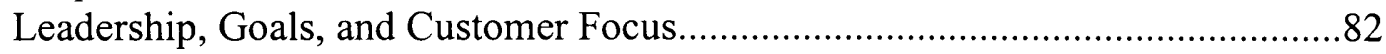

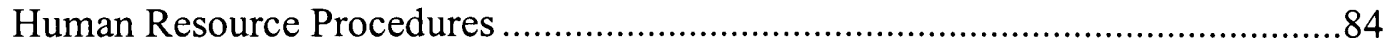

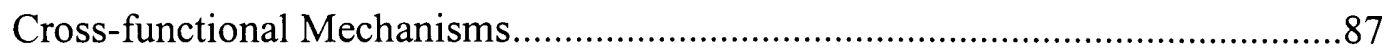

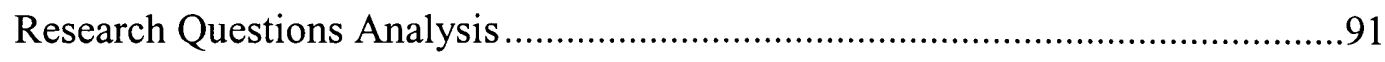




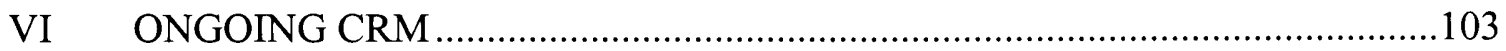

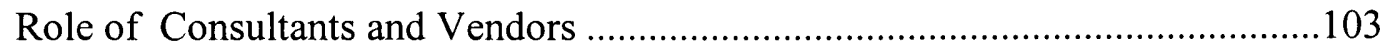

Role of Marketing in a CRM Organization .......................................................115

CRM and Organizational Networks..............................................................122

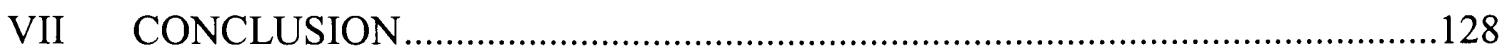

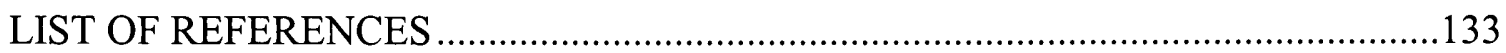

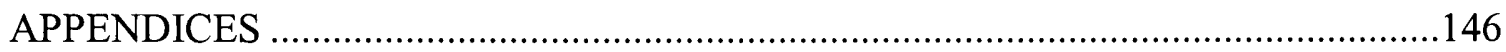

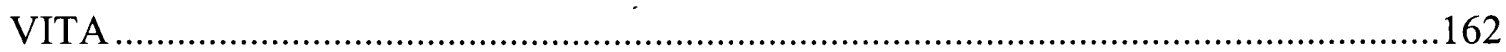




\section{LIST OF TABLES}

TABLE

PAGE

1. Constructs and Categories for Content Analysis

2. Article Sources for Content Analysis

3. Individual Mentions of Categories in Article Abstracts

4. Combination Mentions of Segmentation with other Categories in Article Abstracts 94

5. Combination Mentions of Categories (in pairs) in Article Abstracts

6. Combination Mentions of Categories (in sets of three) in Article Abstracts

7. 2005 CRM Market Leaders and Winners 


\section{LIST OF FIGURES}

FIGURE

PAGE

1. Nested CRM Organization Processes (Dickson et al. 2005)

2. Market-Relating Capability (Day 2000a)

3. CRM Process (Zablah et al. 2004)

4. CRM Process (Payne and Frow 2005)

5. CRM Organization: A Cross-Sectional View 


\section{CHAPTER I: \\ INTRODUCTION}

\section{Overview}

This dissertation is a study of customer relationship management theory and practice. Customer Relationship Management (CRM) is a business strategy whereby companies build strong relationships with existing and prospective customers with the goal of increasing organizational profitability. It is also a learning process involving managing change in processes, people, and technology. The fact that successful customer relationship management capability is not easily imitated hints at the organizational embeddedness and difficulty in its successful achievement. CRM implementation and its ramifications are also not completely understood.

The goal of this dissertation is to study emerging issues and trends in CRM, including the effect of computer software and the accompanying new management processes on organizations, and the dynamics of the alignment of marketing, sales and services, and all other functions responsible for delivering customers a satisfying experience.

In order to understand CRM better a content analysis of more than a hundred articles and documents from academic and industry sources was undertaken using a new methodological twist to the traditional method. An Internet domain name (http://crm.fiu.edu) was created for the purpose of this research by uploading an initial one hundred plus abstracts of articles and documents onto it to form a knowledge database. Once the database was formed a search engine was developed to enable the search of abstracts using relevant CRM keywords to reveal emergent dominant CRM 
topics. The ultimate aim of this website is to serve as an information hub for CRM research, as well as a search engine where interested parties can enter CRM-relevant keywords or phrases to access abstracts, as well as submit abstracts to enrich the knowledge hub. It is hoped that the site will become a dynamic source of learning for emerging CRM issues and best practices and over time be employed by a learning network of academics and practitioners. Thus, this dissertation will tell a story about $\mathrm{CRM}$ by uncovering emerging trends of customer relationship management and the learning paths it is taking.

Research into CRM is scarce in the academic marketing discipline and this exploration provides a modest but solid foundation for conducting further research into CRM. CRM is a valuable business model and, if properly implemented, can be an important driver of organizational profits, customer loyalty and competitive advantage. At least this has been the experience of a number of CRM pioneers who have successfully implemented customer relationship management.

$\underline{\text { Significance of the Research }}$

It is common knowledge that it is lot more expensive to acquire new customers than retain existing ones. In order to be more efficient and effective in their operations companies are striving to foster long-term, deep, rich and profitable relationships with their customers. This requires measurement and knowledge of customers' current and potential profitability, their preferences for products and services, and their channel and contact preferences. It also requires uniform and customized customer interactions at all customer touch points, and the ability to forecast customer needs in order to cross-sell and up-sell products and services to specific customers. 
It is thus understandable that companies, seeking first mover advantage, are quickly implementing technologies which they hope will increase profits by satisfying and retaining existing customers. Customer Relationship Management (CRM) is one such technology.

Why CRM? In virtually every industry and every global region, forward-looking organizations are investing in customer relationship management (CRM) technology to support the adoption of more customer centric strategies. "Organizations that understand sooner than others the strategic value of CRM technology to achieve dramatic increases in revenue, productivity, and customer satisfaction will have a significant lead on their competitors who lag in the adoption of this technology" (Siebel eBusiness 2001, p. 1). The goal is to improve a company's marketing, selling and service processes. An IBM CRM Global Survey in 2004 of over 370 companies in The Economist Intelligence Unit's global executive panel found that CRM is a high priority. Results have been mixed. The survey found that CRM adopters are completely satisfied with results only 15 percent of the time and 85 percent of companies, large and small, have not been fully successful in introducing CRM. The survey also emphasized that with careful planning and introduction the likelihood of CRM success can be bolstered to more than 70 percent (Badgett, Ballou and LaValle 2004). So where is it that companies that have been early innovators in the adoption of CRM, are going wrong and what are the secrets of the small percentage of companies who have been fully successful? What is the link between CRM technology implementation and successful customer retention and profitability? The answer lies beyond simple technology adoption, within the organization itself, its people and processes. 
The importance and criticality of CRM for the long term success of organizations, coupled with the skewed and incomplete understanding of it by the industry, makes it a topic worthy of detailed investigation. Moreover, marketing academics have investigated CRM from varying viewpoints and found that there has been no deliberate attempt to consolidate the conceptualizations into a holistic understanding, with the exception of Zablah, Bellenger and Johnston (2004). This is important given the nascent and evolving nature of CRM.

To mention some of the important veins of academic CRM scholarship, Day (1994, 1999, 2000a, 2000b, and 2003) has concerned himself with CRM as strategic market-relating processes and capabilities, Zablah et al. (2004) with knowledge management and interaction processes, Reinartz and Kumar (2000, 2002, 2003), Kumar and Shah (2004), and Venkatesan and Kumar (2004) with customer loyalty, profitability, acquisition and retention. Very little space and thought have been devoted to the people management issues of CRM implementation. Moreover, except for Zablah et al. (2004) no concerted efforts have been made in academia to incorporate the thoughts and findings of consultants and software vendors in order to enrich the academic understanding of CRM. Consultants and software vendors together have had thousands of experiences in implementing CRM into their customer/client organizations and this experience is a fitting complement to academic knowledge.

For example, Siebel Systems' experience with more than 3000 CRM initiatives has shown that the most successful companies approach CRM as a complete business strategy, one involving change throughout the organization, with the objective of 
improving how the company sells to, markets and provides services to its customers (Siebel eBusiness, 2001).

The stance taken by Marketing academics towards CRM is evidenced from the contents of the special CRM section in the Journal of Marketing's October 2005 issue.. There was only one article by Adrian Payne and Pennie Frow which took a holistic look at CRM but did not explain how the processes laid out would be integrated crossfunctionally. The rest nine articles included in that section dealt with empirical investigations of the effect of CRM micro processes on CRM outcomes. Even though these were laudable efforts in empirically establishing a business model, their conclusions have already been reported in industry case-studies of successful implementation of CRM. What is more crucially needed is an understanding of how the whole organization comes together to implement CRM, how CRM changes the roles and processes of an organization and how these processes can be made to run smoothly. Consultants can definitely make a meaningful contribution here, but surprisingly there was only one article from the consultant's point of view in this special section of the Journal of Marketing.

It is thus important to understand the underlying causes of the success and failure of CRM implementation and of its long term adoption. This dissertation is a starting point for such an ongoing effort; it is an amalgamation of thoughts and interpretations on CRM from both the academic as well as the industrial perspective. It takes a holistic look at CRM through a combination of the perspectives of academia, industry and consultants, and thus extends the understanding of the field. The goal here is to study what effect the software and the accompanying new management processes are having on a company, its 
customers and its profitability, and the dynamics of the alignment of marketing, sales and services -- all the functions responsible for giving customers a satisfying experience. This process of discovery should help industry and academia to better understand the importance of the role and the interplay of technology, processes and people in customer relationship management.

\section{Purpose and Objectives of the Research}

The overall purpose in undertaking this research flows from the importance of the research highlighted above. The purpose behind this effort is to clarify the understanding of Customer Relationship Management by exploring its evolving nature and requirements. More specifically, the objectives are to determine how CRM can be managed and applied successfully for the benefit of both the organization and its customers, break the technology mindset of organizations about CRM, investigate the role marketing will or should play in a CRM-centric organization, and also speculate on where CRM organizations are headed in the future. CRM innovation has become synonymous with technology initiative powered by IT and analytics. To break this narrow mindset, which has landed companies in trouble in their efforts at implementing CRM, one must strive to present a comprehensive picture of CRM as it relates to an organization. These research objectives can be translated into the following research questions, which will be explored and addressed in this dissertation:

1. How will CRM change the customer segmentation processes?

2. What is the strategic impact of CRM on cross-functional integration and collaboration within the firm? 
3. Will technology and cross-functional collaboration reinforce each other leading to a learning cycle?

4. What kind of change management is needed to bring about the organizational transition required for CRM?

5. If integration of marketing, sales and customer service is required for CRM implementation, what will these departments look like at the end of such integration?

Given the radical and evolving nature of the CRM business model as compared to existing or previous models, traditional roles of functions are bound to change in a CRM-Centric organization. I explore in which direction CRM efforts are likely to take an organization and what role marketing will play in this change.

\section{CHAPTER II}

\section{RESEARCH METHOD}

A content analysis of articles and documents from academic and industrial sources was undertaken utilizing a new methodological twist to the traditional method with the help of the Internet. The process involved creating a domain (http://crm.fiu.edu) primarily for the purpose of this research, uploading abstracts of articles and documents onto it to form an expert/knowledge database and then running searches to unearth discussion of emerging dominant topics in CRM.

As far as content analysis for the present research, over one hundred abstracts have been uploaded to the website. The process commenced with searching for CRM 
related documents in both academic and industrial literature. 114 articles were finally selected for content analysis. One and two page abstracts were developed for each article including critical comments of the abstractor and these were then uploaded onto the domain to create a database. As mentioned earlier, the domain which also acts as a search engine was then used to check for the frequencies of CRM relevant categories and unearth discussion of emerging dominant CRM topics. As more abstracts are uploaded the analysis will be enriched. As academics and practitioners take advantage of this site in the future and upload their contributing abstracts, the width and depth of analysis and knowledge about CRM will continue to increase

Such online content analytic procedure will not only help overcome the inefficiencies of the cumbersome manual coding process of traditional content analysis, but will also be a methodological contribution to research with the ultimate consequence of knowledge enrichment through information sharing and contribution.

The nascent stage of CRM implementation in industry along with the high percentage of disillusionment associated with it, the importance of CRM for corporate profitability, and the budding stage of academic research in CRM, call for an exploratory method of investigation. This exploratory research will pool industrial and academic knowledge about successful CRM implementation. The effort will help identify best practices in CRM implementation and usage in industry, clarify the issues that have been explored, and provide answers to questions. At the same time, it will expose additional concerns and questions which are critical to the understanding and execution of CRM implementation and adoption, which will then need to be further explored by both industry and academia. 
Issues and best practices regarding CRM implementation are still emerging and positive trends have not yet been defined; organizations and consultants are still grappling with implementation issues and adoption problems, and academic research is only budding. Therefore it was deemed appropriate to do a content analysis of articles and documents both from academic journals and industry sources on CRM. Research in CRM is still not deep and rich enough to do a meta-analysis. Content analysis also has advantages compared to more traditional analysis techniques such as primary surveys and interviews. Content analytic procedures operate directly on texts of communications, which is a central aspect of social interaction. Further, compared with surveys and interviews, content analysis yields unobtrusive measures in which the people involved with the creation of the document are not aware that it is being analyzed; thus bias is reduced during data collection (GAO 1996; Weber 1985, p. 10).

Content analysis is concerned with answering descriptive and impact questions from communications about social processes. The research objective here is expressed in the form of descriptive and impact questions. When this is coupled with the fact that the information to be collected is in the form of written text, content analysis was deemed to be an effective research method. At the same time a new method, the creation of which by itself is a contribution, is being used. For creating this online database one or two page abstracts critically summarizing, discussing and analyzing the dominant topics in each article, were developed of the 114 articles on CRM from academic and industrial literature. Each abstract also included the abstractor's comments. Once the database was created searches were run on the domain using CRM related keywords to unearth emerging dominant topics in CRM. The discussion in these article abstracts were then 
amalgamated and analyzed together to draw inferences. The online version thus will allow more flexibility and ease of adding more abstracts to the existing knowledge database in turn allowing better management of the information. The search engine will facilitate interested parties to narrow down and target a specific issue in CRM, and the search results and analyses will become richer as people upload more and more abstracts. This will allow a dynamic form of content analysis to evolve as information builds on information with the result that the academic community will benefit. The ultimate aim of this domain is to serve as an information hub for CRM research, as well as a search engine where interested parties can enter CRM-relevant keywords or phrases to access abstracts, as well as submit abstracts to enrich the knowledge hub. Thus the online content analytic procedure will not only help overcome the inefficiencies of the cumbersome manual coding process of traditional content analysis, but will also be a methodological contribution to research with the ultimate consequence of knowledge enrichment through information sharing and contribution.

The online domain also offers some unique advantages when compared with other CRM related websites. It was compared with three major CRM domains: 1) Teradata Center for Customer Relationship Management in Duke University, 2) CRMProject.com, a joint effort by Montgomery Research and Accenture, and 3) IBM CRM. All of these websites have made landmark strides in helping clients and disseminating and enhancing CRM knowledge and expertise. At the same time crm.fiu.edu makes some unique contributions. First of all the domain acts both as a database and as a search engine allowing downloading as well as uploading of CRM information. Neither Teradata nor CRMProject serves this dual purpose. IBM has both these functionalities in its website, 
but IBM's database is highly complex and technical making it difficult to navigate and find the right information easily. The crm.fiu.edu website is comparatively much simpler. Part of the simplicity lies in the abstracts in the database. An abstract is a critical summary in a couple of pages of the main topics discussed in an article. It also includes the abstracters comments, making it easier as well as enriching for both academics and industry to achieve an understanding of the issues of CRM. The IBM site does not contain abstracts and the abstracts in the Teradata site are far too short to give a critical overview of the documents. To make this understanding more holistic crm.fiu.edu includes perspectives from both academics and industry. CRMProject.com which otherwise is an excellent source of CRM knowledge largely excludes academic thinking on CRM. Overall the domain created in this dissertation gives the freedom to academic and industry researchers as well as organizations not only to customize their search with whatever aspect of CRM they want to use as keywords which helps them to understand the linkages and impacts of keywords on each other, it also allows them to upload their own knowledge to the database enriching it overtime. Adequately developed over time it will act as a fitting complement to domains like CRMProject.com. The website is still in its infancy and needs to be developed. Search engine functionality will have to be bolstered, the database will have to be enriched by adding more abstracts, case studies, video lectures to enhance the knowledge of business students, and interviews with thought leaders.

\section{Content Analysis}

In content analysis evaluators/researchers classify the key ideas in a written communication, such as a report, article or film. The main focus is on analyzing the 
principal idea in the written text and make suitable inferences from the data through a classification process. "It is a systematic research method for analyzing textual information in a standardized way that allow evaluators to make inferences about the information" (Krippendorf 1980 p. 21-27; Weber 1990 p. 9-12).

The classification process breaks down the textual data and assigns them to meaningful categories which later help in forming associations between them and making inferences from these associations. These categories come out of initial literature review and the research questions to be evaluated through the content analysis. The categories are used to define the major research constructs or topics under investigation. To classify a document's key ideas the evaluator identifies its themes, issues and topics over time, in different situations and from different groups. Thus content analysis not only helps to summarize the formal content of the written material, it also describes the attitudes and perceptions of the author. In the present research, content analysis will help integrate the perceptions and attitudes of academic and industry experts towards CRM, its implementation, its impact on customer satisfaction and profitability, and also facilitate effective analysis and thorough understanding of the issues involved. This interpretive research will be a firm stepping stone for further evaluation of CRM using other forms of quantitative research methods based on surveys or qualitative analysis of interviews.

\section{$\underline{\text { Use of Content Analysis }}$}

Since content analysis is capable of accepting relatively unstructured symbolic communications as data and also since most social processes are transacted through symbols, the widest use of content analysis is found in the social sciences and humanities. However, other disciplines like Information Systems, have started to realize the benefit of 
content analysis (Ang \& Endshaw 1997; Davidson 1997; Phillips 1998). Phillips (1998) employed public discourse analysis to reveal the way in which concerns about anonymity, surveillance, security and privacy are integrated into public understanding of a consumer payment system. Davidson (1997) employed narrative analysis to analyze project history narratives contained in research interviews. Ang and Endeshaw (1997) drew from legal case analysis to develop an approach for representing prototypical disputes in IT management. Common uses of content analysis have been in the following areas (Krippendorf 1980 p. 33-34):

- $\quad$ to describe trends in communication content

- to audit communication content against objectives

- to expose propaganda techniques

- $\quad$ to identify the intentions and other characteristics of the communicators

- $\quad$ to determine the psychological states of people and groups

- $\quad$ to secure military intelligence

- $\quad$ to reflect attitudes, interests and values

- $\quad$ to describe the attitudinal and behavioral responses to communications The essence of content analysis and the above examples of its applications make it an effective tool in exploring the research issues and questions posed in this dissertation. Moreover, the online version makes the method more flexible, and the analysis richer over time thanks to its dynamic nature. 
The four planning steps of a content analysis are, identifying and defining the constructs and categories to be studied, selecting the material to be analyzed, defining the recording units, and developing an analysis plan (GAO 1996).

Identifying and defining the constructs and categories: The research constructs are derived from the research questions expounded above and also from the documents chosen for content analysis. These constructs are conceptualized and then broken down into further categories for analysis. Conceptualizing a construct is the process of identifying subjects, those things or events that will help answer the question. The categories emerging out of this exercise from each construct can be used as keywords while searching for abstracts in the domain. The four major topics or constructs that are highly relevant to CRM and investigated in this dissertation are strategy, process, people, and technology. These four constructs were generated from review of literature on CRM in both academia and trade. Because of the broad nature of these constructs, each of these were then broken down into several categories that help define it as shown in Table1. This categorization process was based on how these constructs were discussed in the articles and what elements were associated with each. For example the construct process was discussed differently as processes of learning, resource allocation, collaboration, knowledge management etc. All these were related to the process aspect of CRM and thus all of them together define the process construct. The strategy, people and technology constructs were broken down into categories in a similar process of literature exploration. It was necessary to break down the constructs into categories because the constructs are too broad and searches run with the constructs on the online search engine 
would not have brought out the links and connections between the underlying categories which are important to understand CRM at a granular level. At the same time due to the evolving nature of CRM, the categories are also evolving and this dissertation may not include all possible terms used by academics and practitioners to describe the constructs. In other words, as the understanding of CRM grows, new categories will be used to describe and explain a construct. Also, as more and more abstracts are added to the domain, the database will become enriched and result in more successful searches across a wider range of categories. This will deepen and broaden the understanding of CRM. Table 1 shows the four CRM related constructs and the range of categories.

Selecting material for analysis: A variety of documents from a variety of sources was used as a sample, not only because this enriches the analysis but also because it clarifies differing attitudes and perceptions. This is essential to get a grasp of the real issues, particularly when these issues or their effect on the outcome (company profitability, customer loyalty) are not clearly understood. Traditional content analysis demands this diversity in contents. Even though generalization to the population of any research finding is important, the primary objective of this research is to understand the underlying issues of CRM and its importance for organizational profitability. Thus it was more practical to use non-probabilistic sampling. CRM is an organizational model and a wide variety of documents will be directly and indirectly applicable to CRM. To be more specific however I have predominantly selected articles which directly mention and discuss CRM. A small portion of the articles however discuss issues directly related to CRM such as change management. Even though these did not use the term CRM (and this in a few cases was because the CRM term was not commonly used when the article 
was written) the articles did discuss one or more of the four major constructs. In essence those articles were chosen which either discussed CRM and/or any of its constructs: strategy, people, process and technology. This process facilitated generation of a wide variety of categories to be used as keywords in searches. Initial literature review helped us determine that CRM consists of the four main constructs of strategy, process, people and technology and we selected articles which discussed these. Other peripheral articles even though indirectly related to CRM were left out of selection for this dissertation. The article search and screening process resulted in a final count of 114 articles from a wide variety of academic and industry literature which were then abstracted in a couple of pages and uploaded onto the domain to create a database. Table 2 gives a list of sources from both academia and industry that formed the basis for the content analysis.

Defining the recording unit: The recording unit in a content analysis is a portion of the text to which a researcher applies a category label. A recording unit could be a word, sentence, paragraph, theme or even the whole text. Even though frequency of a certain relevant word may be useful for analysis, words can have different meanings and are more complete only when taken in the context of a sentence or a theme. Therefore, careful consideration has to be given to the context in which certain words or phrases are found. Each article abstract acts as a recording unit in this content analysis. The search engine will look for matching keywords (categories) in the text of an abstract in the database and bring up abstracts that contain those keywords. Even though an abstract is the recording unit in this case the context in which the keywords or phrases are used in the abstract will lead to richer and more diverse inferences and interpretations. 
CONSTRUCTS AND CATEGORIES FOR CONTENT ANALYSIS

\begin{tabular}{|c|c|c|}
\hline Constructs & & Categories \\
\hline Strategy & $\begin{array}{ll}\text { - } & \text { Profitability } \\
- & \text { Segmentation } \\
\text { - } & \text { Loyalty } \\
\text { - } & \text { Retention } \\
\text { - } & \text { Capabilities } \\
\text { - } & \text { Customer Centric } \\
- & \text { Acquisition } \\
- & \text { Shared Vision } \\
\end{array}$ & \\
\hline People & $\begin{array}{ll}- & \text { Change Management } \\
- & \text { Training } \\
- & \text { Teams } \\
- & \text { Leadership } \\
- & \text { Cooperation } \\
- & \text { Hiring } \\
\text { - } & \text { Restructuring } \\
\end{array}$ & \\
\hline Process & $\begin{array}{ll}- & \text { Metrics } \\
- & \text { Learning } \\
- & \text { Resource Allocation } \\
- & \text { Collaboration } \\
- & \text { Cross functional } \\
-\quad & \text { Information sharing } \\
- & \text { Process thinking } \\
-\quad & \text { Knowledge Management } \\
\end{array}$ & \\
\hline Technology & $\begin{array}{ll}- & \text { ERP } \\
- & \text { Data base } \\
- & \text { Analytics } \\
- & \text { Data mining } \\
- & \text { Systems integration } \\
\end{array}$ & \\
\hline
\end{tabular}

Developing an analysis plan: This is the final step of the planning process and this links the data back to the research questions. A number of analysis patterns will be used to obtain a proper understanding of the issues involved, answer the research questions and make further inferences. The analysis pattern will include:

- Identifying occurrence of a category in the article abstracts: Presence or absence of a category determines, to an extent, the relevancy of the category to the outcome or the process: e.g., absence or presence of positive or negative views 
Table 2

ARTICLE SOURCES FOR CONTENT ANALYSIS

\begin{tabular}{|c|c|c|c|}
\hline $\begin{array}{l}\text { Academic } \\
\text { Journals }\end{array}$ & $\begin{array}{l}\text { Company } \\
\text { Journals }\end{array}$ & $\begin{array}{c}\text { Trade } \\
\text { Magazines }\end{array}$ & Websites \\
\hline $\begin{array}{l}\text { Journal of Marketing } \\
\text {-Journal of Sales } \\
\text { Management \& Personal } \\
\text { Selling } \\
\text {-Knowledge } \\
\text { Management } \\
\text {-Academy of Marketing } \\
\text { Science } \\
\text {-MIS Quarterly } \\
\text {-Organization Science } \\
\text {-Business Process } \\
\text { Management } \\
\text {-Harvard Business } \\
\text { Review } \\
\text {-Sloan Management } \\
\text { Review }\end{array}$ & $\begin{array}{l}\text {-IBM } \\
\text {-Siebel } \\
\text {-Oracle } \\
\text {-PeopleSoft } \\
\text {-Microsoft } \\
\text {-Teradata } \\
\text {-Bain \& } \\
\text { Company }\end{array}$ & $\begin{array}{l}\text {-Sales \& Marketing } \\
\text { Management } \\
\text {-CRM Daily } \\
\text {-Customer } \\
\text { Relationship } \\
\text { Management }\end{array}$ & $\begin{array}{l}\text {-Destination CRM.com } \\
\text {-CRMguru. } \\
\text { com } \\
\text {-Line56.com } \\
\text {-Siebel.com } \\
\text {-Oracle.com } \\
\text {-PeopleSoft. } \\
\text { com } \\
\text {-IBM.com } \\
\text {-Accenture. } \\
\text { Com } \\
\text {-Computerworld.com } \\
\text {-Optimizemag.com } \\
\text { TechnologyEvaluation.com } \\
\text {-CRM Project.com } \\
\text {-McKinsey.com }\end{array}$ \\
\hline
\end{tabular}

expressed by authors. To perform this, searches done by using specific categories will be included. The number of abstracts returned in a search result should give an indication of the importance or the relevancy of that category. This can be compared to the corresponding number of documents returned from another search conducted with a different category. Comparison within and across individual, paired, and in sets-of-three occurrences of categories in the article abstracts will also help highlight the stage of 
thinking about CRM existing in both - academia and industry and underscore the degree and need of holistic thinking about CRM.

- Descriptive Analysis: This narration will probe and answer the research questions posed supported by the objective comparison mentioned above. Inferences will also be drawn about emerging trends in CRM implementation and adoption and its possible long term effects on companies and their customers. The presence or absence of categories in the abstracts and comparison of their individual, paired, and sets-of-three occurrences in the article abstracts, along with the width and depth of search results, will help in subjectively and objectively evaluating issues important and critical to CRM implementation. Also, what academic and industry experts say about how these issues and factors will be evaluated. This will give insights into emerging thoughts and trends, current thought processes about CRM, allow logical speculation on the path that CRM will follow and its future role. It will'also be interesting and instructional to follow the development of CRM in industry given the mixed results organizations have had so far. The narration will track the evolution of CRM toward the possible goal as industry and academia learn about the success factors in CRM and the best way to implement them. What role marketing plays down the road or what it needs to do to play a deciding role in a CRM organization will also be examined.

The above mentioned analyses will help bring out the key ideas relevant to CRM implementation, the associations between the factors critical to CRM implementation, how to manage those factors, and how it will lead to the desired outcomes of enhanced organizational profitability and customer retention. This will also help identify emerging trends of CRM and possible outcomes for the future. 


\section{CHAPTER III \\ EVOLUTION OF CRM}

\section{Early Development}

Although CRM is a recent acronym for Customer Relationship Management, the model has been in use since the first millennium BCE (www.Salesboom.com). Customer Relationship Management began as a practice after early Mesopotamians learned farming and ended up with more crops than they could eat, thus wishing to trade their surplus products. Early merchants kept accurate business records on clay tablets, keeping track of what products were sold to which customers, when and in what quantities. CRM was thus born in the commercial ancient world and diffused through the centuries, sometimes namelessly and sometimes under different names, until half of the $20^{\text {th }}$ Century had passed. It is only then that certain radical changes in the commercial world helped CRM begin to take shape in its present form.

The 1980's saw the evolution of database marketing, which is the practice of setting up customer service groups to communicate individually to all of a company's customers, and using customer information for better targeting, tailoring and tying (Cespedes and Smith 1993; Roberts 2004). For larger clients it was a valuable tool to maintain communication and tailor services and products for clients. As companies tracked database information they realized the most important data to collect included what customers buy regularly, how much they spend and what they do. In the 1990's CRM transformed into something more than just a contact management and information tool. It began evolving into a two-way customer oriented strategy that enhanced customer experiences and automated processes easily and efficiently for the first time in 
the history of commerce (www.salesboom.com). CRM software vendors catered mostly to large companies who could afford expensive, lengthy CRM deployments. Mediumand small-size companies were left out. The history changed dramatically in the current millennium with the emergence of more advanced solutions that can be customized across industries. This provided for dynamic use of information in company databases and large-scale utilization of the Internet technology for economically communicating, sharing and using information in ways not possible before. With increased fluidity of these technological programs and the expansion of Relationship Marketing, came less rigid relationship between marketing, sales, and customer service. Today most companies are rushing to implement CRM because of its distinctive advantages in the areas of customer service and technology.

Rise of Relationship Marketing

Relationship Marketing emerged as a popular new paradigm in the 1980's. This happened, in part, as a result of a shift in focus from customer acquisition to customer retention (Sheth 2002). Three factors were responsible for the rise of the popularity of Relationship Marketing in the late 1980's and early 1990s.

First, because of the energy crisis in 1970 and the consequent economic stagflation there was excess capacity and high raw material costs. Competition intensified on a global basis in consumer electronics, textiles, steel, chemicals and other industries. American companies realized that they needed to defensively focus on retaining customers and lower acquisition related marketing expenditures and other activities. This resulted in the emergence of the ongoing relational exchange in contrast to one-time transactional exchange (Sheth, Garden, and Garrett 1988). 
The second factor emerged in the form of services marketing, which was becoming a popular new domain for research and understanding (Sheth 2002). Leonard Berry was the first scholar in services marketing to coin the phrase "relationship marketing" as early as 1983 (Berry 1983). Relationship Marketing got a boost because services are generally direct offerings to end users (telephone, banking) and there are usually direct records of transactions over time with each individual customer, enabling researchers to analyze and theorize about customer loyalty and one-to-one marketing (Peppers and Rogers 1993).

Finally stimulated by the quality drive in the 1980s (Total Quality Management philosophy) and a desire to reduce the number of suppliers to improve quality at lower costs, most companies in business-to-business markets began to establish key account, national account and global account management processes and programs to consolidate and increase share of each account's business to fewer suppliers (Sheth 2002).

Relationship Marketing, also called one-to-one marketing, shifts the focus of marketing exchange from transactions to relationships with individual customers (Buttle 1996; Christopher, Payne and Ballantyne1991; Foss and Stone 2001; Peck et al. 1999). The essence and nature of these relationships and their value to the business can be varied and has been explored. The markets that fall within the realm of Relationship Marketing are internal markets, referral markets, supplier and alliance markets, recruitment markets, and influence markets. Relationships in all these markets contribute to the market effectiveness of the organization (Christopher et al. 1991; Peck et al. 1999). To put the concepts of Relationship Marketing into practice firms need to identify the customers they want to enhance and maintain relationships with, differentiate each customer as to 
their unique needs and preferences, interact with those customers to enhance customer learning and finally customize products and services for each customer. This process of customer relationship management requires information and communication processes to be in place, as well as technology and data repositories of customer data. The better and more sophisticated these are the more they will enable Relationship Marketing.

\section{Advancement of Marketing Information Technology}

Since the development of the Relationship Marketing paradigm, one of the main forces shaping the business environment, has been the information technology (IT) revolution. It is only about 50 years ago that the first mainframe computer was developed, 35 years since the introduction of the personal computer and 20 years since the Internet was introduced, and yet their influence on business operations is pervasive. The paradigm of Relationship Marketing also formed the basis for much of the thinking behind Information Technology (IT) based Customer Relationship Management (CRM) systems (Holland \& Naude 2004). The role that developments in IT have played in defining the role of marketing goes much deeper than just CRM systems. The impact of IT on business has been so dramatic and encompassing that it is no longer appropriate to view IT as an external agent causing change. The use of information systems is now embedded in organizations to such an extent that a more appropriate way of viewing the inter-relationships between IT and marketing theory is to conceptualize marketing primarily as an information-handling problem targeted at enhancing customer experiences and company profitability (Holland \& Naude 2004). This informational aspect of Relationship Marketing theory is being revisited to take into account the tremendous developments in the power of IT (Haeckel \& Nolan 1993; Naude \& Holland 
1996; Verity 1995). When relationship marketing tasks such as customer analysis, development of marketing strategy, communication and collaboration with customers and distributors are viewed as information intensive relationship development problems, it becomes much easier to understand and interpret the role of IT because the relationship marketing task is expressed in information terms which can be closely related to the development of new IT-based relationship marketing systems. The following example helps to underscore the importance of Information Technology to Relationship Marketing activities.

In the process of implementing Relationship Marketing, Levi Strauss \& Co. is making mass customization an instrument of customer satisfaction. In a score of the company's stores, women can purchase a "personal pair" of blue jeans. These jeans are custom-manufactured to the customer's exact size and fit. To produce these perfectly fitting jeans, the customer and Levi Strauss must collaborate and share information. However the genius in the process is the customization process itself. This customization is possible with technology bought by Levi Strauss (Pitta 1998). This customization also requires acquisition and management of a large amount of customer information. Marketing information is thus becoming a key strategic issue for organizations (Fletcher and Peter 1996).

Implementation of marketing strategy is being affected by development along two dimensions -- that of addressability (the ability to individualize offers) and that of responsiveness (the degree of two-way communication possible between customers and firms) (Blattberg and Deighton 1991). These developments have been supported by the increased role of IT in designing and implementing marketing strategies. The main thrust 
of IT utilization within the firm has moved away from a concentration on improving process efficiency alone. It is developing as an enabler for information production and distribution within the firm, as well as a tool for adding value externally to customers and suppliers through real time communication and customized product offerings.

IT systems that facilitate the utilization of customer information for innovation of products and services, can provide opportunities for firms to enhance and create satisfactions thus encouraging loyalty in customers through stronger ties. For example, hotels record and utilize customer feedback information and then customize offerings according to the accommodation preferences cited by the customer in the previous visit. Handhelds display relevant customer information. At Marriott guests are reminded by their waiter of previous breakfast choices and asked whether they would like to change their breakfast order for that day (Peters 1997).

IT systems used in facilitating one-to-one marketing lend themselves to economies of scope rather than simply those of scale. These systems are called "systems of scope" (Boynton 1993). "Systems of scope are designed to maintain stable, permanent reservoirs and conduits of knowledge about internal capabilities or experience as well as capabilities of competitors. They are designed to be dynamically responsive for managers who have a need to know and must be able to access firm-wide knowledge in response to local, fast changing business environments" (Boynton 1993, p. 63). Such IT capabilities will thus help broaden and deepen the scope of the product/service offerings, exploit customer knowledge, and define the business according to the customers the company both understands and serves best (Blattberg and Deighton 1991). An example is the Virgin brand name that includes not only music, but travel, food, and personal 
finance -- all driven by an understanding of the core Virgin customer. Thus, records of customer purchase behavior held and accessed on a database will become the primary marketing resource of many firms. Technology helps gain and store actual transaction behavior which can lend greater accuracy and confidence to managerial decision making. In return, the customer may benefit from customized and specially targeted promotions which help to increase their satisfaction. For example, a regular wine purchaser may be invited to a special wine tasting with a wine expert (Peters 1997).

Another type of IT system outlined by Boynton is the "Vertical System," where the information relating to market and product changes is disseminated in real time to those managers within the organization who evaluate and allocate resources. These systems allow optimal use of resources through real time feedback and information. One of the fundamental principles of this system is a dedication to knowledge sharing. These two types of IT systems, the system of scope and the vertical system are termed by Boynton as "systems of knowing" because they involve developing, gathering, storing and disseminating of various types and levels of information (Boynton 1993). Information technology, through the appropriate use of customer information, can facilitate goal satisfaction and compatibility between the firm and its customers and provide ways in which to recognize and enhance the long-term value of customers. At the same time what makes IT-enabled Relationship Marketing strategies both powerful and unique is their impact on and interaction with parties outside the immediate firmcustomer relationship, such as partners, suppliers, and regulatory or legislative bodies (Peters 1997). Taking an information view of Relationship Marketing we also see how technologies such as data warehousing permit firms to focus on the individual buying 
unit. Database marketing and data mining help in the process of knowledge discovery in databases. Database marketing is based on analyzing customer databases using techniques such as interactive querying, and predictive modeling to select existing customers more accurately. The technique is so familiar that Business Week reported that over 50 percent of U.S. retailers use database marketing with good results (Pitta 1998). Data mining is more descriptive and focused on finding patterns that help marketers make better decisions. As technology and techniques have developed segmentation and target marketing initiatives have sharpened. Research findings support the inclusion of an IT dimension through the range of transactional-relational marketing continuum, where sections along this continuum are matched to the stages of IT sophistication (Brady, Saren, and Tzokas 2002). With a dominant transactional marketing approach there is a focus on IT at the automation stage of IT assimilation. For relationally focused marketing there is greater IT focus at the informational stage of assimilation. All the above mentioned benefits of technology come at a cost however: cost of training to increase the statistical and database skills of marketers, cost of crossfunctional collaboration, and costs of information technology resources which can run to millions of dollars. Hence managers must carefully analyze the costs versus potential payoff of technology deployment in Relationship Marketing. The Relationship Marketing Concept thus supported by developments in Information Technology formed the foundation for the development of Customer Relationship Management.

Marketers must however realize that IT assimilation in marketing is not always change-oriented or beneficial. IT can simply reinforce existing behaviors rather than change them for the better (Davies \& Mitchell 1994; Douzou \& Legare 1994). IT has no 
inherent ability to introduce change and is just an enabler rather than a driver for change. Change must therefore occur before IT can enable implementation of CRM (Applegate 1994).

\section{CHAPTER IV \\ PROGRESS OF CRM}

\section{Present Understanding}

The disappointing experiences of companies with CRM underscore the incomplete and faulty understanding about Customer Relationship Management. This is evidenced by the fact that, while most companies have been unsuccessful in reaping all of the expected benefits of Customer Relationship Management, a handful of companies have done it right.

Customer Relationship Management today is most popularly seen as a technological innovation (harking back to one of its foundation pillars) which, when installed in companies, enhances customer satisfaction and boosts company revenues and profits (Badgett, Ballou, and LaValle 2004; Kale 2004; Petersen 2004; Schultz 2000). This is not particularly surprising considering that CRM evolved a decade ago as a technological innovation from sales force automation. Advancement in information, computing and database technologies have expanded the opportunities of companies to glean increasingly deeper information about their customers and trends and, in turn, to exploit all this insight into customized offerings. This should help companies implement the precepts of relationship marketing more effectively through the provision and 
analysis of customer information. However, software vendors have been touting the value of their applications and literally pushing their products onto companies across industries with big promises of perfect information and higher returns. This has been done without consideration of unique objectives of companies, differing needs and structures across markets and industries and the organizational nature of the CRM model. Thus, in the beginning of this millennium, Customer Relationship Management in its infancy was misunderstood as a mere-technological tool, resulting in many disappointments.

The story just begins here. Over the last few years a handful of companies like Harrah's International and Dell began to attract the attention of industry, consultants and academics. They were curious about whether CRM was just another fad or a genuine leap in business innovation.

People started to understand that the essence of Customer Relationship Management is not just CRM software with capabilities of integrating marketing, sales and customer service but something much larger at the organizational level. At the same time, consistency and consensus in the definition of what Customer Relationship Management is has not evolved. The only known fact is that, technology only forms a necessary part of CRM.

\section{Definitions of Customer Relationship Management}

Definitions of Customer Relationship Management have been as varied as its understanding. This is evident in the increasing importance of CRM to industry and academics and its evolutionary nature. A common and clear conceptualization is still lacking; proper understanding of CRM is necessary before it can be effectively managed. 
A review of academic and industry literature, as well of company websites of top CRM software manufacturers and consultants, yielded 45 distinct definitions of CRM (Zablah et al. 2004). The analysis brought out five broad conceptualizations about CRM. CRM has been conceptualized as: (1) a strategy (e.g., Adenbajo 2003; CRM Guru 2003; Croteau and Li 2003; Deck 2003; Deștination CRM 2002; Tan, Yen, and Fang 2002; Verhoef and Donkors 2001); (2) a technological tool (e.g., Gefen and Ridings 2002; Shoemaker 2001; (3) a process (e.g., Day \& Van den Bulte 2002; Galbreath \& Rogers 1999; Gonroos 2000; Plakoyiannaki \& Tzokas 2002; Reinartz, Kraft, and Hoyer 2003; Srivastava et al. 1999); (4) a capability (e.g Day 1999, 2000a, 2000b, 2000c, 2003; Peppers, Rogers, and Dorf 1999); and (5) a philosophy (e.g., Fairhurst 2001; Hasan 2003). There were also cases where the authors simultaneously professed multiple perspectives (e.g. Kim, Suh, and Hwang 2003; Pantazopoulos 2003; Rigby, Reichheld, and Schefter 2002).

Keeping in mind the varied and sometimes overlapping conceptualizations of CRM, industry today appears to have selected the following three dimensions of Customer Relationship Management. These are Analytical CRM, Operational CRM and Collaborative CRM. Analytical CRM is concerned with applying sophisticated analytical tools to transactional data stored in data warehouses to uncover future trends and purchasing patterns of customers. Operational CRM promises business processes that will optimize management of relationships with customers. Collaborative CRM is all about collaboration and integration of resources within the organization and between itself, its business partners, and its customers (Paas and Kuijlen 2001). 
Strategy is defined as an "overall plan for deploying resources to establish a favorable position" (Grant 1998, p. 14). The 'CRM as a strategy' view emphasizes that customers vary in loyalty and profitability. Relationships must therefore be managed differently or selectively and resources deployed accordingly (Cholewka 2000; Hopkins, Lusher, and Manasco 1999; Langerak and Verhoef 2003; Paas and Kuijlen 2001; Park and Kim 2003; Winer 2001; Zeithmal, Rust, and Lemon 2001). These resources deployed for relationship development and maintenance must be allocated based on customers' lifetime value to the firm or customer equity (CRM Guru 2003; Kracklauer, Passenhiem, and Serfert 2001; Tan et al. 2002). Lifetime value of a customer or customer equity is the estimated net profits earned by the company over the course of the relationship with that customer. It is the contribution of each customer over his or her lifetime towards offsetting the company's fixed costs (Blattberg and Deighton 1996). Enhancing profitability of customers requires optimally balancing acquisition and retention spending and resource deployment leading to optimal rates of acquisition and retention (Blattberg and Deighton 1996; Reinartz, Thomas, and Kumar 2005). Balancing acquisition with retention and keeping optimal rates of each is crucial for profitability because expenditure for both acquisition and retention show diminishing marginal associations with the likelihood of customer acquisition, lifetime duration and customer profitability (Reinartz et al. 2005). The right type of relationship is the more profitable relationship, which in some instances, implies choosing not to build one at all (Verhoef and Donkers 2001). "The focus of this view is not on how relationships are developed and maintained, but more so on how building the right type of relationships can have a 
substantial positive impact on corporate profitability" (Zablah et al. 2004, p. 478). Hence the overwhelming notion here is to manage a portfolio of customer relationships to maximize profitability.

\section{CRM: A Technology}

It was the emergence of CRM technology that propelled relationship management to the forefront of marketing practice. Even so, today the enlightened both in industry and academia do not view Customer Relationship Management as an exclusively technological venture. Technology's effect on the overall success of the firm's relationship management effort has been found to be weak to moderate (Day and Van den Bulte 2002; Reinartz et al. 2003). "In fact, one of the most common views expressed in the literature is that "CRM is much more than technology" and that a lack of understanding about its true nature is, in part responsible for the failure of numerous CRM initiatives" (Zablah et al. 2004, p. 479).

In short, quality CRM technology and customer data-base creation and management is necessary but not sufficient for successful implementation of CRM strategy. CRM as a strategy is overwhelmingly concerned about customer profitability. CRM as a technology helps achieve this through development of massive systems databases which store transaction data gathered from all corners of the organization, analytical tools which allow segmentation based on transactions, calculation of customer lifetime values and net present value (NPV) of marketing campaigns, churn modeling, data-mining (analysis of trends and future purchase patterns) so that products and services can be properly targeted. An additional component of the technology that is less frequently discussed is technology that improves collaboration and communication with 
colleagues, partners, and customers (Bose 2002; Chen and Popovich 2003; Greenberg 2001; Xevelonakis 2005). Speaking in IT terms, CRM is a matter of complex integration of hardware, software and application.

\section{CRM: A Process}

A business process is a set or series of activities that convert organizational resources into outcomes (Davenport and Beers 1995). Processes can be categorized into higher and lower level (macro and micro levels respectively) processes working at different organizational levels. Macro level processes are highly aggregated processes made up of a number of sub-processes. These sub-processes could themselves be aggregates of more micro level processes.

CRM has been defined both as a macro level and a micro level process. Srivastava et al. (1999) define CRM ás a highly aggregated process of building profitable and mutually beneficial relationships with customers that include numerous subprocesses such as prospect identification and customer knowledge creation. This macro view of CRM is shared by others (Plakoyiannaki and Tzokas 2002; Reinartz et al. 2003). The process view of CRM taken by Payne and Brown (2005) includes the five interlinked sub-processes of strategy development, value creation, multi-channel integration, information management and performance assessment. CRM is primarily concerned with enhancing customer relationships through improving marketing, sales and customer service of customized products and services. Thus Siebel, the CRM software and consultant company (now acquired by Oracle), sees CRM as a aggregate macro level process subsuming interlinked sales management, marketing management, customer 
service and product development sub-processes across the organization (Siebel 2001 and 2002).

Yet others have defined CRM less broadly as a process that is concerned with managing only customer interactions for the purpose of developing and maintaining longterm, profitable customer relationships (Day and Van den Bulte 2002; Kohli et al. 2001). This micro level customer interaction process view of CRM could be merged into the macro level process view of CRM if customer interaction is considered as one of the sub processes.

"Regardless of the level of aggregation used to define CRM, this process view is different from all others in that it accounts for the process aspects of relationship development and maintenance. That is, the process perspective is the only one that overtly acknowledges that buyer-seller relationships develop over time (i.e are characterized by a life-cycle)" (Zablah et al. 2004, p. 477). Academia seems to favor this process view of CRM. At the same time, this macro process level conceptualization is still evolving and remains in a evolving state of aggregation. Therefore, it is critical to determine and to agree upon what sub-processes are subsumed under this macro CRM process. This is required to get a clear view and understanding of CRM and obtain the most benefit from it.

\section{CRM : A Capability}

Academia has realized that if buyer-seller relationships are to persist and develop over the long-term as professed by the process view of CRM, organizations need to continuously adapt their behavior toward individual customers. This ability to continuously adapt behavior toward satisfying individual customers is the essence of the 
capability view of CRM (Day 1994, 2003; Peppers et al. 1999). "Capabilities refer to the capacity for a team of resources to perform some task or activity. While resources are the source of a firm's capabilities, capabilities are the main source of its competitive advantage" (Grant 1991, p. 119). Capabilities arise out of complex, knowledge based resources and is difficult to imitate or purchase (Grant 1991). The link between the process and capability conceptualizations of CRM is established from Day's definition of capabilities. "Capabilities are complex bundles of skills and accumulated knowledge, exercised through organizational processes, that enable firms to coordinate activities and make use of their assets" (Day 1994, p. 38). This seems to suggest that performing complex business processes through allocation of adequate resources facilitates continuous modification of behaviors to suit individual customers resulting in the development of unique capabilities. Two such unique CRM capabilities are market sensing capability and customer-linking capability.

Market-sensing capability is characterized by organization-wide generation of market intelligence across departments, and organization wide responsiveness to it. "Market-driven firms are distinguished by an ability to sense events and trends in their markets ahead of their competitors. They can anticipate more accurately the responses to actions designed to retain or attract customers, improve channel relations or thwart competitors" (Day 1994, p. 44).

Customer-linking capability is creating and managing close customer relationships. This requires purposeful collaboration with cooperation between functions, joint problem solving and coordination of activities like joint production planning and scheduling. Thus both marketing sensing capability and customer-linking capability 
together subsume analytical capabilities, integration capabilities, operational capabilities, learning capabilities and process thinking capabilities of market driven organizations (Day 1994; Dickson et al. 2005; Plakoyiannaki and Tzokas 2002).

\section{CHAPTER V}

\section{EMERGING ISSUES OF CRM}

It has been sometime since organizations started implementing CRM and, for the most part, they are still grappling with the concept. The learning curve of CRM has been steep and many have faltered along the way. Part of the reason is the organizationally broad nature of CRM which demands a strategic organization-wide approach towards understanding and implementation. However, successful CRM implementation by companies like Harrah's Entertainment, Dell, Wal-Mart, Tesco, FedEx, Corning and a handful of others have resulted in higher profitability and greater customer loyalty. Also emerging empirical research on CRM has shown strong associations between CRM implementation and profitability as well as developed models based on CRM data and principles that help organizations to acquire and retain profitable customers (Cao and Gruca 2005; Gustafsson, Johnson, and Roos 2005; Jayachandran et al. 2005; Mithas, Krishnan, and Forrell 2005; Ryals 2005). Thus CRM as a business strategic model is here to stay and organizations have to wrap their thinking and processes around it in order to ascertain their survival and growth. In this chapter the emerging issues and trends of Customer Relationship Management are analyzed and discussed. The analysis is broken down into discussions of issues in strategy, process, people and technology. 
The organizational approach toward Customer Relationship Management should be strategic since it should be dictated by the vision and goals of the company. Vision and goals of companies will, in most cases, vary depending on type of industry, competition and company resources, with the one common thread being the goal of enhancing customer satisfaction, loyalty, and company profitability. The following is a discussion of what organizations need to keep in mind to strategically align CRM with, and embed it in the company vision and goals.

\section{Customer Centricity}

Over time, the belief system of an organization and the resulting attitude toward work shape the behaviors of its people. One of the biggest obstacles facing companies in implementation of CRM is resistance from company culture (as pointed out by 22 percent of respondents from the Insight Interactive Survey about CRM). To overcome such a challenge organizations need to overhaul attitudes and adopt a customer-centric business model. This is essential since successful CRM is primarily a human-to-human interaction activity with the goal of increasing customer loyalty through marketing, sales, service, pricing and regeneration of business opportunities (Swift 2003). A customercentric model is oriented towards customers. Customer orientation involves activities and behaviors implemented to reflect the degree to which needs and desires of the customer are the basis of the firm's market philosophy (Boles et al. 2001). "Customer orientation is described as a philosophy and behavior directed towards determining and understanding the needs of the target customer and adapting the selling organization's 
response in order to satisfy those needs better than the competition, thereby creating a competitive advantage" (Boles et al. 2001, p. 273).

A 2002 survey of 219 IT professionals by DMR Consulting revealed that, while non-customer-centric companies met an average of just $53 \%$ of their stated goals for a project, companies rated as being customer-centric met $71 \%$ of their implementation goals. Before an organization can expect its culture to be customer-centric it has to adopt a market orientation. Customer orientation is a behavioral component of market orientation and the more market-oriented the organization, the more customer-oriented its culture and people will be ( Siguaw, Brown, and Widing 1994). Being market-oriented is a critical step towards successful implementation of CRM because of its positive influence on profitability (Narver and Slater 1990) and because of its positive impact on directing the organization's focus towards creating customer value (Day 1994; Han, Namwoom, and Srivastava 1998). Customer orientation has also been shown to positively influence service workers' performance ratings (Brown et al. 2002).

Research has also shown the effect in the other direction, that overall job satisfaction of employees, as well as their satisfaction with work, co workers, supervision, and promotion, lead to customer-orientation (Hoffman and Ingram 1992). The importance of customer-centricity to CRM has been stressed by Yim, Anderson, and Swaminathan (2004). The authors discuss and empirically test the four dimensions of CRM; these dimensions are based on four specific organizational activities. For successful implementation of one of these four organizational activities/dimensions, "Organizing Around CRM," there needs to be a presence of a customer-focused culture. "Organizing Around CRM" was shown to positively affect customer retention directly 
and sales growth indirectly (Yim et al. 2004). Day (2000) also sees customer orientation as a key element of market relating capability, which interacts with and reinforces the other two elements "knowledge and skills" and "integration and alignment of processes" to enhance capabilities and learning on an ongoing basis.

A good example of customer centricity is exhibited in the effort made by Canadian Pacific Hotels to attract the business traveler segment, a notoriously demanding group. To change their orientation from serving large tour groups they began by learning in great depth about this segment to find what would most satisfy them (Day 2000). To develop a relation-specific knowledge and skills, and create the organizational capability to deliver on their promise "..they began by mapping each step of the "guest experience" from check-in and parking valet to checkout and setting a standard of performance for each activity...The management structure was changed, so each hotel had a champion with broad, cross-functional authority to ensure the hotel lived up to its ambitious commitment. Finally, they put further systems and incentives in place to make sure every property was in compliance and performance was meeting or exceeding the standards" (Day 2000, p. 26-27). Another example of the importance of customer centricity to successful CRM comes from the experience of Bosc, one of the largest mutual building societies in the UK (Dibb and Meadows 2004). As far as technology and handling customer data are concerned, Bosc has responded effectively to the need for investment in these areas. At the same time the company is struggling with the softer side of the CRM implementation: the company and its staff. "Even though the technology and the rich information is available it is less clear to what extent the belief in one-to-one and relationship marketing prevails at all levels in the organization" (Dibb and Meadows 
2004, p. 119). The authors believe that for customer orientation to diffuse throughout the organization it needs all departments to adopt a consistent strategy and approach.

Literature shows that superior leadership involvement, stronger interfunctional coordination, and use of more intelligence organization wide to make decisions, are logically central to the implementation of customer orientation (Kennedy, Goolsby, and Arnould 2003). This was evidenced in an ethnographic paired comparison study of the implementation processes of customer orientation in two public district schools (Kennedy et al. 2003). Observations suggest that successful implementation of customer orientation depended on an unbroken circuit of commitment and communication down the chain of hierarchy from senior leaders to workers. Data suggest that a "philosophical questioning of the true aim of the school and a personalizing of the resultant insights lead to an internalized customer orientation (Kennedy et al. 2003, p. 75). At the progressing site, staff seldom mentioned senior leaders; stakeholders considered the impetus for change local. In contrast at the struggling site, staff often cited senior leaders' mandate as the driving force for change (Kennedy et al. 2003). The progressive site created an internal system "..by which they identified fifth -grade teachers as the customers of fourth-grade teachers, fourth-grade teachers of third grade teachers and so forth, until the entire school was a tightly connected interfunctional system of customers meeting other customers' requirements" (Kennedy et al 2003, p. 74). At the struggling school, however, there was “... much less enthusiasm and an inward focus prevailed. ... Although teachers were organized into grade-level teams, minimal communication occurred across the teams; rivalry and blame tossing occurred regularly" (Kenndy et al. 2003, p. 74). Also at the progressive site a desire to make decisions based on robust data rather than 
gut feeling emerged, whereas at the struggling site far less importance was placed on using information to make decisions. "Throughout the progressive site, data drove decision making from school to grade and from classroom to students' desks. Staff members disaggregated data to create a robust picture of performance, and data were explicitly linked to the performance requirements of stakeholders" (Kennedy et al. 2003, p. 77).

Another in-depth study by Gulati and Oldroyd (2005) of 17 companies who have made substantial progress towards being customer focused, lays down a path towards stronger customer focus. The three common characteristics across all 17 companies studied are their awareness that they can become customer focused only if (1) they learn all there is to learn about their customers at a granular level to get a complete picture, (2) that such a picture is useless if employees can't or won't share their knowledge about customers, and (3) that they can use this insight about customers to guide not only product and service decisions but also base their basic strategy and organizational design on. Developing a customer-centric company means transforming the business focus of the organization to incorporate the objectives of creating and maintaining a unified view of each customer and segment, creating and maintaining a unified view of the organization and improving internal efficiency and coordination (Kapanen 2004). It also means that all people in the organization will need to incorporate relationship marketing as their jobs, not simply in their jobs (Crosby and Johnson 2002).

This degree of customer focus among employees helps lower or nullify perceptions of both the technology-process and technology-employee gaps (Zablah et al. 2004). These gaps in perceptions are consequences of implementation of new and 
unfamiliar technology and introduction of new processes. They directly affect innovation related cognitive dissonance of employees and hamper the process of transformation of the business focus.

CRM is primarily all about being customer-centric and enhancing the experience of the customers (Kumar 2004). This process of engaging the hearts and minds of employees towards customers is one of the first steps companies need to undertake in their CRM efforts because down the road this orientation will act as the best defense against competition (Day 2000). As realized by successful companies this process does not happen overnight but gradually creeps into the organization in a disciplined, organized fashion through other efforts. These factors and issues will now be discussed.

\section{$\underline{\text { Shared Customer Vision and Goals }}$}

Customer-centric strategy is an essential starting point for implementing successful customer relationship management. However, the whole strategy falls through if employees organization-wide do not share the need to be customer-centric. The first step in the process of being customer-centric for successful CRM, is to plan the whole effort; and the first step in this plan should include laying out a CRM vision and goal for the company showing the long-term benefits from a CRM initiative (Kavanagh 2003). "New York City recently launched a 311 project to enable constituents to better navigate the city's considerable number of departments and services. New York's vision calls for 24/7 service staffed by live operators, streamlined service delivery through electronic routing, centralized/standardized customer service across the city, multi-channel access, and ongoing performance measurement. The city has made good progress...The City's 311 initiative was driven primarily by Mayor Michael R. Bloomberg's desire to reduce 
the 12-page directory of city services to just one number 3-1-1. The mayor's commitment is real...The mayor has personally followed through on this commitment by challenging departments to channel first contacts through the 311 system" (Kavanagh 2003, p. 41).

It is important for executives to realize that getting close to customers is not so much a problem the IT or marketing department needs to solve as a journey that the whole organization needs to take (Gulati \& Oldroyd 2005). This journey is critical to the competitive success of CRM. The journey needs to start with a CRM strategic focus based on a clearly articulated vision for their customer relationships. The vision will tell who the present or prospective customers of the organization are, what kind of relationships these customers want with the firm, and what capabilities the firm needs to build and sustain that relationship (Battista and Verhun 2000). Such a vision will be helpless to achieve the CRM goals unless it permeates the whole organization and is shared by all employees. The CRM journey plan must be publicized organization wide so that everyone is aware regarding the transformation. CRM success depends on how well organizations join together around the same goal (Fleischer, Hersch, and Hochman 2001). In a study of CRM efforts of three companies (Edison Security based in San Dimas CA, 3Com, a Santa Clara CA based vendor of networking equipment and State Farm the insurance company), respondents cited common and shared inter-departmental customer focus as the most important and positive organizational effort towards successful CRM implementation (Fleischer et al. 2001).

The importance to CRM of this organization-wide orientation of collective responsibility of relationship building with customers can be seen in the light of it's giving rise to marketing and customer relating capability (Day 2000a, 2003). An 
organization's marketing relating capability, which subsumes the organization's customer relating capability, spans several functions and levels within the organization. It enables firms to determine the degree of relationship desired by the customers, their profitability to the firm, and helps formulate the right customer strategy and competition plan. It thus allows companies to develop separate strategies for individual or small segment of customers (Day 2000a, 2003).

A good example is the strategy followed by Capital One. The essence of this strategy is to deliver the right product, at the right price, to the right customer, at the right time (Day 2003). The company has deliberately avoided the "low-profit, high churn prime market" and has focused on the "superprime" and the "subprime" segments. This orientation of Capital One is shaped by a belief in how the company identifies and keeps those who are most valuable. Employees act as customer advocates and service representatives are measured on performance and collegiality. The sense of shared values and collaboration contributes to a low turnover rate which improves service and keeps costs down. Capital One is also a leader in its use of information. The company regularly runs tests on product variants, procedural changes and customer interactions. "The alignment of the whole organization with strategy is further reinforced by Capital One's configuration. The company structures its U.S. card business by market-segment groups based on customers' credit quality, their activity with the card, membership in affinity groups...Each segment is treated as a profit center" (Day 2003, p. 80).

CRM is an innovative business model with very little common consensus as to its nature. These disparate meanings give rise to confusion among employees and leads them to perceive that there are gaps in alignment between employee, process and technology. 
These perceptions of gaps directly affect the amount of innovation-related cognitive dissonance which in turn negatively affects buy-in into CRM efforts (Zablah et al. 2004). The authors show that learning and customer orientation of employees helps to lessen these gap perceptions. In turn, getting the whole organization to share customer focused visions and goals is a way to generate that customer and learning mind set. "Clearly, the vision of customer-centricism which involves an in-depth customer understanding and an overriding desire to create a consistent experience for valued customers across all functions, divisions, and communication channels, needs to be the prime driver of CRM projects" (Kale 2004, p. 45). Shaping the customer vision and understanding the need for change management are crucial for CRM success; engendering common customer mindset is just the beginning of that process. Strategic vision and goals need to have broad ownership and employee engagement for the CRM effort to be successful. "An organization's members do best when there is a line-of-sight understanding between strategy for delivering superior customer value and their individual contributions" (Day 2000c, p. 21). Efforts of companies like Owen Corning, Sears Roebuck, and Euro Tunnel are exemplary. To help employees understand their proper role in the bigger picture, Sears prepared learning maps which were discussed by teams of employees at "town hall meetings." In Eurotunnel, about one-third of the 300 employees were involved in one of the 87 cross-functional teams (Day 2000c). These very same companies have also used two approaches to get deep understanding of the need for change to permeate the organization. The first consists of exposing employees to customer judgments about products and services, and secondly, soliciting candid assessment by management about organizational effectiveness required to implement the change management (Day 2000b). 
There is a discomforting disparity in the way functions in an organization conceptualize CRM because of siloed vision and goals. Plouffe, Williams, and Leigh (2004) stress that a "shared understanding" of CRM across all functions mediates the extent of valued CRM outcomes achieved. The consistency, clarity and prudence of business goals and objectives ("to-market strategy") and power struggles and conflicting priorities within the organization ("socio-political dynamics") moderate the achievement of this shared understanding. The authors also provide helpful guidelines to best handle these effects. The first step involves acknowledging the multiplicity of intraorganizational stakeholders, their particular frames of reference, and their inherent biases and potential hidden agendas. The second step involves a dialogue about developing interfacing strategies with chosen market segments; and the third step involves consideration of appropriate outcome measures to utilize to evaluate the CRM program. Thus “..the method by which firms achieve a shared CRM understanding involves making important choices, gaining a level of consensus about those choices, and assessing the success and failure of the choices through clear and well articulated metrics" (Plouffe et al. 2004, p. 332).

Experience of companies provide evidence of ineffective CRM when they do not take care to create a shared customer-focused organizational mind set. One such company is Bosc, one of the largest mutual building societies in the UK. Even though Bosc has effectively responded to the need for technology and customer data in their CRM efforts, they are struggling with getting buy-in from their company and staff (Dibb and Meadows 2004). This lack of organization wide belief in a common vision of CRM hampers its implementation despite installation of efficient technology. 
The benefit and importance of shared understanding in building customercentricity and successful CRM implementation can be seen even beyond the boundaries of traditional industries. A comparison of the two public district schools in their CRM implementation efforts mentioned earlier is a good example (Kennedy et al. 2003). The progressive school, in comparison to the struggling school, showed more use of organization-wide intelligence to make decisions. Inter-functional coordination at the progressive school was also seen to be enhanced more than the struggling school's through definition of customer requirements and shared goals to achieve (Kennedy et al. 2003).

Hence "..in the absence of articulating clear, commonly understood (or shared) CRM metrics and outcomes at the front-end of CRM program, ultimately and by definition, "success" becomes an elusive, if not inherently unachievable, goal" (Plouffe et al. 2003)

The best defense against competition lies in engaging the hearts and minds of employees towards profitable retention of customers (Day 2000).

\section{Customer Segmentation}

Customer segmentation has taken on new meaning and significance in the CRM world. The goal of CRM is not only to engender customer loyalty through enhancing their experience but also to increase the organization's profits. This dual goal has brought into question the benefit of developing strong relationships indiscriminately with all customers (Cholewka 2000). More specifically, the goal of profitability demands a critical examination of the returns on relationships from customers, loyal and otherwise. Successful CRM results in varying types and degrees of relationships between 
organizations and their customers which will depend on the customers' need for relationship and their value to companies (Paas \& Kuijlen 2001).

CRM challenges an organization to manage customer profitability as a portfolio, maximizing the potential of existing customers, acquiring new customers that are profitable or have the potential to be so, and retaining customers who are profitable. (Petersen 2004). This is because serving customers with no present or potential value to organizations is a huge drain on resources; this may even happen with loyal customers. Thus segmentation forms the backbone of successful CRM implementation, where profitability should be the preferred criterion (Battista and Verhun 2000; Hopkins et al. 1999; Xevelonakis 2005).

The criticalness of effective segmentation is reflected in the airline industry's plight due to a lack of effective segmentation. Despite CRM efforts by Southwest and JetBlue, a survey of 17 major airlines around the world reveals that even the most sophisticated among them have only a rudimentary understanding of who their most valuable customers are or could be, which factors affect the behavior of these customers, and which CRM levers are most effective in ensuring loyalty" (Binggelli et al. 2002). To make matters worse airlines rarely know how much their customers spend with competitors. The good news, however, is that CRM based on effective segmentation can increase an airline's revenue by as much as 2.4 percent a year, representing a bottom-line annual impact of $\$ 100$ million to $\$ 250$ million for a large carrier (Binggelli et al. 2002). "The challenge for airlines is to understand the actual and potential value of each customer and to pinpoint the actions and incentives needed to maximize it" (Binggelli et al. 2002). 
Evidences also exist in other industries. "We've gotten a lot smarter about separating the customers we do want from the customers we don't" says AT\&T chief executive officer Michael Armstrong (Hopkins et al. 1999, p. S5). CRM wisdom underscores the need of segmenting customers by relative value and serving them accordingly, and the folly of treating all customers the same way. This differentiated customer approach can build up desirable customer relationships.

The customer segmentation process has to have input from all corners of the organization and the presence of adequate CRM technology (Hopkins et al. 1999). Customer transaction and communication information from different functional areas of the company have to contribute to the central customer database. The database has to be supplemented with decision support models which will analyze the customer information stored there to determine lifetime values of customers (Hopkins et al. 1999; Olsen 2001; Park \& Kim 2003).

Customer Lifetime Value (the returns from a customer over his or her lifetime as a customer) analysis helps to assign a profit figure to each customer over his or her lifetime as a customer, thus helping managers to target profitable customers (Winer 2001). It is an effective metric for selection of customers and allocation of resources for relationship development and maintenance. Customer Lifetime Value (CLV) has been defined as "... a function of the predicted contribution margin, the propensity for a customer to continue in a relationship (customer retention) and the marketing resources allocated to the customer" (Venkatesan \& Kumar 2004, p. 108). In their development and estimation of the CLV model the authors found that a supplier's contact strategy affects both frequency of purchase and the contribution margin. There is a inverted $U$ 
relationship between supplier's contact strategy and provision of relationship benefits and customer's predicted purchase frequency. This led Venkatesan and Kumar (2004) to believe that there is an optimal level of marketing communication for each customer. This in turn calls for an optimum level of resource allocation for each channel for each customer. Resource allocation is effective if customized communications are geared toward up-selling and cross-selling. The latter two have been shown to affect customers' purchase frequency (Venkatesan \& Kumar 2004). Thus, resource allocation strategies that maximize CLV should result in huge increases in profits and returns on marketing communications when compared to status quo resource allocation strategy. In comparison to other metrics for customer segmentation and resource allocation, such as previous period customer revenue, past customer value, and customer lifetime duration, CLV was also found superior (Venkatesan \& Kumar 2004). The importance of profitable customer segmentation to CRM can be illustrated via the service industry where the presence of distinctly identifiable profiles of customers, their different views on service quality, their varying impact on profitability and presence of different factors driving incidence and volume of new business have made it necessary to categorize customers into tiers of profitability (Zeithmal et al. 2001). The customer segmentation process goes beyond traditional segmentation based on usage, to analysis of costs and revenues for groups of customers, thereby capturing their financial worth to companies. The resulting customer tiers are overlaid in the form of a pyramid starting from the least profitable (lead) in the base to the most profitable (platinum) at the tip. Following the platinum tier from the top are the gold and the iron tiers respectively. Segmentation also acts as a guide to companies for developing strategies to move customers up the profitability 
pyramid. For moving its gold customers to platinum Home Depot became a full service provider through the creation of Expo Design Centers which are one-stop shopping locations for major renovations, making contractors, designers and materials available to customers all under one roof. Examples of other strategies for transitioning customers from gold to platinum: providing outsourcing for a function, increasing brand impact by line extensions (Liz Clairborne for the female baby boomer generation), and creating structural bonds (creation of the "hospital-specific pallet architecture" by Allegiance Healthcare Corporation) (Zeithmal et al. 2001).

Tied to the concept of customer profitability and also highly relevant to successful CRM implementation is the issue of customer loyalty, since one of the goals of CRM is customer retention. Industry and academia have long equated customer loyalty with profitability. This was based on the premise that loyal customers are cheaper to serve, are less price-sensitive and hence more profitable. Recent research has however shown that contrary to popular belief, there is only a moderate linear association between lifetime duration and lifetime profits (Reinartz \& Kumar 2000, 2002). "What we've found is that the relationship between loyalty and profitability is much weaker-and subtler-than the proponents of loyalty programs claim. Specifically we discovered little or no evidence to suggest that customers who purchase steadily from a company overtime are necessarily cheaper to serve, less price sensitive, or particularly effective at bringing in new business" (Reinartz \& Kumar 2002, p. 87). Actually, the average price paid by short-term customers is significantly greater than that paid by long-life customers. Efficiency and costs are positively related to customer revenues regardless of lifetime duration, and long-life customers have more information and experience about the firm's 
products than short-term customers helping them to find ways of identifying lower-priced but better quality products. Reinartz and Kumar (2002) based their study on four companies: a high-tech service provider, a French grocery store, a large U.S. mail-order company and a German direct brokerage house. The findings point to the disconnect between customer loyalty and profitability. Loyalty should not be measured as a proxy for profitability. "Companies will have to find ways to measure the relationship between loyalty and profitability so that they can better identify which customers to focus on and which to ignore" (Reinartz \& Kumar 2002, p. 87-88). Thus, both loyalty and profitability and their inter-relationship are integral parts of an effective segmentation process.

Reinartz \& Kumar (2002) proposed a model of buying behavior, which takes into account both customer loyalty and profitability. This model is a special case of "eventhistory modeling" which tells organizations when to lose a customer. This statistical tool helps determine the probability that some future event will occur based on statistical patterns observed either theoretically or empirically in the past. Only three simple pieces of information are needed: "When did the customer buy for the first time? When did she purchase last? and When did she purchase in between?" In its simplest form, the formula is $\mathrm{t}^{\mathrm{n}}$, where, $\mathrm{n}$ is the number of purchases made in the entire time period, and $\mathrm{t}$ is the fraction of the period represented by the time between her first purchase and her last one. “This approach is particularly good at predicting how quickly a customer's purchasing activity will drop off, as the probability of their being active in the future drops steeply with time, so it clearly has the potential to prevent heavy overinvestment in profitable but disloyal customers" (Reinartz \& Kumar 2002, p. 91). Important for CRM is to assign 
customers to the following categories based on profitability and loyalty and implement the corresponding strategies to manage them (Reinartz \& Kumar 2002):

True Friends: Very Loyal and very profitable. "In managing these true friends, the greatest trap is overkill." (p. 93). The strategy to follow is to turn these true friends into "true believers" by rewarding them for their loyalty. For example, a French grocery chain grants loyal customers preferred access to company sponsored seasonal events -buying better wines with limited availability.

Butterflies: Profitable but transient. "Instead of treating butterflies as potential true believers, managers should look for ways to enjoy them while they can and find the right moment to cease investing in them" (p. 94). This is because conversion of butterflies to true friends was less than $10 \%$ for the four companies studied. The strategy to adopt is “... short-term hard sell through promotions and mailing blitzes that include special offers on other products" (p. 94).

Barnacles: Loyal but “... do not generate satisfactory returns on investments made in account maintenance and marketing because the size and volume of their transactions are too low" (p. 94). The first step is to determine whether the problem is that of a small wallet or small share of the wallet. Then, depending on potential profitability of loyal customers, offer them products associated with those already purchased as well as other items in seemingly unrelated categories.

Strangers: Customers with low loyalty and low profitability. Here the strategy is simple. "Identify early and don't invest anything" (p. 94).

"Whatever the context, we believe that no company should ever take for granted the idea that managing customers for loyalty is the same as managing them for profits. 
The only way to strengthen the link between profits and loyalty is to manage both at the same time. Fortunately, technology is making that task easier everyday, allowing companies to record and analyze the often complex, and sometimes even perverse, behavior of their customers" (Reinartz \& Kumar 2002, p. 94).

"Consequently, an implication for managers is that a firm strategy focusing on relational buyers only, as opposed to transactional buyers, would be disadvantageous. Thus the firm must develop and maintain operational and communication tools that effectively cater to each of the two groups" (Reinartz \& Kumar 2000, p. 26).

Customer Acquisition and Retention

Understanding who a company's most profitable and loyal segments of customers are also helps to understand why these customers respond to different product package offerings, where they prefer to buy or seek customer service, and when to cross-sell or up-sell. This customer knowledge aids in building effective customer strategies, delivering the value proposition through campaign and channel management and developing appropriate performance metrics (Olsen 2001; Plakoyannaki \& Tzokas 2002). Customer strategies will be effective at retaining customers only when companies model and analyze the reasons for customer churn (Xevelonakis 2005). Competition, convenience, image, quality and price have been found to be the major reasons for customer churn (Xevelonakis 2005). Companies can apply datamining techniques for identifying variables in databases that can approximate reasons for churn as well as for understanding these reasons and predicting future churn. Recent research has found significant negative effects of prior churn, customer satisfaction and calculative commitment on tendencies of customers to churn in the future (Gustafsson et al. 2005), 
and significant positive effects of affective commitment ${ }^{1}$ (the psychological attachment based on loyalty and affiliation, of one exchange partner to the other) on customer retention and customer share development (Reinartz et al. 2005).

It is important to take into consideration these determinants of customer churn before initiating or revamping a customer loyalty program for retention and profitability. Kumar and Shah (2004) has developed a framework for simultaneously cultivating and sustaining customer loyalty and profitability, especially for the retailing industry. The framework builds and enhances behavioral loyalty, cultivates attitudinal loyalty and links loyalty to profitability.

The Tier 1 reward schemes which are essentially standard one-dimensional reward strategies where customers are given rewards or points on the basis of their total spending, help to capture customer transaction data as well as build loyalty across all customers. These rewards are, however, very easy to duplicate by competitors. “Contrary to Tier 1, Tier 2 rewards are forward looking and aimed at influencing customer behavior or attitude in future given the.past performance of the customer. Thus, Tier 2 rewards would be special rewards given to select customers to cultivate attitudinal loyalty or enhance behavioral loyalty" (Kumar and Shah 2004, p. 323). The challenge lies in selecting these special customers and determining the types and values of the highly differentiated Tier 2 rewards, for example, “... determining which customer should get a ticket to the Superbowl and which customer should get a ticket to an exotic destination or something else" (Kumar and Shah 2004, p. 325). The answer lies in

\footnotetext{
' Calculative commitment and affective commitment are two dimensions of relationship commitment. Calculative commitment as compared to affective commitment, is the colder, or more rational, economicbased dependence on product benefits due to a lack of choice or switching costs (Gustafsson et al. 2005)
} 
research. Systematic data mining of attitudes, behaviors, customer profile information, and customer life time value measures enables researchers to develop an algorithm to configure the most optimal and relevant Tier 2 reward for a customer (Kumar and Shah 2004). Even though customer loyalty and retention are important CRM goals it is crucial that the company does not invest more resources than the expected return from the customer (Kumar and Shah 2004). The forward-looking Customer Lifetime Value measure helps manage both loyalty and profitability by taking into account all cost and revenue components associated with the customer, including Tier 1 rewards that may have been awarded to the customer to date (Kumar and Shah 2004). For effective CRM it is very important to calculate the profitability of loyalty campaigns for maximum effect. To maximize the net present value (NPV) of a loyalty campaign targeting customers with product, services and pricing packages, only customers with an NPV $>0$ should be contacted. Further, to gauge the benefit of a loyalty campaign for a specific target group, its NPV has to be compared with the NPV of the same target group without the campaign. Cost is an inherent component of profitability since organizational resources are scarce and, if not allocated and deployed efficiently, will lead to higher costs and lower profits. Successful CRM plays a critical role in growing a business which can be framed as allocating resources for obtaining and retaining customers to maximize the growing customer base (Blattberg \& Deighton 1996). Hence, CRM demands optimum resource allocation for customer acquisition and retention, and marketing thus divides itself into the work of acquisition and the work of retention of customers (Blattberg \& Deighton 1996). Therefore, it is critical that managers determine the optimum balance between acquiring and retaining their company's customers. 
Recent research has been helpful in developing a strategy for customer acquisition and retention. Blattberg \& Deighton's (1996) solution to the question lies in determination of customer equity. The balance between acquisition and retention is optimum when the customer equity is at the maximum. Customer equity is determined by how much each customer contributes over his or her lifetime toward offsetting the company's fixed costs. More specifically, the authors express customer equity as the sum of the net present value of returns from acquisition spending and from retention spending. Decision-calculus shows that customer equity is at the maximum for optimal acquisition and retention spending. In a closely related study investigating resource allocation to contact strategies, Reinartz et al. (2005) found that optimal levels of acquisition and retention expenditure leads to optimal rates of acquisition and retention, which maximizes profitability. This is because expenditures for both acquisition and retention show diminishing marginal associations with likelihood of customer acquisition, lifetime duration of customer and customer profitability. Hence, acquisition and retention are both important, but there is an inherent trade-off between the two. Maximizing long-term customer profitability maximizes neither the rate of acquisition nor retention, because resource allocation has to be optimized for maximizing long-term customer profitability. The implication for this is that firms have to invest sufficiently to acquire and maintain relationships and maximize the effectiveness of customer acquisition and retention by optimizing the costs. There is a trade off between the effectiveness of communication strategies and the costs involved in carrying them out. "We find that under spending is more detrimental and results in smaller ROIs than does over spending. When firms trade off between expenditures for acquisition and those for 
retention, a suboptimal allocation of retention expenditures will have a greater impact on long-term profitability than will suboptimal acquisition expenditures. ... Although the investment in the customer may become less efficient beyond the optimal expenditure level, the decreased efficiency does not outweigh the lost value that the firm would incur if the customer's potential was not fully realized" (Reinartz et al. 2005, p. 77). The lesson here is that firms can manage their customer base profitably but it requires resource allocation decisions that involve trade offs (Reinartz et al. 2005). The good news is that optimal resource allocation for effective loyalty programs have been shown to have a positive effect on both customer retention and customer share development (Verhoef 2003).

To affect customer share development and make efficient use of financial resources, firms must ensure that the right customers respond to the cross-selling offer. Many times companies have customers responding to offers whom the firm do not want to approve, and the customers who are eligible for the offer do not respond. This also frequently happens in financial services like loan and credit card offers. To allocate resources efficiently and save costs, companies need to ensure that the customers responding to offers are acceptable for approval. To accomplish this, customer communications should be selective. Cao and Gruca's (2005) segmentation model based on simultaneous analysis of response and approval likelihood can help companies target customers who will respond and who the company can approve for the loyalty program or cross-selling offer. This model could also be applied to non-financial industries.

Following are examples of strategies certified by research and experience of successful companies that should assist organizations in effectively balancing resource 
allocation between acquisition and retention (Blattberg \& Deighton 1996; Thompson 2005; Vandermerwe 2000; Winer 2001):

- Invest in highest-value customers first: Targets with particularly high equity may justify major investments (Blattberg \& Deighton 1996). Recent research has found that lifetime revenue is highly correlated to lifetime value (Ryals 2005). The airline companies tie in customers through frequent-flier miles incentives. Similarly, long distance telephone companies work hard at retaining the new immigrant segment who regularly keep in touch with their relatives back home.

- Transform product management into customer management: "Retention programs if skillfully designed can be much more than volume discount programs... The key is to deliver benefits that appeal more to heavy users than to light users, that draw attention to a brand's claimed distinction, and then enliven the buying experience so that the heavy user becomes an even heavier user" (Blattberg \& Deighton 1996, p. 141). For example, Nintendo and Lego designed clubs showing members new ways that children could enjoy their games and toys. Through the clubs, children also came in contact with other users. Corvette and Harley-Davidson have also followed the club model. Hotels, too, have made club membership a source of customer recognition (Blattberg \& Deighton 1996).

- Consider how add-on sales and cross-selling can increase customer equity:

- Look for ways to reduce acquisition costs: With high acquisition costs, retention needs to be high too. If acquisition costs are brought down, the long-term payoff improves dramatically. 
- Relate branding to customer equity: Brands are instruments to attract new customers and an anchor to hold existing customers (Blattberg \& Deighton 1996).

- Swing the power from the company to the customer: Amazon encourages customers to give feedback much of which has been implemented in their offerings. This also gives thousands of unknown writers the power to be read through their website.

- Achieve customer lock-on: Customers lock-on (as against lock-in) of their free will because of ongoing, superior value at low delivered cost. "With lock-on it is not the products that keep competitors away, nor is it the technology; it is the customers" (Vandermerwe 2000, p. 29).

- Articulate new market spaces: Concentrate on dominating activities that produce customer results in new market spaces. Vandermerwe (2000) provides specific guidelines on how to define market spaces. To Unilever, cleaning supplies is only one market subspace of home-care management, which CEO David Ball describes as "anything related to saving time at home." Here, Unilever will be able to extract yet more value from customers, because once they have locked onto cleaning management, the enterprise will be able to move into more diverse areas of home-related spending, such as gardening, security, do-it-yourself, decoration, insurance and chores (Vandermerwe 2000). Mapping new market spaces also helps to reveal real competitors. When IBM defined its market space as "global networking capability" it realized possible competitors in Anderson Consulting or even in Cisco.

- Deliver an integrated customer experience: Work with each step of the customer activity to decide where the gaps are and filling them with value add-ons and even creating breakthrough value to give customers a seamless experience. IBM earns more 
money from value-add-on services than from its hardware or software; Virgin Atlantic joined limousine companies to give free transportation, free check-in and an invitation to join Virgin's Clubhouse lounge to their business-class passengers. The value add-ons for Baxter Renal UK a dialysis company selling dialysis bags and other related services came in two waves. The first included all activities to obtain depth and length of spending by getting more people on $\mathrm{PD}^{2}$ earlier and longer. The loss of margin on core items and the investments required to deliver value-added services were covered by selling more bags. The second wave involved getting more breadth and diversity of customer spending by moving into associated drugs (many renal patients suffer from additional diseases), competitive HD treatment (delivered at home) and transplantation research. From the customer's viewpoint all these areas are part of the same renal-sufficiency market-space" (Vandermerwe 2000, p. 33).

- Monitor the intrinsic retainability of your customer: This is based on monitoring how the customer uses a product or service and then enhancing retention by providing benefit to that particular usage pattern (Blattberg \& Deighton 1996). Federal Express accomplished this with the creation of an airline dedicated to nothing but freight. This gave shippers more control over customer satisfaction.

The essence of operationalizing a loyalty program is to: 1) determine which are the right customers for you to win back and/or retain, 2) find out what they want or why they left, 3) fix the problem, and 4) make it hard for them to leave or invite them to return (Thompson 2005). Taco Bell repositioned its offerings to realize the full potential of its

${ }^{2}$ PD (Pre Dialysis) 
most profitable customers and attract new profitable sub-segments. In a similar manner AT\&T revamped its long distance offerings by refining its segment profitability and aligning that with segment-wise investment strategies (Grant and Schlesinger 1995).

A superior segmentation process guides a superior resource allocation process to increase retention of profitable customers. Improvement in product development, and enhancement of customer communication and interactions aids positive return on marketing, sales and customer-service investments (Siebel ebusiness 2002). An example of the link between effective segmentation and resource allocation is the effectiveness of the use of customers' channel preference as a segmentation variable to determine channel specific marketing communication and contact strategies that demand and result in efficient allocation of expenditures. Future channel preferences can be predicted and new customers can be assigned to appropriate categories. At the same time because channel preferences change over time this process has to be in a constant shuffle (Thomas and Sullivan 2005).

One challenge of CRM is understanding the actual and potential value of each customer and pinpointing and implementing the actions and incentives for maximization (Binggelli et al. 2002). Coming back to the example of the airline industry, analyzing only frequent flier miles usage gives an incomplete picture of customers. "Customers within the same tier often represent widely different levels of value to airlines, and a small significant number of passengers in the lower tiers could be of greater value than passengers in the upper ones" (Binggelli et al. 2002, p. 10).

Segmentation is just the start of a successful CRM program. It's effectiveness in guiding complete understanding of profitable customers and efficient and effective 
allocation of resources to acquisition and retention will depend entirely on supporting technology, processes and people of the organization.

\section{Technology Issues}

Devising a CRM strategy without a proper understanding of the benefits and opportunities of the enabling technology is unrealistic (Croteau and Li 2003). Understanding CRM technology needs is one of the essentials for enabling information exchange and strategy development and enhancement (Gordon 2002; Sowalskie 2001). Having an accurate 360-degree view of the customer, which is largely technology driven, is crucial for customer segmentation (Battista and Verhun 2000). Successful companies have realized this. There is no better example than Harrah's Entertainment, the casino giant. For Harrah's, CRM consists of two elements: first, it uses database marketing and decision science analytical tools to ensure that operational and marketing decisions are based on facts rather than on intuition. Second, it uses this insight, together with marketing experiments, to develop and implement service delivery strategies that are fine tuned to customers' needs. Harrah's spends considerable time integrating data across properties, developing models, mining the data and running experiments. Every one of their units is tied to the same systems which allows them the expertise to track customers at any of their locations. The data derived from players using their Total Rewards II loyalty cards is fed into the Winners Information Network which contains an enterprisewide data warehouse information on more than 30 million customers and uses multiple CRM tools that support a number of progressive and highly exciting customer- centric projects. Their latest CRM project is the Player Contact System. A cross between a targeted marketing solution and a sales force automation tool, the application proactively 
makes casino hosts aware (through PCs and wireless handhelds) when they should be contacting specific customers about offers and events. Harrah's uses this system to convey targeted offers. This is possible because at any given moment Harrah's can view how many of its active loyalty cards are in use on the gaming floor, which games cardholders are playing, and how much they are spending. They even gain insights from anonymous players. Using business intelligence software and its proprietary casino floor management system the company can query its database to see which machines are attracting more people and generating the most revenue (Barth 2004; Bernstein 2004; Bligh and Turk 2004; Cherkassky 2005; Sowalski 2001).

CRM Technology becomes a source of strategic capability because it allows for developing, managing, and analyzing customer information for profitable segmentation, cross-functional collaborative communication and customer interaction (Gordon 2002). Sawhney and Zabin (2002), in their systems view of relationships, put technology at the core of the relationship structure and processes. To implement the adaptive relationship management process firms need to put the enabling technologies in place (Sawhney and Zabin 2002).

\section{$\underline{\text { Databases }}$}

The first enabling CRM technology that needs to be in place is the Data Warehouse. "Data is the king in the world of CRM" (Davids 1999, p. 24) and "Data Warehouses are the lynchpins of the CRM technology architecture" (Battista and Verhun 2000, p. 37). Experience of companies from a wide range of industries underscores the importance of having a flexible database. This database must contain the right type of customer information and marketers must have easy access to that to allow them to 
utilize it well enough to segment and target appropriately. (Abbott et al. 2001). Data warehouses must contain a history of customer transactions, contacts, descriptive information and marketing stimuli response information (Winer 2001). Companies utilize different methods for gathering customer information for enriching the database. The networking company $3 \mathrm{Com}$ builds customer records from emails, direct mails, telemarketing and other customer contacts. Thomson Holidays, the British tour company, collects customer descriptive information and data on trips taken with the help of travel agents (Winer 2001). This information must be fed into a database by functions from across the organization, making the integration of all the functional databases with the data warehouse vital. If this integration is not improved, perfected and updated regularly, the organization will be working with incomplete and sometimes incorrect data which will lead to ineffective segmentation and customer retention strategies, and inefficient resource allocation. A chain of wrong decisions will end up hurting profitability.

\section{$\underline{\text { CRM Analytics }}$}

To critically understand and use data effectively beyond just rigorous data collection and storage, companies need powerful marketing analytical tools that yield meaningful insights and accurate predictions of customer responses (Freeland 2004). Analytical marketing drives market segmentation, identifies the most profitable customers and develops predictions of individual customers' behaviors (Freeland 2001). A big part of the successful implementation of customer relationship management rests on effective analysis of collected customer data. Customer Lifetime Value analysis helps to assign a profit figure to each customer over his or her lifetime as a customer, thus helping managers to target profitable customers (Winer 2001). Companies are able to 
overhaul their customer strategies affecting acquisition, retention, and allocation for service levels, pricing, product offering and customer divestment as a result of seeing customers in the new light of lifetime values (Ryals 2005). CRM analytics drives complementary product and service offerings to enhance customer loyalty, increase customer profitability and raise switching costs (Winer 2001). Methods and tools, such as market basket analysis, econometrics, return on investment measurement, and budget allocation software, now make a more scientific approach to customer relationship management possible. More specifically, in the areas of sales, marketing and service performance, CRM applications provide capabilities such as lead management, opportunity management, team selling, proposal generators, configurators, campaign management, self-help, and wireless that directly affect measurable profitability outcomes like gross profit generated per sales function dollar expended, revenue growth, new customer acquisition, and ratio of response rate to marketing dollar expended (Petersen 2004). Leading companies are already using these data-driven techniques to measure and subsequently improve the return on their marketing investment (Freeland 2004).

Seoul-based Samsung, one of the world's most successful consumer electronics companies in its bid to compete with the stronger brand name of Sony's, took Accenture's help to scientifically analyze how it invested its marketing resources in 14 major product categories across more than 30 countries. Marketing analytics helped it determine which category/country combinations offered the greatest growth potential, and reallocate its marketing investments accordingly (Freeland 2004). Despite the rapid growth of sophisticated applications, very few companies possess this level of 
intelligence about their products, markets and customers. Many organizations are still struggling to identify their most profitable customers, much less predict which will remain profitable (Freeland 2004). The solution partly lies in organization-wide integration of legacy applications. Disparate systems scattered around different parts of the company need to be integrated so that analytics can take advantage of data from all corners of the organization (Battista and Verhun 2000).

\section{$\underline{\text { Systems Integration }}$}

The process of systems integration is one of the fundamental dimensions of CRM implementation. This seems to hint that technology plays the role of a channel for managing organization-wide customer knowledge. Not surprisingly, recent studies found that where the level of technological resources available to the organization for CRM had no significant effect on customer satisfaction, customer retention, and profitability, knowledge management capabilities did (Croteau and Li 2003; Yim et al. 2004). In addition, organizational CRM technology readiness was found to be positively linked to knowledge management capabilities (Croteau and Li 2003). This link among technology, knowledge management and customer relationships could be gleaned from Yim et al.'s (2004, p. 270) comment that the positive effect of knowledge management on customer relationship “... may be attributable to the importance of knowledge responsiveness taking the form of customization, which acts as a critical value driver in building relationships with customers." CRM assorted technology enables such customization. In other words, technology does not seem to significantly increase customer satisfaction and loyalty over the long run; it only makes the efforts more efficient (Yim et al. 2004). 
Technology is essential to CRM but it (CRM) is essentially an ongoing project rooted in processes and people.

To make knowledge management more efficient and effective, applications and systems need to have the capabilities to integrate across the entire organization and be customizable to the integration needs of the organization. Unfortunately, organizations and CRM software vendors are still struggling to develop and implement this customizable integration capability. CRM packages appear to be built on the idea of relationship marketing, but the capabilities of the software are often not congruent with the concept -- relationship marketing must involve the entire organization. Unfortunately, a lot of these software packages also embody standardized views of relationship management processes (Light 2003). In a study of CRM implementation experiences of three companies (a global consumer goods company, a small engineering company and a professional services company) CRM packages were implemented in functional silos such as sales, marketing and call centers (Light 2003). This resulted in reinforcing functional silos, which goes against information sharing across functions and hence is detrimental to customer relationship management.

Role of the IT Department

Building customer knowledge competence is essential to CRM and, beyond technology, needs shared organizational values and cross-functional coordination. To achieve this it is critical to align IT with other customer facing functions (Campbell 2003). The lack of strong marketing-IT interface tends to create problems of (1) “... complex technology that does not integrate customer data and allow access to information by all departments", (2)“... poor data exchange when employees switch 
responsibilities from one customer to another”, and (3) “... the lack of comprehensive business processes to drive relationship building" (Campbell 2003, p. 379). These problems can be avoided by creating joint domain similarity between marketing-IT through joint committees, project teams and cross functional integration. The challenge in alignment lies in converging the outlook and goals of IT and marketing which are traditionally worlds apart. Wehmeyer (2004) proposes a solution with his "IT infrastructure fusion" model which creates a weighted relationship between marketing and IT issues in CRM implementation. The fusion model proposes joint efforts of IT and marketing executives in strategy and in organizational redesign rather than on technological excess. This is likely to lead to crucial functional integration at the organizational level without disregarding IT potential. The British retailer Tesco serves as a good example for the fusion perspective. Tesco committed itself to a relationship marketing approach by focusing on earning customer loyalty. The company began with a modification of its marketing strategy, but deployed IT for improving efficiency and enabling advanced operations. IT also impacted Tesco on a strategic level when the electronic marketing channel was added. Thus Tesco is likely to have gone through a balanced process of aligning marketing and IT, and IT seems to have been granted a more active and influential role on the external, strategic level, as well as on the internal, operational level (Wehmeyer 2004).

In view of the importance of IT-marketing alignment for CRM, the role of the IT manager takes on special significance. He/she has the challenging task of creating the technical infrastructure and managing the systems development tailored to the unique requirements of CRM. Bose (2002) outlines the job of an IT manager in CRM 
implementation by discussing eight phases of a CRM development plan based on a typical systems life-cycle approach. These are the pillars of IT success in the CRM arena. The whole process begins with planning what the IT manager needs for recording different ways of customer interaction into an information database, as well as identifying critical decision making data (Phase 1). This is followed by research wherein the IT team identifies methods to address the needs of the organization within the CRM framework (Phase 2). Next comes system analysis and conceptual design (Phase 3). The critical issues here are ascertaining successful customer interaction through provision of all necessary information, staged implementation, data integration across legacy systems, maintaining data quality, and ensuring system scalability. Phase 4 is designing the specifications. In this stage it is determined what software packages are needed and what core technologies are required. The next two stages are design execution (Phase 5) and system implementation (Phase 6). The responsibility of IT here is to provide training to all line level employees as well as to decision makers. Because the marketplace is dynamic, CRM requires continual evaluation of the system performance and data quantity and quality. IT needs to continuously work with other functional areas to ensure that the system is meeting the needs of the decision makers (Maintenance and documentation) (Phase 7). Finally as new products are introduced and customers' channel preferences change overtime; customer interaction points or the types of data required will also change. If IT fails to make the changes, the company will quickly lose the competitive edge of customer-centric orientation (Phase 8).

In spite of its critical necessity, technology only plays a supporting role in customer relationship management. It is in the changed and integrated processes, 
together with the customer centricity of the people who believe in and perform these processes, wherein lies the secret of successful customer relationship management. Technology is as effective as the people and processes are (Jabali 2003).

\section{Process Issues}

“Today's organizations increasingly seek to drive corporate performance by maximizing the value of their customer relationships. Beyond technology, however, many companies fail to appreciate the importance of developing specific, well-defined, and integrated business processes focused on the customer" (Siebel 2002, p. 1). Companies have implemented call centers and sales force automation software but many have simply added new technology to existing processes (Freeland 2001). For successful companies, "CRM is a series of strategies and processes that create new and mutual value for individual customers, builds preferences for their organizations and improves business results over a lifetime of association with their customers" (Gordon 2002, p. 1). At a tactical level too business process integration is a critical challenge companies face in CRM implementation (Kotorov 2003).

The goal of CRM is to improve company marketing, selling and service processes to enhance customer relationships profitably. Siebel Systems' experience with more than 3,000 CRM initiatives has shown that the most successful companies approach CRM as a complete business strategy with a focus on improving the way a company markets to, sells to, and provides service to customers (Siebel 2001). Beyond changing the core marketing, sales, and customer-service processes it is just as important to bring about changes in medium and higher order organizational processes, with each process reinforcing the other. 
Selection on Selection (SOS) theory (Dickson 2003) conceptualizes a firm's configuration as an overlying system of processes which wraps around one another in a hierarchical fashion (Porter 1984). Wrapped around the core added value processes such as marketing, sales, customer service and manufacturing, are system controls used by management to deploy resources. The control and deployment processes of these intermediate level systems manifests an organization's capabilities. Wrapped around these lie the higher order learning processes and the process thinking capabilities of key executives. SOS theory contends that it is these highest order processes that are most important to the firm and fundamental to its prosperity and survival (Dickson et al. 2005). It also stresses that in a CRM organization each of these processes reinforce the one below it with the consequence that the organization becomes a dynamic system of interlinked processes that drive learning and innovation (Dickson et al. 2005). Since this system has to be customized for each organization, it is not easily replicated and becomes a source of competitive advantage. Figure 1 below shows a CRM organization with nested processes.

CRM's better system control processes (basically the knowledge management processes) improve the performance of the core added value processes. Some examples would be: better lead identification and call center response processes, decreased quote/proposal generation process time and costs, reduced order-delivery process costs, better pipe-line demand forecasting, better servicing of existing customer problems, and faster more integrated response to customers, with the help of information on contact and marketing channel preferences of customers and their responsiveness to direct marketing. Customer knowledge is used in a disciplined and integrated manner to increase return on 
marketing investment. In essence, better systems control processes lead to improved transactional, operational, knowledge and interaction processes. Beyond these processes lie the domain of senior management where strategic resources are allocated to activities and budgets are approved. Senior management will only be able to allocate resources effectively and efficiently if they have the information regarding the comparative need

Figure 1

NESTED CRM ORGANIZATION PROCESSES (DICKSON ET AL. 2005)

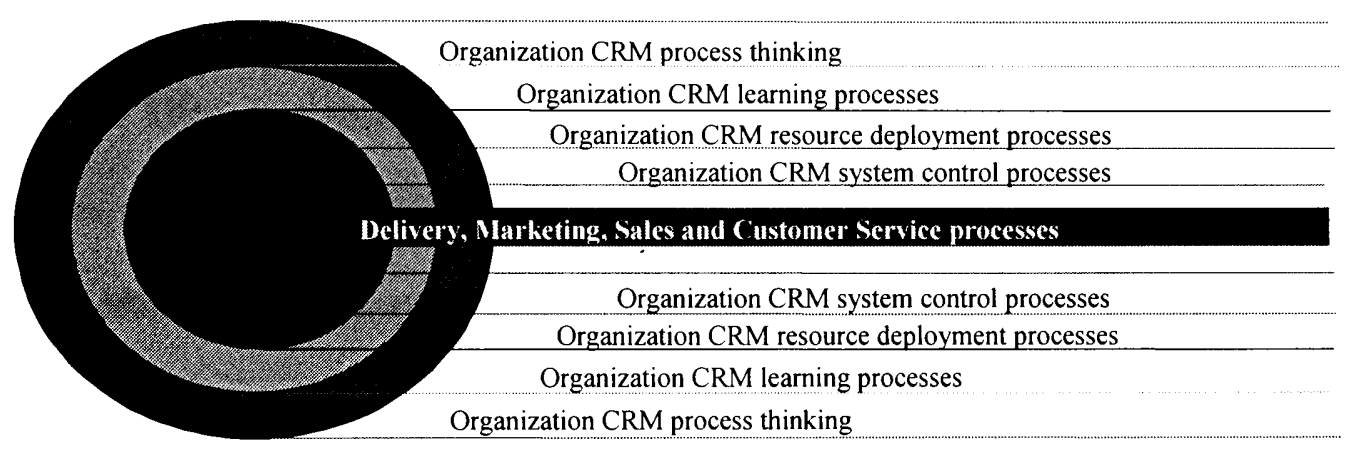

and efficacy of a particular marketing program versus a sales incentive campaign or a product category development initiative (Dickson et al. 2005). For the added-value, systems control, and resource deployment activities to feed into each other, crossfunctional communication and collaboration processes between marketing, sales and customer-service, open performance measurement processes, and collaborative decision making processes need to be developed and improved. This open communication and performance measurement system will have a positive effect on the successful reorganization of front-line marketing, sales and customer service operations (Dickson et al. 2005). "Companies today must begin to use a disciplined, cross-functional process to configure the offerings required by their target customers....it (value exchange optimization) is a cross-functionally integrated learning process" (Grant and Schlesinger 
1995, p. 67-68). At the senior management level where strategic resources are deployed, open communication and performance measurement sharing also has positive implications. Senior management will learn through the CRM performance metrics, aggregated in various ways, how to better deploy resources across budgets. Histories of past programs and their efficacy will enable companies to decide whether or not further investment in particular marketing, sales incentive or product development programs should be made (Dickson et al. 2005):

These iterative, collaborative and transparent, core added-value, knowledge, and resource allocation processes transform and revolutionize a firm's learning processes. This learning, in turn, manifests itself in better resource deployment and more efficient and effective operations. For example, with the right metrics, and with a supporting costing system, the varying profitability of different test campaigns undertaken by customer service/call centers or by Internet direct marketing channels can be measured, thus allowing better redeployment of resources. This is calculated experimentation and improvisation. In addition, the system will capture the history of the success of various sales, marketing and customer service campaigns directed to particular segments. "This is a learning library far superior to any individual manager's memory and experiences” (Dickson et al. 2005, p. 7). Day (2000a, 2003) too recognizes the importance of learning and coordination processes in developing market-sensing, market-relating and customerrelating capabilities. "The defining feature of a market-relating capability is the processes that span boundaries between firms and between functions inside a firm or link the firm to each of its customers" (Day 2000a, p. 28). The three components of these capabilities are the transactional, collaborative partnering, and value-added relationship 
capabilities arising out of the joint effort of customer orientation, organizational configuration (integration and alignment of processes), and knowledge and skills (Figure 2). In essence, Day is referring to cross-functional and collaborative core added value marketing, sales and customer service processes, intermediate-order knowledge management and resource deployment processes and higher order cross-functional learning processes. The learning will depend to what extent the activities in the processes are integrated across functions and to what extent people collaborate. The more this

Figure 2

MARKET-RELATING CAPABILITY (DAY 2000a)

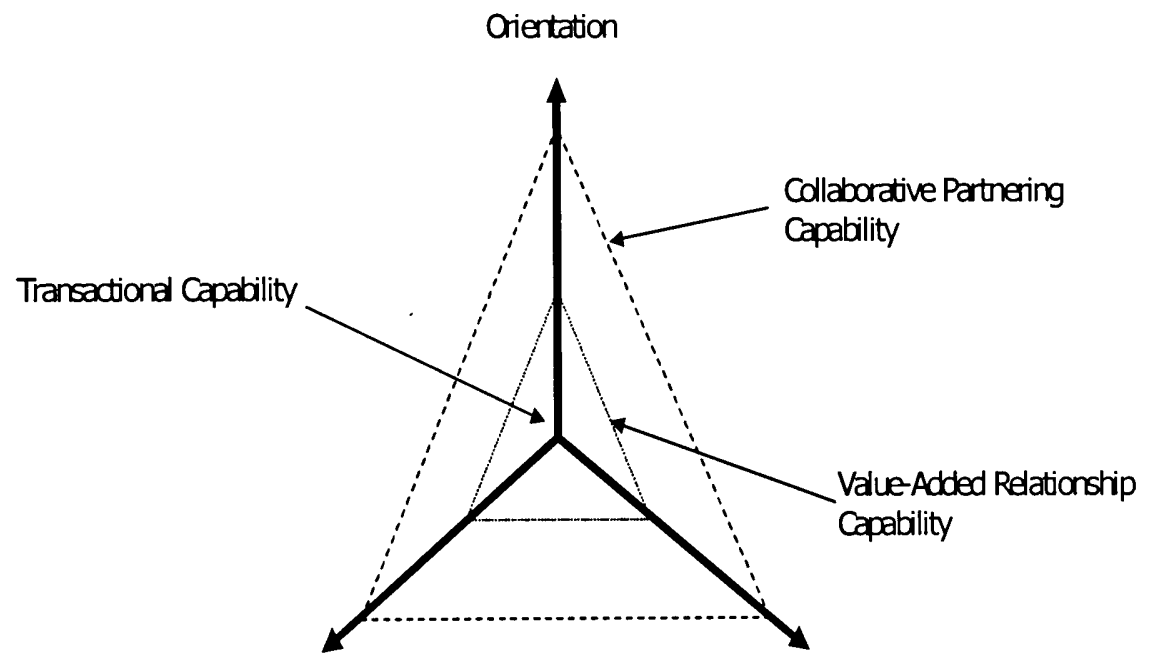

Integration \& Aligrment of Processes

Knowledge and Stills

integration, the higher the learning. "The activities in these processes may be integrated and aligned with interactive technologies (including data interchange), coordinated sales teams, mass customization services, and numerous other devices" (Day 2000a, p. 28-29). These technologies facilitate management of information and development of 
market/customer knowledge and skills. The United States Automobile Association (USAA), the San Antonio based financial service firm serve as a good example of an integrated process organization. All the USAA capabilities are built on a computerized, integrated member database platform. When a member's file is revised, all relevant departments are informed simultaneously. The updated information may also trigger a review of all coverages, leading to proposals for cost savings or new benefits. USAA knows its customers intimately and shares this knowledge widely within the firm. Member files are accessible to all 2,500 service representatives, who can use the information to personalize and customize each service encounter (Day 2000a).

Zablah et al. (2004) also posits that knowledge management and interaction management are the two primary processes through which the objective of the CRM macro process is achieved -- creation of market intelligence and utilization of such intelligence to achieve profit maximizing portfolio of customer relationships (Figure 3). "The knowledge management process is concerned with all of the activities directed towards creating and leveraging the market intelligence that firms need to build and maintain a portfolio of customer relationships that maximizes organizational profitability... The interaction management process leverages available intelligence to build and strengthen customer relationships by enhancing the quality of individual exchange episodes. More specifically, the derived market intelligence is utilized to influence the productivity (i.e efficiency and effectiveness) of interactions in which the buyer and seller engage in" (Zablah et al. 2004, p. 482-483). Key aspects of the interaction management process are customer evaluation and prioritization. Here, the authors are referring to customer segmentation processes which direct efficient and 
effective allocation of resources (Zablah et al. 2004). “An organization's perceived level of responsiveness to the available market intelligence is contingent upon the customer evaluation and prioritization sub-processes" (Zablah et al. 2004, p. 483). Like Dickson et al. (2005) and Day (2000a) these authors also stress that collaborative processes have to be an integral part of all CRM macro and micro processes for superior market and customer learning to take place.

Figure 3

CRM PROCESS (ZABLAH ET AL. 2004)

\section{The Customer Relationship Management Process}

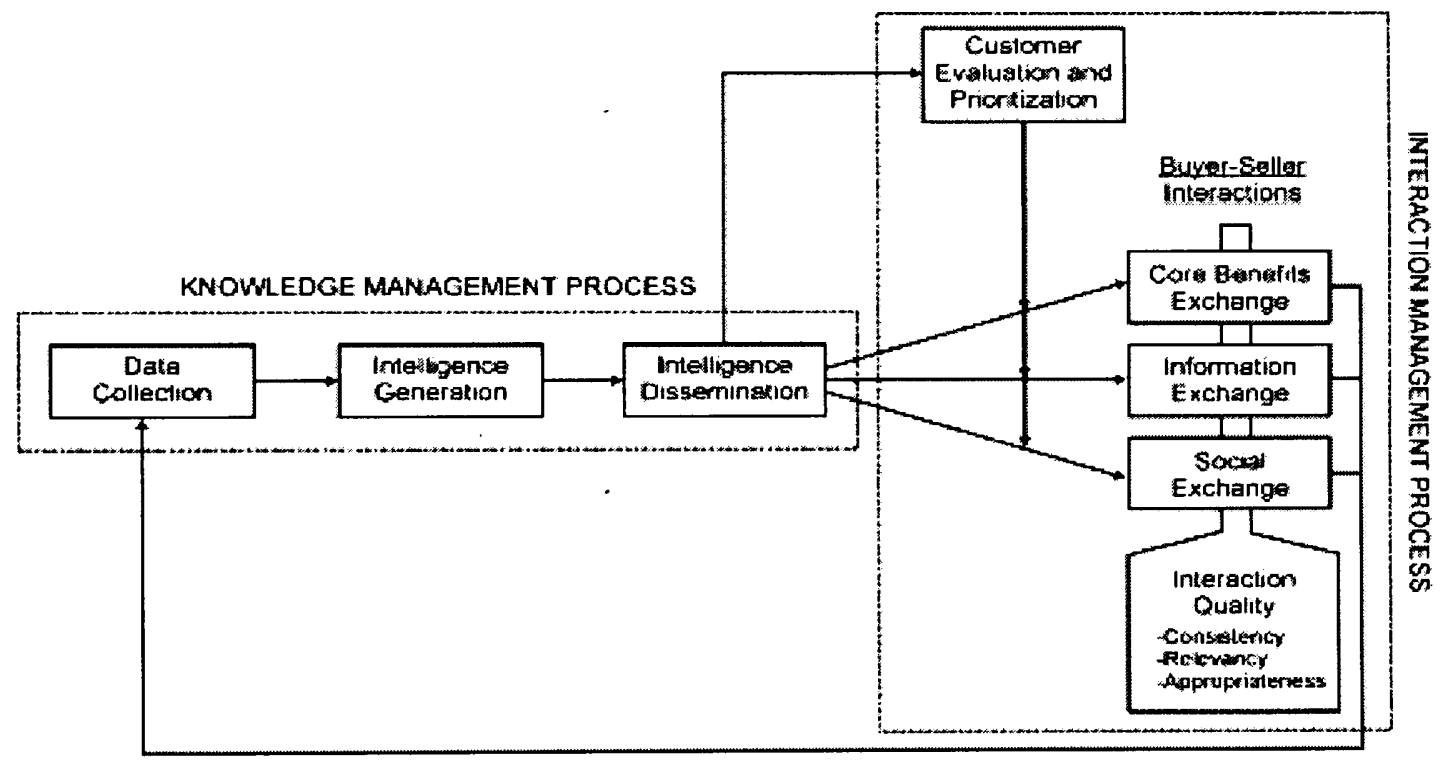

Payne and Frow's (2005) CRM model also takes the same strategic process based approach based on five key cross-functional processes which are also integrated up and down each functional hierarchy: the strategy development process, the value creation process, the multichannel integration process, the information management process, and the performance assessment process (Figure 4). This approach commences with a detailed review of an organization's strategy (the strategy development process) and 
concludes with an improvement in business results and increased shareholder value (the performance assessment process). The value creation process helps create competitive advantage for the company through building superior customer experience in each touchpoint where the customer and supplier interact (the multichannel integration process), and superior learning develop from collecting and intelligently utilizing customer and other relevant data (the information management process).

All the above process based approaches build up the picture of a CRM organization as a system of interlinked processes integrating the people towards a common customer-centric mind-set and a common goal of customer relationship enhancement and company profitability. Technology overlap is mandatory but does not add any value by itself alone. The essence of this process-based approach to CRM lies in

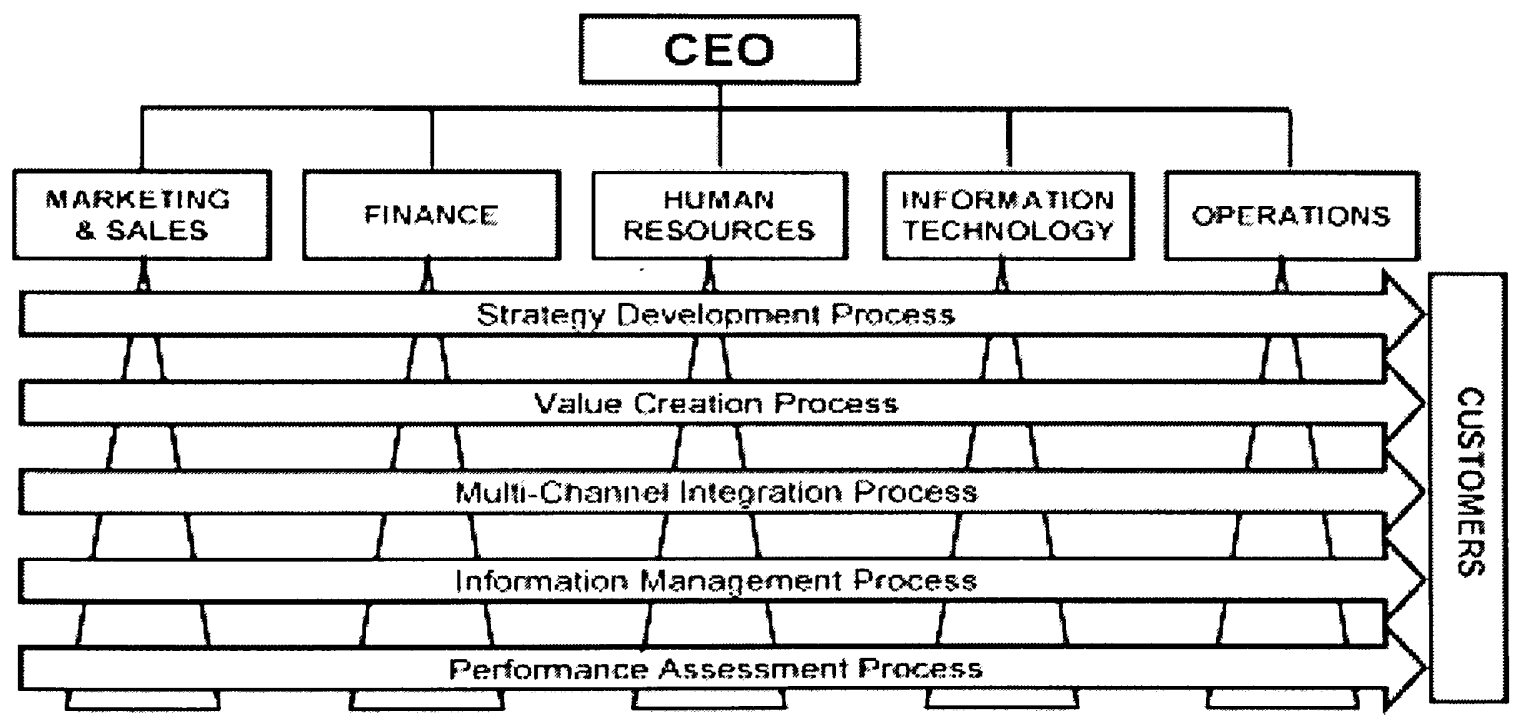

its pan-organizational nature. All processes, beginning with the core added-value processes to the highest learning processes, need to be in collaboration across functions 
and up and down the hierarchy within functions. Non-collaboration sets off a negative chain reaction adversely affecting knowledge management processes, segmentation processes, and the customer interaction processes. The learning processes becomes severely crippled with the ultimate consequence of absence of value creation for the customer. It is the organizational learning processes which essentially improve the company marketing, sales, and service processes, enabling acquisition and retention of the most valuable customers.

CRM is an iterative process that builds up customer and market learning over time to such a level that companies are able to enhance customer relationships through innovative products, sales approaches, customer campaigns, service, interactions, and deliveries. At the heart of all this integration and learning lies coordination across functions without which the whole CRM effort would fail. "If the "competitive bidding" to the senior management for resources for competing initiatives, programs and budgets between functions (marketing, sales and customer service) and between product groups continues with the launch of CRM then it will inevitably lead to competitiveness which is the antithesis of the collaboration and coordination of resource deployment required at the implementation level" (Dickson et al. 2005, p. 7). Therefore, the onus is on senior management to steer the people in the right direction so that they learn to collaborate and collaborate to learn.

$\underline{\text { People Issues }}$

The processes and technologies that help implement CRM strategies and achieve CRM goals will only be as effective as the people performing them. Collaboration between people is the key to successful customer relationship management. 
One of the greatest challenges in customer relationship implementation is aligning the people with the customer strategy and processes (Dickson et al. 2005; Gavern and Panaro 2004; Gulati and Oldroyd 2005). 23\% percent of respondents (executives of large North American companies) interviewed in a 2003 Forrester survey on organizations' efforts in implementing customer relationship management, said that they ran into difficulties in the adoption phase of the CRM, and $46 \%$ percent said that one of the biggest obstacles was resistance to process changes (Temkin et al. 2003). Another similar CRM survey of 1337 firms by CRMProject.com found that $32 \%$ of the respondents thought gaining user acceptance was one of the toughest challenges in a CRM implementation (Dickie 2003).

CRM entails new processes, the value of which the entire organization must understand and appreciate. Due to resistance to change, user acceptance will be hard to attain. Selling CRM to the users and convincing them to collaborate thus becomes of critical importance (Brendler 2001; Day 1999, 2000; Davids 1999; Kale 2004).

Successful CRM implementation takes place only with organizational change, and “..change occurs when people understand clearly what changes are expected of them, why they are necessary, and how their efforts to change are shaped, reinforced and rewarded by all the internal systems that are designed to drive behavior. If those systems send inconsistent messages, the change effort often collapses in confusion. If however, they all point in the same direction, the desired change becomes virtually inevitable" (McGovern and Panaro 2004, p. 33). The criticality of collaboration in realizing the benefits of process integration is highlighted in the study by Majchrzak and Wang (1996) of US electronics manufacturers. Process complete departments were compared to 
functional departments on cycle time which is an important measure of performance in that industry. It was found that process complete departments did not necessarily have faster cycle times; only in those process complete departments that cultivated a collective sense of responsibility among workers, were the cycle times faster. Surprisingly, the rest of the process complete departments had longer cycle times than the functional departments.

Understanding this need for change is just the beginning. Implementers need to understand what changes are needed, what barriers there are to change, and how the change program will benefit the organization. Deep understanding for the need for change comes from getting feedback from customers about the products, services, their expectations and competitors' abilities and then doing an assessment of the company's progress towards the change (Day 1999, 2000).

Obstacles to change appear in the guise of absence of leadership, initiative burnout, stifling cultures, management turmoil, lack of urgency and poor implementation (Day 2000). These are toxic to customer focus and collaboration (Dickson et al. 2005).

Survey results of managers from 107 companies across a wide range of industries suggest that four barriers to change exist in multinational companies (Hansen and Nohria 2004). The first barrier (Unwillingness to Seek Input and Learn from Others) may stem from norms of self-dependency in units in an organization, from reward systems geared more towards heroic individual efforts or from simply a mindset that others have nothing to teach them. The second barrier (Inability to Seek and Find Expertise) is a "needle-ina-haystack" problem where someone in the company knows the answer to a problem but it is almost impossible to figure that out and connect to that person to whoever needs that 
expertise (Hansen and Nohria 2004). The third barrier (Unwillingness to Help) is a result of a "hoarding-of-expertise" problem. Competition between subsidiaries selling products in the same market lessens cooperation and emphasis on individual performance management makes employees feel “... that they don't have the time to help others' or they just don't care; all that matters is delivering their own numbers" (Hansen and Nohria 2004, p. 25). The fourth and last barrier (Inability to Work Together and Transfer Knowledge) comes out of the "stranger" problem where employees are unable to share the content and nuances of their tacit knowledge to employees of a different unit. The lack of a relationship between units makes the knowledge harder to understand, share, modify and incorporate into local conditions. However not all companies will face the four obstacles. Some will have one, some two and some all four. It is important to diagnose which obstacle is the source of the problem.

Researchers and practitioners more or less agree on the levers of change management for CRM implementation. Even though they use different terminologies, in essence all change management efforts can be arranged under three broad categories. These categories have been adopted from Hansen and Nohria (2004); they are: leadership, goals and customer focus; human resources procedures; and cross-functional mechanisms.

Leadership, Goals and Customer Focus

These levers motivate people to develop a collective mind set and responsibility towards developing customer relationships. "As leaders signal the importance of collaboration by working together among themselves, articulating the shared values related to teamwork and developing unifying goals, employees are more likely to be 
motivated to seek and provide help" (Hansen and Nohria 2004, p. 28). Leadership needs to shape the CRM vision and then demonstrate commitment (Day 1999, 2000). They need to make sure all employees understand and are excited about what they will be achieving, understand how to create superior customer value and see what they have to do differently (Badgett et al. 2004). Strategic priorities need to have broad ownership and employee engagement for the change program to be successful.

It is also advantageous to show early wins through grassroots hothouse experiments. These are less disruptive and will act as bottoms-up examples of success to follow (Day 2000; Rigby and Ledingham 2004, Yu 2001). The approach taken by Brother International is a good example. The U.S. based distribution arm of the Japanese maker of typewriters, printers, fax-printer-copiers, and sewing machines, faced a persistent problem of high product returns, which they discovered was due to high dissatisfaction with their level of customer service. Brother wanted to remedy this "pain point" by implementing CRM in their call centers. The company rolled out the new system in stages; this phased approach allowed Brother to refine the system as it was implemented and adjust the training program as circumstances warranted. The results have been impressive (Rigby and Ledingham 2004). The benefits have reached beyond the call centers. Information gathered via the incoming calls has given new insights into customers' needs and behavior and has improved Brother's ability to tailor outreach campaigns to well-defined segments.

Senior leaders themselves also have to walk the talk by demonstrating their commitment to CRM (Day 1999, 2000; Kale 2004). Top leaders need to signal their commitment with occasional direct interventions to help solve a customer's problems, 
spending time visiting customers and listening aggressively to their point of view and insisting on senior management doing the same, emphasizing customer and market issues and insisting on calibration of the performance of the business against the "best of breed" (Day 2000). Managers need to actively support the CRM initiative by using the tools and leading by example (Brenner et al. 2003). Beyond their own involvement, CEO's need to set up a team to mobilize the commitment and champion the CRM program (Day 1999, 2000). This champion will lead the CRM team. Research findings underscoring this found that “... those companies that have adopted a customer czar are twice as likely to say their CRM project is doing 'better than expected' or 'is a runaway success' " $(\mathrm{Yu}$ 2001, p. 19). It is only through the combined effort of leadership, program management and change management working in unison to create a necessary combination of decisions and actions that a successful CRM initiative is generated (Petersen 2004). CRM demands the whole organization to be on the same wavelength. Only the CEO and senior management can achieve this and convince the whole organization to use customer profitability as a driver for decision making and action (Petersen 2004). It is important to realize that leadership behaviors and the articulation of shared values and goals are necessary but not sufficient conditions for effective change management (Hansen and Nohria 2004).

\section{Human Resource Procedures}

Human resources can and should be a part of an organization's CRM implementation efforts. "Crucial to an organizational redesign is "reengineering" the core value development and delivery processes and realigning them with supporting processes such as human resources" (Day 2000c, p. 22). Human resources can support 
the CRM effort by aligning performance metrics, compensation and rewards, and recruitment and promotion, with CRM goals. Strategy should first dictate the new roles of employees and then the required corresponding behavioral changes should be brought about by tying in compensation with the desired performance success criteria (McGovern and Panaro 2004). "The compensation link should not be just a tweaking of commission rates. The pay plan should be redesigned based on the organization's position on the relationship scale" (McGavern and Panaro 2004, p. 32), for example rewarding teams instead of individuals.

Sears has taken the concept as far as any company by basing long-term executive compensation on non-financial as well as financial performance (Day 2000). "Intuit Inc., the financial-software company, has implemented an annual performance system in which employees are evaluated on two questions: "What was accomplished?" and "How were the goals accomplished?" The "how" part evaluates an employee's collaborative efforts across functions and business units in reaching those goals. An employee who did not collaborate enough will receive a lower mark for the year, even if he reached the individual goals" (Hansen and Nohria 2004, p. 28). "Making demonstrated collaborative behaviors a criterion for promotion to senior positions in a company ensures that the top team will, over time, be composed of leaders who exhibit collaborative behaviors. In addition, having such a promotion criterion sends a powerful signal to employees vying for leadership positions; those who do not have the inclination to collaborate are likely to leave a company that enforces that rule consistently" (Hansen and Nohria 2004, p. 28). Harrah's Entertainment showed how seriously it took collaboration and customer relationship initiative by eliminating the recalcitrant resisters (Gulati and Oldroyd 2005). 
To improve collaboration and customer focus, performance might be based on both company as well as customer perspectives. For improving performance management, all metrics should be integrated to reflect CRM objectives and be available in a timely fashion so that corrective actions can be taken. Management of metrics should primarily be restricted to activities critical to the business in order to remain focused. Finally a good performance measurement system should use benchmarking to compare performance and foster a healthy competitive spirit that encourages various groups to share information (Gregory 2004).

For companies that are serious about upgrading and updating their social and technical systems, a part of the culture must be continuous training (Weisbord 1990). Training must focus on skills development, both social (e.g group dynamics, communication, leadership) and technical (e.g. sales and business skills) (Colletti and Chonko 1997). This entails learning to use new technologies, understanding the need for the new processes, the importance of team work and sharing information across functions (Brendler 2001). SBC Communications, the massive telecom carrier, conducts training exercises on a large scale to keep customer initiatives at the forefront of everyone's minds. The company's marketing department offers its employees programs like 'Campaign List Generation 101' and 'Campaign ROI 101.' It is also very important to identify training needs early. Training is often an afterthought during CRM implementations and therefore rushed, underbudgeted, and ineffective (Brenner et. al. 2003). If the organization does not have an internal education department training should be outsourced to a professional training provider (Brenner et al. 2003). 
Training, even though critical for CRM, is always a huge expense whether inhouse or outsourced. One way to balance this need and the expense is by selective hiring. By selecting job candidates who have an inclination to collaborate, an organization will, over time, be populated with people who thrive on cooperative work (Hansen and Nohria 2004). At EMC Corporation, to strengthen and give their CRM efforts a solid base on which to develop, managers carefully screen system engineers and service employees for their customer focus and their ability to interact well with people before they are hired (Lorge 1998). Hiring sales, marketing, and customer service people with some CRM experience and skills should give organizations a head start over others hiring people who are not CRM minded. This should apply even to employees apart from sales, marketing and customer service since CRM should be an organization-wide strategy and effort. People with the CRM mindset should adopt the new customer-centric processes more easily and save the organization effort in changing attitudes and beliefs, which does not happen overnight. Therefore, hiring the right people should clearly give the company an edge.

\section{Cross-functional Mechanisms}

Reengineering delivery processes to span across functions in an organization form the most critical part of change management. It is only with effective cross-functional processes supported by active senior management commitment and human resource efforts that organizations become customer focused and work together as a team. Leadership and human resources motivate employees to shed silo mentality and collaborate to effectively perform cross-functional CRM processes, and these processes themselves lend some discipline to coordination across functions (Gulati and Oldroyd 
2005). To facilitate people to work together and share customer knowledge within these processes, the organization structure needs to be revamped with the creation and development of cross-functional teams and committees that organize and structure regularly occurring interactions (Day 1999, 2000). These also provide a forum for people to get to know one another and develop personal bonds that heighten sharing of information and dissemination of CRM strategy (Colleti and Chonko 1997; Hansen and Nohria 2004; Hartline et al. 2000). The ultimate goal is to cross-train employees so that they can comfortably move between departments to create solutions (Kaydo 1999). Majchrzak and Wang (1996) suggest the following after their study of U.S. electronics companies: make responsibilities overlap by assigning people to multiple teams, rotating assignments with teams frequently and holding unit-wide meetings on a regular basis to discuss process improvements; change the physical layout by allowing people to see each others' work and setting up a special area for continuous improvement where work groups can sit and discuss and solve problems with the help of data analysis tools; and redesign work procedures by providing employees with computer terminals connected to an email network and electronic reporting and tracking system. The problems and comments are routed to the people assigned to provide solutions. This should encourage collaboration especially if the problems, the responses, and the speed of the responses are tracked and measured.

Gulati and Oldroyd (2005) in their in-depth study of 17 diverse set of companies that have made considerable progress towards becoming more customer focused, found striking similarities in the cross-functionally coordinated process paths undertaken by each. This path runs through four distinct stages of successively increasing coordination 
until collaboration and customer focus are institutionalized. Many companies get stuck in this process of "dynamic give-and-take" (Gulati and Oldroyd 2005). This is because this degree of coordination "... requires people in several units who have no formal reporting relationship to interact in spontaneous and unsystematic ways through constant give-and-take. Work is not handed off serially from one group to another; people are learning together in real time. ... This calls for major structural changes" (Gulati and Oldroyd 2005, p. 99). The Royal Bank of Canada organized itself by customer segments that cut across products, technology and geographic boundaries. Harrah's Entertainment took a different approach by adding a new organizational unit to ensure coordination between centralized IT and analytics and the front line. "It created a core marketingleadership team and an analytics group responsible for building scientific-learning capabilities. Then it made front line casino managers responsible for implementing these new methods in their markets within guidelines that offered "several degrees of freedom ... The idea is to foster a test-and-learn culture ... To ensure proper coordination between groups, the company created a new division structure, organized geographically: East, Central, and West" (Gulati and Oldroyd 2005, p. 99). In this process of organizational coordination, employees incorporate their customer orientation into all of their daily operations. In one example, a Continental flight attendant approached a passenger and apologized for a flight delay he had experienced less than 16 hours earlier. In another, a ramp agent -- an individual who works on the tarmac loading luggage -- noticed that the airline had lost the bag of a high value customer on a previous flight. That customer was currently on board, so the agent notified her personally that her bag had been loaded onto the plane (Gulati and Oldroyd 2005). To ensure consistency in customer management, 
coordination needs to be continuously revitalized. Harrah's realizing that there is a lack of understanding and existence of customer oriented skill sets, launched an enterprisewide marketing training program that educated the head of marketing, the director of marketing, and finance officers of each property.

Such change processes as discussed above, crucial in building an organizationwide customer orientation and developing a customer-relating capability, takes time, usually years to complete (Day 1999, 2000). "The journey can be arduous, it takes a long time -- years, not months -- but there are rewards all along the way" (Gulati and Oldroyd 2005, p. 101).

At the same time organizations do realize that ultimately “... shifts in attitude cannot be forced. Employees can only be nudged, pressured, coaxed-and provided incentives. Harrah's invested $\$ 40$ million in 2004 alone to reward those employees who according to their managers had delivered outstanding customer service. And after changing its incentive structure and providing comprehensive training, Harrah's showed how seriously it took its customer focus initiative by eliminating the recalcitrant resisters" (Gulati and Oldroyd 2005). To mitigate the problems of firing and the costs of hiring to the extent possible, quell the resistance to change, and make the recalcitrant employees more tractable and customer oriented, organizations need to create energy. Cross, Baker, and Parker (2003) discovered in their study of energy in seven large networks in a strategy consulting firm, a financial services organization, a petrochemical business, a government agency, and three technology companies, that “... those who energized others were higher performers, even after controlling for people's ability to get the information they need from their own networks and technologies" (Cross et al. 2003, p.52). This is 
because energizers motivate others to action, they get more from those around them (people devote more fully to interactions with an energizer), they attract commitment and better performance and have a positive impact on what individuals and networks as a whole learn over time (Cross et al. 2003). A CRM organization is one in which senior management creates energy and manages change by creating a compelling (but not overwhelming) CRM vision, tying this vision to individual employees' contributions towards it, engaging people fully in the CRM effort, showing early and continuous progress, and finally making people believe that the objective is worthy and attainable (Cross et al. 2003). The last can be attained where senior management " ... speak their minds rather than harboring hidden agendas... and maintain integrity between their words and their actions" (Cross et al. 2003, p. 55).

\section{$\underline{\text { Research Questions Analysis }}$}

Keeping the previous discussion of what current literature from academics and industry have to say about CRM and its implementation in the backdrop, I will now revisit the research questions posed, in an effort to answer them by integrating the knowledge gained from interpretation of analysis of CRM by academics and practitioners supported by the frequencies of mentions of individual and paired categories (typical of content analysis) generated through searches performed on the online database. These are shown below in Tables 3, 4, 5, and 6.

1. How will CRM change the customer segmentation processes?

Both academics and industry believe that profitable segmentation is the backbone of successful CRM implementation. This is evidenced by the high number of times 
(compared to other categories) segmentation and profitability turned up individually (35 and 50 times respectively) as well as together (18 times for the profitability-segmentation pair), in searches run on the online database (Table 3 and 4).

Traditionally customer segmentation is the domain of marketing. However to understand the current and future profitability and loyalty of customers, and their product,

Table 3

INDIVIDUAL MENTIONS OF CATEGORIES IN ARTICLE ABSTRACTS

\begin{tabular}{|c|c|c|}
\hline Constructs & Categories & Frequency in Article Abstracts \\
\hline Strategy & $\begin{array}{l}\text { Profitability } \\
\text { Segmentation } \\
\text { Loyalty } \\
\text { Retention } \\
\text { Capabilities } \\
\text { Customer centric } \\
\text { Acquisition } \\
\text { Shared Vision }\end{array}$ & $\begin{array}{l}50 \\
35 \\
32 \\
31 \\
30 \\
21 \\
20 \\
1 \\
\end{array}$ \\
\hline People & $\begin{array}{l}\text { Change Management } \\
\text { Training } \\
\text { Teams } \\
\text { Leadership } \\
\text { Cooperation } \\
\text { Hiring } \\
\text { Restructuring }\end{array}$ & $\begin{array}{l}36 \\
33 \\
24 \\
20 \\
10 \\
8 \\
5 \\
\end{array}$ \\
\hline Process & $\begin{array}{l}\text { Metrics } \\
\text { Learning } \\
\text { Resource Allocation } \\
\text { Collaboration } \\
\text { Cross functional } \\
\text { Information Sharing } \\
\text { Process Thinking } \\
\text { Knowledge Management }\end{array}$ & $\begin{array}{l}24 \\
20 \\
13 \\
10 \\
8 \\
5 \\
5 \\
4 \\
\end{array}$ \\
\hline Technology & $\begin{array}{l}\text { ERP } \\
\text { Database } \\
\text { Analytics } \\
\text { Datamining } \\
\text { Systems Integration }\end{array}$ & $\begin{array}{l}28 \\
22 \\
7 \\
7 \\
1 \\
\end{array}$ \\
\hline
\end{tabular}

contact and service preferences, marketing needs a complete picture of customers.

Moreover this picture is dynamic because customer preferences and profitability change 
over time and need continuous updating. Thus the challenge lies in getting this 360 degrees view of each customer. In order to achieve this marketing needs help from all corners of the organization; from production, order and delivery, finance, sales and customer service. These functions need to share customer information with a central database on a continuous basis so that marketing can identify trends, run campaigns and collaborate with sales, customer service, finance and delivery to enhance the experience of customers as per their preferences. This sharing of information overtime enhances organizational learning which is reflected in more effective segmentation and more effective resource allocation to customer experiments. Essentially what profitable segmentation in CRM demands is integration of functions through cross functional processes so that there develops a discipline of collaboration which overtime needs to be internalized for learning to occur so that resources can be effectively and collaboratively deployed for enhancing customer relationships and company profitability. The high failure rate of CRM implementation can be traced to ineffective segmentation due to the lack of coordination across functions to the extent demanded by CRM. Segmentation in CRM cannot be improved without improving team work and learning, and ineffective segmentation leads to ineffective resource allocation. This ineffective piece meal approach towards CRM is also largely reflected in the articles chosen for content analysis. Searches for common mentions of pairs of segmentation-teams, segmentationlearning, and segmentation-resource allocation numbered only 6,5 , and 4 respectively. Contrast this with the high common mentions for the pair segmentation-profitability (18) and even higher individual mentions of profitability (50) and segmentation (35) (Tables 3 and 4). Most glaringly not a single article discussed the interactions between databases, 
Table 4

COMBINATION MENTIONS OF SEGMENTATION WITH OTHER CATEGORIES IN ARTICLE ABSTRACTS

\begin{tabular}{|c|c|}
\hline Category Sets & Common Occurrences \\
\hline Segmentation-Profitability & 18 \\
\hline Segmentation-Teams & 6 \\
\hline Segmentation-Learning - & 5 \\
\hline Segmentation-Resource Allocation & 4 \\
\hline
\end{tabular}

Table 5

COMBINATION MENTION OF CATEGORIES ( IN PAIRS) IN ARTICLE ABSTRACTS

\begin{tabular}{|c|c|c|c|c|c|c|}
\hline & ERP & Database & Learning & Metrics & $\begin{array}{c}\text { Change } \\
\text { Managemen } \\
\mathbf{t}\end{array}$ & Teams \\
\hline ERP (28) & & 5 & 8 & 6 & 4 & 4 \\
\hline $\begin{array}{c}\text { Database } \\
(22)\end{array}$ & & & 3 & 4 & 3 & 5 \\
\hline $\begin{array}{l}\text { Learning } \\
(20)\end{array}$ & & & & 5 & 5 & 10 \\
\hline $\begin{array}{c}\text { Metrics } \\
\text { (24) }\end{array}$ & & & & & 7 & 7 \\
\hline $\begin{array}{c}\text { Change } \\
\text { Manageme } \\
\text { nt (36) }\end{array}$ & & & & & & 10 \\
\hline Teams (24) & & & & & & \\
\hline
\end{tabular}


COMBINATION MENTIONS OF CATEGORIES (IN SETS OF THREE) IN ARTICLE ABSTRACTS

\begin{tabular}{|l|c|}
\hline \multicolumn{1}{|c|}{ Category Sets of Three } & Common Occurrences \\
\hline ERP-Learning-Change Management & 1 \\
\hline Database-Change Management-Metrics & 1 \\
\hline Database-Learning-Teams & 0 \\
\hline Database-Segmentation-Resource Allocation & 0 \\
\hline Change Management-Training-Hiring & 1 \\
\hline Metrics-Learning-Resource Allocation & \\
\hline
\end{tabular}

segmentation and resource allocation. Search resulted in (0) common occurrence of the trio in the article abstracts.

2 What is the strategic impact of CRM on cross-functional integration and collaboration within the firm?

CRM is a super innovative business model and requires collaboration to be institutionalized in the organization. If the functions are not integrated through new CRM cross-functional processes and collaboration is not internalized, companies will not be able to get the benefit of enhanced customer relationships and higher profitability.

A CRM organization is a system of reinforcing processes which is coordinated up and down the hierarchy within functions, and also across functions. In order for these processes to function properly and support each other there has to be collaboration. Industry largely and academics to some extent have concentrated on the issue of profitability and customer retention in CRM without holistically understanding and discussing the connection between the same and cross-functional integration and 
collaboration. Comparing frequencies of individual occurrences (Table 3) in articles, collaboration and cross-functional were mentioned only 10 and 8 times respectively. They not only took a back seat when compared to frequencies across all categories of the four variables but were also mentioned less frequently than some other categories within the "process" variable (Table 3). Organizational learning from successful CRM implementation comes out of the collaboration in cross-functional CRM teams. Learning and collaborative teams should go hand in hand in CRM. This is however not strongly reflected in the articles. Even though learning and teams were mentioned 20 and 24 times respectively, their joint presence occurred only 10 times indicating that there is still a lack of holistic understanding of the criticality of collaboration in cross-functional teams to organizational learning (Tables 3 and 5).

3. Will technology and cross-functional collaboration reinforce each other leading to a learning cycle?

The highly complex and innovative nature of the CRM business model coupled with the rapid increase in the sophistication in databases and CRM applications over the past decade has made it easier for companies to equate CRM implementation with technology implementation. However technology at best can be an enabler of crossfunctional processes of segmentation, knowledge management and collaboration. To be an effective enabler it has to align its capabilities with what the processes are trying to achieve. Also since CRM processes are cross-functional CRM technology will also have to be integrated with other legacy systems in the organization for seamless transfer of information across functions and teams. Customization of applications and systems integration are the key issues companies need to concern themselves with and this is the 
role of consultants and the software vendors. Properly aligned technology should lead to organizational learning overtime as sophisticated databases and analytics allow all kinds of analyses that drive experimentation based on decision analytic tools, which in turn drives innovation. Harrah;s Entertainment is a perfect example of a company who has extensively relied on Analytical CRM to drive their Operational CRM (p. 63-64). At the same time strong leadership and an atmosphere of customer centricity and collaboration are primary reasons why they been able to take advantage of the technology. That CRM technology plays a necessary (but not sufficient) part in organization learning, change management (e.g training), and contributes to the effectiveness of cross-functional teams through enhancing collaboration and information sharing does not come through strongly in the articles. Individual mentions of the terms ERP, database, learning, change management and teams were much higher than combination mentions of the same in pairs as well as in trios. For example database, learning and teams were mentioned 22, 20 and 24 times individually, 3, 5, and 10 times in pairs and only 1time together (Tables 3,5 and 6). Systems integration which is one of the key issues of technology alignment in CRM was mentioned only once. Only when organizations think of CRM holistically will they be able to understand how the technology needs to be customized and integrated to suit their purpose. It is then that they will be able to get the most benefit out of it.

4. What kind of change management is needed to bring about the organizational transition required for CRM?

CRM Implementation demands a complete overhaul of processes to crossfunctional, a culture of collaboration throughout the organization and a total change from a function-centric attitude and mind-set to a customer-centric one. Managing a change of 
this gigantic proportion is usually overwhelming and does not happen overnight. At the same it is an absolute necessity for successful CRM.

Because of the strategic nature of change management it becomes the CEO's and the senior management's responsibility to manage change. This is one area where companies are struggling. They are struggling because senior management not having an holistic organization wide understanding about CRM fail to pin point all the areas of change management. Main stream CRM academic literature too has not elaborated on aspects of change management. Yes, they realize change management is important, evidenced by the mention of change management 36 times and training 33 times. At the same time in their discussions they have failed to closely tie in change management to aspects like team work, measurement of performance, organizational learning, and hiring. Combination mentions of change management with training, teams, metrics, learning and hiring surface in only $13,10,7,6$, and 1 articles respectively (Table 5). Search for change management, training, and hiring together resulted in 0 occurrence (Table 6).

A customer database is a crucial backbone for learning about customers. This organizational learning is one important aspect of change management. So are the metrics chosen to evaluate CRM implementation progress because an open measurement system tied to CRM goals and compensation helps enhance collaboration and learning. Combination mention of database, change management, and metrics in the article abstracts occurred only once. Similarly, metrics, learning, and resource allocation when searched together were mentioned only in one article abstract (Table 6).

Change management should start with a strong leadership who has to create a customer vision. This vision has to be supported by training, cross-functional team work 
leading to effective segmentation and resource allocation, performance measurements aligned with CRM goals, and compensation tied to achievement of those goals. It has to be a top down approach flowing down from senior management. This is because it is the CEO and senior management only who have the credibility and control to steer the whole organization.

5. If integration of marketing, sales and customer service is required for CRM implementation, what will these departments look like at the end of such integration?

Marketing and its new role in CRM will require serious attention to the department's culture, organization structure, job descriptions, and physical environment. It is quite likely that reporting relationships and job duties will change to accommodate the new approach and this will likely require and give rise to a different culture and require new workspaces. There is not much information in current literature as to how the marketing, sales and customer service functions are being reorganized. Winer (2001) puts forward the idea that as CRM becomes established in organizations the marketing function will split into an acquisition and retention section with different managers leading these sections, the contention being that acquisition and retention requires two different sets of skills, tactics, programs and processes. Dickson et al. (2005) draw the following picture of a reorganized marketing function based on the requirement that the marketing organization needs to be tailored to support the organizational CRM business strategy. This requires a cross-functional approach across marketing, sales and customer service. "Segment managers will lead the cross-functional teams directed at serving different segments. They will be responsible for segment performance tracking metrics agreed on by their team. The senior marketing manager will be responsible for ensuring 
these metrics are guided and directed by corporate goals and also responsible for reorganizing teams around new emerging segments. Each cross-functional segment team will be responsible for all products, services, sales and marketing programs directed at the segment. The segment team as well as coordinating with marketing, sales and service programs directed at the segment will also coordinate directly with research and development, design and engineering, the advertising agency and any outsourced call centers....In the team will be a CRM information manager who primarily but not exclusively interacts with the IT system. Other members of the cross-functional team will include sales, service and product/service development engineers...A major division of the marketing function will be between the CRM analytics section (that includes IT consultants and high-level analysts) and the marketing line management which is organized by segment" (Dickson et al. 2005, p. 11).

The essence of CRM as a business model lies in the organization-wide collaborative efforts to enhance and sustain profitable relationships with customers. Its success lies in successfully motivating and disciplining the whole organization to perform cross-functional customer-oriented processes. Cross-functional processes discipline the people to work together, technology facilitates them to work together, and change management motivates them to work together. It is the holistic and integrated workings of these three that determines whether CRM will survive or not. For learning to occur out of CRM, the processes, the technology, and the people part (change management, the metrics, the compensation, the training) all has to change and impact each other in positively reinforcing ways. The workings of the whole organization will change as a whole. It will start working as a inter-linked and united entity instead of as loosely 
connected sets of functional silos. Figure 2 below gives a cross-sectional view of integration of and interaction among people, process and technology in a CRM Organization. Industry has to get their heads around CRM and holistically understand how these important dimensions affect each other. That industry and even academics do not have this holistic understanding of CRM is evidenced from the content analyzed articles. This understanding even if present does not strongly come through in the articles.

Comparing frequencies in Tables 3, 4, 5, and 6 it is clear that there are no consistently strong connections established between the important issues. They have been discussed individually many times, mentioned only a few times together as a pair and sometimes zero or only one time in sets of three. Discussion and analysis of how they interconnect and impact each other is largely absent. Where segmentation, database, and resource allocation each was mentioned 35, 22, and 13 times, paired occurrence of segmentation and resource allocation was a paltry 4 times and occurrence of the trio together was zero. Taking the most glaring example, the categories change management and learning have been individually mentioned in 36 and 20 articles respectively but together only in 5 articles. Delving deeper into the articles that mention these two terms together we see in the discussions that change management and learning has to be inextricably entwined for CRM to be successful. For example Chonko et al. (2002) stresses that change management through use of technology and through change of culture and climate help salespeople learn. Change management efforts also help to remove their negative perceptions about CRM and affect their learning (Zablah et al. 2004).Moreover Grant and Schlesinger (1995) points out change management strategies 
such as segmenting employees to match attitude and skills necessary and focusing investments such as pay, training and promotion to motivate employees to engage in cross-functional learning, reinforcing their point with an example from Fedex. Day (2000a, 2000b) discusses in detail about change management strategies and how they affect learning in organization and Gulati and Oldroyd (2005) lays down an

Figure 5

CRM ORGANIZATION: A CROSS-SECTIONAL VIEW

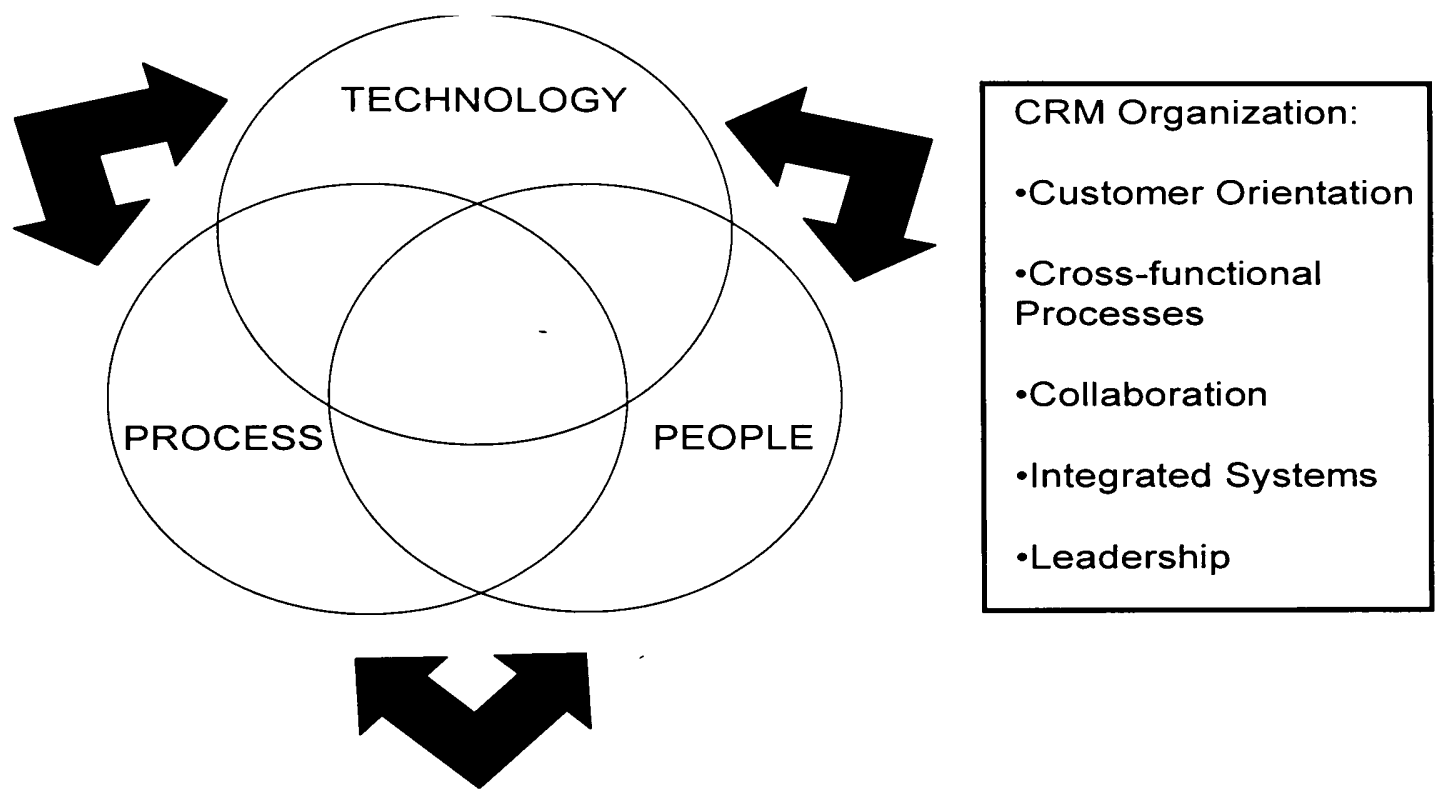

organizational learning journey (based on experiences of 17 companies) driven by process changes that discipline employees to work together and collaborate. More articles like these from academics and practitioners are needed. This is important if CRM has to progress as sub-discipline and if it is to be successful in industry. Finally it will be the CEO and the senior management who will be held responsible for the success of CRM, because they are the ones to lead the organization. In order to do so successfully they will 
have to develop process thinking skills which is necessary to understand the nature of

CRM and its implications. They should have a helping hand in consultants, vendors and academics who also have to think holistically about CRM in terms of people, process and technology, because there is no simple technology solution.

\section{CHAPTER VI \\ ON GOING CRM}

\section{$\underline{\text { Role of Consultants and Vendors }}$}

The following is an example of the impact of a Software Vendor, Siebel Systems (Now a part of Oracle Corporation) on their customers' CRM initiatives. The survey was conducted by Satmetrix on behalf of Siebel Systems (Siebel Systems 2002).

The median results of the impact on the seven different metrics reported by customers as a result of using Siebel ebusiness Application are:

- 8 percent increase in revenue

- 13 percent increase in customer retention

- 23 percent increase in employee productivity

- 23 percent increase in customer satisfaction

- 13 percent reduction in operating costs

- $\mathrm{ROI}$ in 12 months

- Customer Loyalty at more than $90 \%$

The survey also concluded that both Overall Performance and Product effectiveness of Siebel meets/exceeds industry standards. Determinants of Overall Performance include 
product, consulting and technical account management effectiveness, technical support, training and ease of doing business. Determinants of Product effectiveness include product functionality, ease of product configuration, ease of integration, ease of system administration, ease of day-to-day use, scalability of product and software reliability (Siebel Systems 2002).

Another survey of 1337 firms uncovered that some of the toughest challenges these firms faced in their CRM implementation were populating/maintaining data (46\%), customizing CRM tools (28\%), effectively rolling out the system (24\%), and supporting remote users (13\%) (Dickie 2003).

These factors point to the complexity but the necessity of effective technology integration within a CRM strategy and underscore the importance of the role of software vendors and consultants in CRM implementation. The technology requirements vary not only from industry to industry but also from company to company within the same industry because CRM strategies and goals are organization-specific. This highlights the challenge to consultants and CRM vendors in successfully executing their part.

The CRM industry is broadly categorized based on the extent of technology products and expertise vendors provide to an organization in their process of implementing CRM. The products and services offer a variety of functionalities spanning the whole CRM process from the front-end to the back-end of the organization. The categories and the leaders in each category for 2005 are given in table 7 below. The leaders and winners for 2005 have been chosen by CRM magazine where for each category one winner and four leaders are awarded. The overall award rating is based on a composite score of CRM revenues; year-over-year revenue growth; and analyst ratings 
for customer satisfaction, depth of functionality, and company direction (Bailor et al. 2005). The enterprise suite CRM market is characterized by rampant corporate restructuring and consolidation (Both PeopleSoft and Siebel now belongs to Oracle) and the competitive landscape continues to evolve. Amdocs is 2005's winner in this category with its highest customer satisfaction score of all leaders and solid scores in company direction and functionality. Also Amdocs is clearly the most vertically focused. It is second to none in telecommunications and has been strengthening in other verticals, notably financial services and high-tech. The other leaders in this category are Oracle, Peoplesoft (still being rated independently because Oracle CEO Larry Ellison has announced support for PeopleSoft solutions through 2013), SAP, and Siebel Systems (also being rated independently since at the time of the report the acquisition had not yet taken place officially). Oracle is yet to articulate a clear road map for the stuff they bought; SAP continues to improve functionality with increasing customer satisfaction score ("if you need the entire ball of wax, CRM, ERP, supply chain, SAP is the company"); Siebel is offering very strong functionality with not so strong customer satisfaction; and PeopleSoft is awarded solid numbers in customer satisfaction and depth of functionality and its applications remain easy to intergrate with HR and financial systems. "PeopleSoft has always had a reputation for going above and beyond for their customers" (Bailor et al. 2005, p. 2).

The sudden rise in the on-demand model in the mid-market and small-business suite CRM market and the increased competition has rattled the leadership in that market with Salesforce.com coming out as winner in both the categories. "Salesforce.com has relentlessly focused on its "no software" mantra- and it has worked, as the company 
outpaces all midmarket contenders in company direction and scores for customer satisfaction" (Bailor et al. 2005, p. 2). Salesforce.com also jumped to the forefront of the small business space by continuing to deliver on its promises of simple pricing, breadth of functionality, and low IT overhead for users (Bailor et al. 2005).

Table 7

2005 CRM MARKET LEADERS AND WINNERS

\begin{tabular}{|l|l|l|}
\hline MARKET & LEADERS & WINNER \\
\hline $\begin{array}{l}\text { Enterprise- } \\
\text { Suite CRM }\end{array}$ & $\begin{array}{l}\text { Oracle } \\
\text { PeopleSoft } \\
\text { SAP } \\
\text { Siebel Systems }\end{array}$ & Amdocs \\
\hline $\begin{array}{l}\text { Midmarket } \\
\text { Suite CRM }\end{array}$ & $\begin{array}{l}\text { PeopleSoft } \\
\text { RightNow Technologies } \\
\text { Sage Software }\end{array}$ & \\
\hline $\begin{array}{l}\text { Small } \\
\text { Business Suite } \\
\text { CRM }\end{array}$ & FrontRange Solutions & Salesforce.com \\
& Maximizer Software & Salesforce.com \\
\hline $\begin{array}{l}\text { Sales Force } \\
\text { Automation }\end{array}$ & Sage Software & \\
& Entellium & \\
\hline CRM & FrontRange Solutions (Goldmine) & Sage Software \\
Analytics & Maximizer Software \\
& Salesnet & \\
& Business Objects & \\
\hline Consultancies & Cognos & SAS Institute \\
& SPSS & \\
& Teradata & Accenture \\
& Bearing Point & \\
& Capgemini & \\
& Deloitte Consulting \\
IBM BCS &
\end{tabular}

The CRM analytics and Business Intelligence (BI) category has grown to more than $\$ 5.5$ billion in 2004 primarily because it is no longer just targeted to power users. All companies now are looking to adopt a standard BI platform. SAS Institute has once again come out as the winner here with its stellar customer satisfaction score and high customer retention (98\%), followed closely by Teradata. SPSS is still doing catch up because it is still too tech-focused and has a way to go before reaching the everyday 
business user. However it has done well by coming out with products that target specific groups within an organization and provides innovative text-mining tools in which companies sort through structured and unstructured data to predict customer needs. Both Business Objects and Cognos are also leaders in the CRM Analytics market but they do not operate in the same field as SAS, Teradata or SPSS. These two companies may not be as strong as SAS and Teradata in customer satisfaction score but they are the best as far as being very good in two fundamental pillars of analytics, analytic reporting and enterprise reporting tools.

The consultancy market category is worth discussing. Consultants are critical to CRM implementation because of the complexity involved and more than 80 percent of large enterprise CRM initiatives in the past year have used consultants, according to Gartner's 2005 Magic Quadrant Report (Bailor et al. 2005). If there is one company on most large enterprises' short lists, it's Accenture. It continues to lead with its strong strategy capabilities and considerable systems integration resources. In addition, the company's industry and geographic reach continues to be a strong suit (Bailor et al. 2005). While not being as broad as Accenture in their range of services, BearingPoint is still one of the market leaders. The company focuses on specific industries and continues to get good feedback from clients. Deloitte Consulting concentrates on what it knows best. The company remains focused on CRM and demonstrates a solid understanding of client issues, challenges, and the benefits of CRM strategies, particularly in e-business consulting and price optimization. Deloitte's customers 'walk away loving Deloitte. They provide an outstanding client relationship' (Bailor et al. 2005). Finally IBM Consulting Services added depth and functionality to its strategic consulting. The company leverages 
a broad knowledge of and solid relationships with leading software and hardware partners, namely Siebel. This is supported by its vast global reach and combination of process and technical capabilities across a broad spectrum of industries (Bailor et al. 2005).

Looking deeper into the CRM market categories and technology needs in CRM implementation three issues stand out through which the role of consultants and vendors in an organization's CRM efforts can be understood and summarized: 1) Data Management and Systems Integration, 2) Process/Technology Alignment, 3) Supporting the Troops.

- Data Management/Systems Integration: CRM technology consists of front-end systems for customer contacts for sales, marketing and customer service, as well as back office systems that provide the market intelligence by linking customer transaction information with information from finance, accounting, and production. Also, it goes without saying that the foundation is the data warehouse which stores customer information pulled from all corners of the organization and from outside of it (Davids 1999). As CRM systems have become more and more complex encompassing a variety of functions in an organization, the data warehouses these are built on have also grown in complexity. To realize the full benefit of CRM, information from a wide variety of sources, both inside and outside the company, need to be pulled together to create a single and comprehensive view of each customer. Failure to do this correctly can kill a project. If your data is flawed the whole project falls apart (Dickie 2003). Also when users stop believing in the validity of the data they stop using the system. To overcome all these challenges, companies turn to database management specialists such as 
Onesource, Dun \& Bradstreet, or Dataflux for assistance in data rationalization and ongoing data update tasks. While this is an added expense for organizations, the costs of not outsourcing are far greater (Dickie 2003). Microsoft, Pizza Hut, and Western Union do it. These giants with plenty of IT knowledge still find it more effective not to mention more profitable to outsource their datawarehouse to expert providers. These companies have realized that they do not possess the specific expertise needed to get the most out of data warehouses. As for the matter of trusting outsiders with sensitive data, trustworthy vendors will address any confidentiality concerns (Davids 1999).

For effective data management and for acquiring effective market and customer knowledge, systems across the organization need to be integrated. Till today only a handful of vendors specialize in connecting the front and the back in an effective and sophisticated manner.

- Process/Technology Alignment: A company earns the full benefit from CRM, (high customer retention and ROI) when it implements technology that facilitates the processes of customer relationship development and maintenance. In order to do this effectively process problems need to be addressed as well CRM tools need to be customized to fit the processes (Dickie 2003). Global eXchange was able to increase representative leads from one and a half leads per day to seven perday, by optimizing the process the reps used and then leveraging the CRM tools to support the new practices (Dickie 2003). Most of the software that's been developed works. The devil lies in the deployment of the technology in alignment with the process Unfortunately a lot of software vendors do not look at the business problem the end user is trying solve and where the end user is going with their whole CRM strategy and process. "Too often 
software vendors don't help end users define CRM systems' place in their business processes.." (Campbell 2001, p. 34). Part of the problem is that CRM vendors lack the technical staff to follow up with end users- specially mid size and small companies-and are not always able to deploy engineers if a problem occurs says Kevin Rosen, director of the CRM practice at Silverine Technologies, a Piscataway, N.J.-based consultant. (Campbell 2001).

The deficiencies in the role played by software vendors in an organization's CRM efforts, however does not mean companies have to take on this project of technology/process alignment all alone. This where the consultants and solution providers step in. (Campbell 2001; Dickie 2003; Sowalski 2001). Large consulting firms, such as Accenture and Deloitte, as wẹll as smaller boutique firms such as Extraprise and Statera received high marks for the help they can provide in determining the problems associated with existing CRM processes, determining how CRM tools could help optimize the process flow, and finally customizing the applications so they support the new way you want your people to work (Dickie 2003).

To respond to the trinity needs of data management, systems integration and technology/process alignments, consultants and software vendors have struck alliances to more effectively service these CRM related technological and organizational needs. Siebel Systems for example brings in.channel partners for 85 percent of its CRM implementations and sees them as a key to helping clients reach customer satisfaction goals. "We're a software company, not an integration company. Our approach to delivering a solution is to go with a partner" says Steve Garnett, vice-president of alliances in Siebel (Campbell 2001, p. 32). 
Industry executives and analysts agree that integration remains a key challenge in leveraging CRM solutions. "Upto 20 percent of CRM implementation are wasted because of overlapping software and a lack of coordination of among marketing, sales, and call centers according to Bob Chatham, principal analyst at Forrester Research" (Campbell 2001, p. 32). With this need for integration comes the challenge for the consultants (solution providers) to work closely with the customer to focus on the business issue as opposed to the technology (Campbell 2001).

- Supporting the Troops: Considering the complexity of achieving an organizationwide acceptance of a customer-centric model, organizations should consider seeking the expertise of consultants in CRM implementation, and for providing solid plans for developing competitive advantage with CRM (Sowalskie 2001). That means helping in change management which as we saw earlier is a critical factor in deciding whether an organization can get the most out of their people, processes and technology for enhancing customer relationships profitably.

It is worth noting that the most commonly reported under-budgeted items associated with CRM projects are training and ongoing support (Dickie 2003). "CRM introduces new ways of working. Unless the new work skills are taught up front, users will go back to doing things the way they have always done them. Once the systems have been deployed, if a user runs into a problem and has no one to call for help, has their hardware crash and no easy way to get a replacement unit, or they get a new version of the tools and no one explains how to use them, their adoption rates will erode rapidly" (Dickie 2003, p. 61). 
Some consultants and vendors have teamed up to fill that role, Siebel being a good example. In addition firms like $\mathrm{C} 3 \mathrm{i}$ and TRG can take over the full training, asset management, and help desk responsibility for the CRM project (Dickie 2003).

CRM is an innovation and the implementation partner's expertise and knowledge about this innovation can have a considerable effect on organizational members' perceptions of the change initiative. (Zablah et al. 2004). For example, implementation partners can set expectations regarding the implementation process and the performance of the innovation once it has been implemented. Furthermore, implementation partners have the expertise to map-out and coordinate the implementation process such that the deployment of the innovation runs smoothly, and organizational problems stemming from the implementation of the innovation are minimized (Zablah et al. 2004). Evidence suggests that implementation partners with adequate technical, communication, and project management skills boost the implementation process (Meyers et al. 1999). More specifically in the case of CRM, effective external implementation partners can help assure organizational members that the implemented business processes constitute "best practices" and there is a good fit between the CRM tools and these business processes (Zablah et al. 2004). Moreover research on CRM has shown that the strong responsiveness of the implementation team (a big part of which should be an expert CRM consultant) helps to create more positive perception of the correctness of the CRM technology configuration (the extent of technology configured as per the user request), which in turn has been found to be positively related to user approval and acceptance of CRM technology (Gefen and Ridings 2002; Morgan and Inks 2001). 
But are CRM vendors and specially the consultants living up to fulfill this need? Not always, according to Christina Pries and Merlin Stone (Pries and Stone 2004). The authors interviewed senior and middle management in consultant firms specializing in the Financial industry in the U.K., France and Germany. There findings hint that consultants are paying lip service to facilitating change management in their clients' CRM efforts. More specifically they found that even though change management has been widely accepted as a critical path to successful CRM implementation, surprisingly, “..not a single interviewee mentioned training in change management, or in implementation procedures. This shows the strong focus of consultancies on selling CRM projects rather than on implementation procedures" (Pries and Stone 2004, p. 357). Complicating this matter are the strong ties of consultants with CRM software vendors (often both being the same company), which might influence the consultancy in its advice to its client on the choice of software (Pries and Stone 2004). The reasons as per the consultants, for implementing CRM was either to increase profits or reduction of expenses. The strong focus on costs rather than on customers increases the risks that CRM projects will eventually lead to customers being managed less well. Consultants tend to blame clients for weaknesses in change management and "one consultant even said that the company culture had never changed in a project-all that had been done was to build up a stronger sales and service orientation...Two consultants were convinced that the attitude of employees does not have to change; only the sales procedures do, and all the efforts of CRM go to supporting the sales force to be able to sell more" (Pries and Stone 2004, p. 365). Surprisingly the respondents interviewed do not seem to have discontented clients, considering the high rate of disappointment with CRM programs in all industries in general. "Apparently all 
projects carried out by 'others' were not successful”' (Pries and Stone 2004, p. 367) Unfortunately none of the consultants studied the results of their own client companies; nor did they know their own client retention rate (Pries and Stone 2004). The authors came to the conclusion that consultants did not always believe in or followed best practices of change management.

The CRM industry over the course of the last year grappled with well-publicized mergers and acquisitions, executive turnover, and product line restructuring. Still the industry's impact-especially in the small and medium business markets-is becoming more widespread across industries and within organizations. "With an eye on ROI, companies are benefiting from lower startup costs, shorter implementation times, ease of use, and more robust analytics, from both the on-demand (hosted) delivery model and on-premise solutions." (Bailor et al. 2005, p. 1). At the same time a lot of challenges still remain high on the agenda if consultants want to enhance higher customer satisfaction and the benefit they receive from successful CRM implementation. Consultants and software vendors need to customize applications to support the CRM processes, better integrate them with legacy systems and incorporate more of the change management concepts in their dealing with organizations. Organizations would get better results from CRM consultants and software vendors if they were better schooled in change management and incorporated these in facilitating an organization's journey to enhance customer relationship management. CRM vendors and consultants need to look more holistically at the needs of organizations for a successful CRM implementation to better suit their specific requirements 
"In tandem with CRM, the discipline of marketing has undergone its own, albeit less pronounced, evolution during the past decade. While CRM sales and service applications took center stage, marketing-or the personalization and communication of brand and value-waited quietly in the wings. As CRM initially focused on improving channel efficiency and customer satisfaction, marketing's role was to assist these efforts through product sales and customer acquisition. When customer interactions became as important (if not more so) than customer transactions in the mid-1990s, marketing took its first timid steps into the CRM spotlight" (Freeland 2001, p. 3).

Marketing has always viewed the core objective of their discipline as attracting and retaining customers profitably. This is also the primary goal of a CRM organization. However when 200 executives were asked in a survey by Accenture, to rate principal corporate functions in terms of their value contribution to the overall company, marketing was given a rating of 3.7 out of 5 (where $5=$ maximum contribution). Also just 23 percent of the executives said marketing made a very significant value contribution and only 21 percent said that marketing was one of the three most important functions (O'Halloran and Mosher 2003).

Executives clearly do not see marketing contributing to the bottom line. This is because firstly many senior executives do not fully comprehend the role and purpose of marketing in an organization and secondly marketing in most cases has not been able to clearly link its activities (e.g a campaign) to the revenues generated from it.

In order to achieve this CRM goal of attracting and retaining customers profitably, “..the organization must design and execute many work practices, most 
commonly known as "business or operating processes", that go considerably beyond those practices traditionally viewed as falling within the domain of control of the marketing function” (Srivastava, Shervani, and Fahey 1999, p. 169). These authors put forward product development management (PDM), supply chain management (SCM) and customer relationship management (CRM) as the core business processes. In order for marketing to play a major role in a CRM organization it not only has to infuse itself within and influence these core organizational processes and instill a customer orientation in all these processes and subprocesses, it also has to be able to measure ROI from marketing operations and show the economic impact of marketing on the organization's bottom line, to senior management (Srivastava et al. 1999). It is only in this way that marketing as a discipline and individual marketing activities can be linked to central operating activities in an organization and through that to the marketplace and financial returns.

Changes in the competitive and macroenvironmental factors affect marketing, which in turn necessitates changes in process designs. Teams involved in the three core processes of PDM, SCM and CRM must acquire marketing capabilities so that these teams responding to changes in the marketplace can implement changes to the design of the core processes. With the emphasis in today's business world on customer orientation, solution customization, relationship management, and networking the core processes must change in ways so as to address these environmental changes.

The market oriented changes to PDM includes an emphasis towards creating products and providing customized solutions that give customer maximum value and benefit at the same time leveraging resources to create products that serve interrelated 
customer segments. This effort might require participating in and leading networks. One good example would be involving customers, their inputs, and taking into consideration competitors' activities for new product development to avoid false starts, delays and missed opportunities. To get these new products to the market faster, firms must integrate the organization's own supply chain with those of suppliers and customers. Market driven supply chain elements should be designed to facilitate the design, development, and delivery of solutions in ways that will benefit customers. One way to do this is to avail of networks to get access to next generation materials, components, and supplies (Srivastava et al. 1999). A customer oriented customer relationship management becomes a means to learn about customers' needs and wants, and how best to create, satisfy, and sustain them. Companies need to work with individual customers as well as form networks of customer relationships involving channel members, end users, and other marketplace entities such as advertising agencies and consulting services to generate economies of scope and increasing returns. In a similar manner individual marketing activities must also infuse subprocesses of the three core processes with customer orientation. CRM subprocesses must be energized with market orientation and the market specific tasks in these CRM subprocesses can be linked to individual subprocesses in both the PDM and SCM processes.

If marketing succeeds in this alignment it is ".. likely to emerge as a lead function in managing customer relationships. It plays an important role in the articulation (i.e defining the value proposition and positioning in the market), navigation (i.e through market sensing and information dissemination), and orchestration (i.e process management and coordination) of the CRM process. However, the role of marketing 
activities in the PDM and SCM processes is likely to be in the domain of articulation and navigation" (Srivastava et al. 1999, p. 172).

The next challenge for marketing is to measure and demonstrate the impact of marketing resources and the marketing activities that utilize them, on current outcomes and on future financial performance. Since the dominant perspective in market value is best reflected by the net present value (NPV) of all future cash flows expected to accrue to the firm (Srivastava et al. 1999), marketing activities must influence and link the core business processes to acceleration and enhancement of cash flows and reduction in the risk associated with cash flows by decreasing both their volatility and vulnerability and indirectly, the firm's cost of capital.

Getting the right inputs from customers and involving them in product development quickens time to market, as a consequence avoiding costly false starts, delays and missed opportunities. PDM enhances cash flows by creating product and solution platforms that enable future, increased return generating product designs, customization of solutions and adaptation of products at much lower costs. Moreover market inputs forecasting growth of segments guide resource deployment for product development, reducing future risk in the process. Reducing cycle times in SCM is crucial in getting the right products to the customer in the right form and faster. Absence of market inputs all too often retards the speed of commercialization and thus the receipt of cash flows. Market inputs also influence SCM to enhance cash flows. Accurate projections of product needs help to streamline logistics, product process technologies and choice of the most effective distribution channels. "Companies such as Benetton, Amazon.com, and Dell have been successful in using market information to identify 
higher demand colors, titles and product configurations, respectively. By promoting these "best-sellers" they drive the market to enhance revenues and reduce costs simultaneously" (Srivastava et al. 1999, p. 175). Better market information also help to reduce procurement and inventory costs. Cash flow vulnerability maybe reduced by the SCM process through process innovation. Gillette reduces risk by designing hard-to-copy manufacturing processes, including the machine tools used for production (Srisvastava et al. 1999). CRM activities such as advertising and promotion result in more rapid product awareness, prompt early product trials, and promote repeat purchases. These facilitate diffusion of innovations. All these results support cash flow acceleration. CRM subprocesses identify customer needs, and adapt solutions as these needs change. This leads to higher satisfaction and increasing awareness and acceptance of brands. Also the customer base can be leveraged to enhance revenues through cross-selling and up-selling by identification of complementary and upwardly mobile needs. Successful implementation of customer oriented CRM subprocesses can also contribute to greater customer switching costs and higher loyalty thus lowering future risks to cash flows (Srivastava et al. 1999).

In order to do achieve the above two objectives of infusing itself into the core processes of an organization and link itself clearly to financial outcomes, marketing has to take a new approach. O'Halloran and Mosher (2003) thinks this approach should have three necessary elements.

First marketing has to "..instill discipline, science, and rigor in the function that enables marketing leaders to systematically and accurately measure the return on their portfolio of marketing activities" (O'Halloran and Mosher 2004, p. 2) In other words 
marketing needs to greatly improve marketing systems control over marketing processes and campaigns by measuring marketing process and campaign performance using Analytical CRM metrics. Second, marketing needs to use a combination of analytical marketing to develop superior insights into customer behavior and needs that make sales and service more effective and creative, and operational marketing in tandem with analytical marketing and sales and service efforts to build and sustain a compelling brand image through satisfying brand experience and positive customer interactions (Freeland 2001). In essence marketing has to undertake in-depth customer segmentation, and targeted campaigns to reachable segments that creates higher growth and profit opportunities. With a better understanding of the profiles of unique customer segments, companies can create and launch new products and services that meet specific needs and, thus beat competition to the market. As companies have adopted this new approach to marketing they have also seen marketing take its rightful place beside sales and customer service as one of the company's most important functions (O'Halloran and Mosher 2003). Third, the organization has to make marketing the owner of the company's customer data and the Analytical CRM and the marketing leader's role broader to ensure coordination between marketing, sales and customer service.

This new approach demands that the marketing workforce be upgraded along with the function's technologies and processes (O'Halloran and Mosher 2003). This upgrading requires developing new capabilities such as the following:

- Marketing executives have to develop financial analysis skills and “..use integrated marketing and customer financial data to develop, implement, and monitor resource allocation strategies to maximize shareholder value...Marketing processes have 
to be able to collect, process, and act on data in as close to real time as possible" (O’Halloran and Mosher 2003, p. 3-4).

- Marketing executives must "reduce the time to learn required competencies...they should be doing things that enable them to more effectively identify the most profitable customers and those customers most likely to grow profitably...The marketing workforce should use relevant customer, market, and competitive insight to craft meaningful customer messages and determine the right mix of channels to maximize reach, consistency, and alignments of the brand image. And if the goal is to maximize the return on marketing investment, marketing personnel must use behavioral and transactional analysis and/or primary research to target the most profitable segments; allocate marketing mix elements across brands and customers based on analytical assessment; and manage external marketing resources for low cost and high impact" (O’Halloran and Mosher 2003, p. 6).

What the authors recommend is to use Analytical CRM to create a "marketing learning environment that enables the department to more precisely understand what works and what does not and to use that insight to improve future campaigns" (p. 3). As marketing executives learn to use CRM metrics to measure and manage campaign performance and are rewarded for its use, and are able to establish the bottom-line value of marketing campaigns, marketing morale will increase, appreciation of the Analytical CRM system will increase and be more valued, will be used more which will further increase the efficiency and effectiveness of marketing allowing it to take a leadership role in a company's CRM efforts. Marketing will need this analysis skill when other functions seek help from marketing in their CRM management, given that marketing is 
now responsible for CRM Analytics. Marketing will have the responsibility to help sales, customer service, product development and senior management learn to effectively query and manage the CRM system for their needs (Dickson et al. 2005). "This is where the marketing function must shine, right from the very outset, in its training of its own people and their skills in using the system and demonstrating how the system is useful for systems control and resource deployment decision-making. They must be able to reach out and creatively think how the system can be used by sales and service so as to promote its use across the three primary customer interface functions and processes. And if these support requests are largely bungled by the marketing function, marketing will be rightly seen to have badly dropped the ball on CRM" (Dickson et al. 2005, p. 11).

This new approach to marketing and its new role will require serious attention to the department's culture, organization structure, job descriptions, and physical environment. It is quite likely that reporting relationships and job duties will change to accommodate the new approach and this will likely require and give rise to a different culture and require new workspaces. There is not much information in current literature as to how the marketing function is being reorganized and how much organizations are seeing. Irrespective of whichever way marketing reorganizes, this major change management of structures, roles, and skills in marketing, demands active leadership support from senior management if marketing is to emerge to lead the CRM effort.

\section{$\underline{\mathrm{CRM} \text { and Organizational Networks }}$}

The rapid enhancement of technology's capabilities in manufacturing, information sharing, and communication and the complexity and flexibility required to understand, satisfy, and retain global markets is changing the structure of industries. The 
emerging result is a "..paradox of scope: a shrinking core and an expanding periphery. While the firm narrows its internal activities to focus resources on the activities that it does best ("the core scope"), it broadens the network of partnerships with suppliers, channel partners, and complementors that it orchestrates to extend it sphere of influence beyond the assets that it owns and controls ("the extended scope"). Firms such as Handspring, General Motors, and Nike focus their internal activities on marketing, sales, design, and branding while relying on a constellation of partners and suppliers to source, realize, deliver, and augment value for their customers" (Sawhney and Zabin 2002, p. 315). Any player that wants to play a significant part in the dynamic global economy has to, sooner or later be actively networked (Achrol 1997), and the one glue that will hold together a network of stakeholders is the "relational equity" sustained through mutual benefits (Sawhney and Zabin 2002) ${ }^{3}$. This is because "..there is a fundamental, even inalienable, nexus between network and relationship concepts and processes..One cannot exist over a significant period of time without the other" (Achrol 1997, p. 56).

Competitive advantage will now stem from this "relational equity" and how successfully organizations build and leverage relationships not only with customers but also with employees, partners, and suppliers (Sawhney and Zabin 2002).

In defining relationships, practitioners and academics alike tend to adopt a somewhat narrow perspective by focusing solely on customer relationship management (Badgett et al. 2004; Campbell 2003; Cao and Gruca 2005; Freeland 2004; Gustafsson et al. 2005; Kennedy et al. 2003; Plakoyiannaki and Tzokas 2002; Petersen 2004; Rigby and

\footnotetext{
${ }^{3}$ Relational equity is the wealth creating potential that resides in the firm's relationships with it stakeholders (Sawhney and Zabin 2002)
} 
Ledingham 2004; Reinartz and Kumar 2002, 2003; Ryals 2005; Siebel ebusiness 2001, 2002; Thomas and Sullivan 2005; Swift 2003; Winer 2001; Zablah et al. 2004; Zeithmal et al. 2001).

The same three success pillars of customer relationship management- process, people, and technology -now has to be extended and applied to developing relational equity with other stakeholders (partners, suppliers and distributors). "Firms cannot think about customer, channel partner, supplier, or employee relationships in isolation. These relationships function as a systemic whole to form the value network, or business ecosystem, that a firm creates around it" (Sawhney and Zabin 2002, p. 315). The essence of the existence of such a network lies in its relationship; the firms' relationships with its stakeholders are not independent of each other. As employees interact with customers, customers with retailers, retailers with distributors, distributors with employees, employees with suppliers, suppliers with channel partners, they mutually reinforce the network bond. The quality of employee relationships, supplier relationships, partner relationships, distributor relationships, and retailer relationships all together affect the quality of customer relationship and consequently the mutual benefit derived from the network (Sawhney and Zabin 2002). Firms thus need to think and manage relationships in a holistic manner. They need to define their "to market strategy" for managing relationships.

Only if these strategies are consistent, clear, and prudent will they help to develop the shared understanding of relational equity across all stakeholders. These strategies need to be managed by well designed, integrated, inter-enterprise and continually adapting processes. In order to enable processes a shared understanding needs to be 
developed in the network as well as a technology infrastructure and application for knowledge management. Network design and processes should be such as to still allow marketing multi-faceted and customized offerings to customers all the time presenting one face to all the stakeholders. Finally, to assess the effectiveness of this relationship process, enhanced network learning and renewed relationship capabilities, appropriate measurement, and control systems need to be in place (Jarratt 2004; Sawhney and Zabin 2002).

This relationship process overtime becomes an adaptive learning process which allows firms to progressively adapt their offers, customize their interactions and integrate their processes more widely and deeply with customers, suppliers, channel partners, and employees (Sawhney and Zabin 2002). This positive reinforcing loop of dynamic capabilities and learning has to be supported by adequate technology structures and collaborative processes.

"This vision of enterprise relationship management demands a "single version of the truth"-a unified enterprise data warehouse that stores information about external entities. This data repository should connect to all external entities, forming an integrated network of applications... There is no distinction between employee portals, partner portals, and customer portals. They are all windows into the same repository of information, differing only in the roles that are defined for each user, the interactions that are associated with each role, and the level of access permitted for each role. The Internet (the customer face), intranet (the employee face), and extranet (the supplier face) simply become different levels of secure access into a common information repository, as well as 
to the applications and content objects that constitute the enterprise infrastructure" (Sawhney and Zabin 2002, p. 324).

An important emerging trend in technology application in networks is that of the hub-based application architecture which is “..designed to centralize and coordinate interactions with all key stakeholders of the firm..The hub-based architecture allows information to propagate synchronously to customers, suppliers, channel partners, and employees" (Sawhney and Zabin 2002, p. 323). This is changing the very nature of interenterprise processes where firms are developing extranets for partners, intranet for employees and the Internet for customers that use the hub as their central metaphor and the value network as their scope of deployment (Sawhney and Zabin 2002). The hubbased architecture allows a firm to present one face to all stakeholders by creating a unified enterprise relationship management infrastructure through integration of CRM, SRM (supplier relationship management), PRM (partner relationship management), and ERM (employee relationship management) applications. Trane, the air-conditioning company utilizes Comfortsite, a hub based architecture to manage and integrate its relationships with contactors, distributors, third-party suppliers, and customers. Comfortsite provides real time interactions and transactions. Contractors can place equipment orders in 9 mins compared to a conventional order taking 56 mins; suppliers can fulfill orders in fraction of the time normally required; distributors can order parts, view inventories, get product updates, training and market support; and customers can find local contractors, schedule maintenance, check warranties and track installations and service history (Sawhney and Zabin 2002). 
To reflect this strategic shift in relationship firms are reorganizing themselves in ways that emphasize relationships. Some of these forms are called the hybrid front back organization (Galbraith 2000), the process enterprise (Hammer 2001), and the synchronized organization (Sawhney and Zabin 2002). A common theme running across all the three is the uncoupling of product expertise, functional expertise, and relational expertise by creating a "decoupled front-back hybrid organization", where it is organized broadly around customers, partners and also into functional and product oriented backend departments to achieve functional specialization and scale (Sawhney and Zabin 2002). Large firms like IBM, Johnson \& Johnson and CitiGroup are establishing organizational structures along similar lines (Sawhney and Zabin 2002)

To effectively share knowledge, create stakeholder value, and achieve competitive advantage in the network, an enterprise relationship management must develop a dynamic relationship management capability to build and manage the relationship overtime. This is the network version of Day's (2000) market-relating capability. Jarrat (2004) conceptualizés this higher order capability as second order capabilities grounded in infrastructure, learning and behavior. "Functionality is derived through systems, processes, expertise, and experiences, in other words, infrastructure, while integration emerges through learning from knowledge residing in the firm (internally and externally), and a culture that fosters learning to enhance or redefine the capability" (Jarratt 2004, p. 296).

It is important to recognize however that (and this becomes evident in the above discussion) in networks the long term character of the relationship is defined and will be shaped by a larger institutional framework than just the dyadic relationship between firms 
and customers (Achrol 1997). Shared understanding of relational equity and it's desired outcomes could be undermined by power struggles and conflicting priorities within and among the stakeholders (Achrol 1997; Plouffe et al. 2003). Successful interorganizational networks has to develop trust and commitment as well as social norms such as solidarity, mutuality, role integrity, harmonization of conflict, and restraint of power. Successful networks have place for only expert, reputational and referent powersinfluences that help build social bonds and close relationships (Achrol 1997). Even though this is where the scope of CRM is most likely headed for the future, seeing the small scale success of CRM and the monumental challenges faced by organizations in its implementation, development of a relational equity through management of interenterprise processes and relationships will require a long and grueling journey by organizations. The good news is that those managing to successfully complete this journey will definitely reap benefits of long term competitive advantages for the whole value network.

\section{CHAPTER VII CONCLUSION}

This dissertation has tracked the evolution of CRM and explored the critical issues for successful implementation of this innovative business model. It has raised important questions about CRM and has qualitatively investigated these to extract emerging trends and a possible destination of it. It has also underscored the part marketing needs to play in this effort, in order to place itself in a position of strategic 
significance in an organization. Finally, the online database and search engine created as a part of the dissertation, besides being a methodological contribution in itself, should also help enhance understanding of CRM as academics take advantage of it and turn it into a dynamic knowledge hub.

One obvious limitation of this dissertation is the breadth and the number of articles used for content analysis. CRM is a pan-organizational model and all parts of the organization plays a part in the implementation success. My analysis is based on 117 documents from both academics and trade. Time limitations did not permit the dissertation to include more documents. Because of the evolutionary and cross-functional nature of CRM the analysis might have been richer by some degrees if substantially more articles from a wider range of research discipline were included. Literature from change management, leadership, and Information Technology, to cite a few examples, can fall under the purview of CRM research. Even though I included few articles from change management and Information Technology the bulk of the academic articles are from marketing and sales. Therefore one obvious extension of the content analysis would be to include more articles from other related sub-disciplines. This will also help to make the online database richer. As far as the website is concerned it has to be improved and the search engine made more sophisticated.

This dissertation will be a base for conducting future research in CRM. Now that a holistic view of CRM, its issues and their interaction has been explored and discussed, complementary research to further investigate the evolution of CRM can be undertaken using surveys, interviews and case studies as research tools. These research will lend further rigority to the sub discipline through statistical analysis. Some specific areas of 
research are investigation of the role of CEOs and consultants in CRM implementation, the role of CRM in networks, and developing scales for measuring CRM constructs and their inter-relationships.

CRM business model is a super-innovation (Dickson et al. 2005) and if given the support of the superstructure of a network of stakeholders to sustain and expand it, can be a source of super-competitive advantage (Sawhney and Zabin 2002). The ultimate aim of CRM is profitable customer relationships. The customer is the stake and at stake are customer relationships and company profits.

CRM has to be an organization-wide effort with active support from senior management. Senior leadership needs to be actively involved in changing processes to make them more customer-centric and cross-functional, facilitating these new processes with technology, instilling disciplined cooperation and collaboration in carrying out the cross-functional processes, training employees to become more customer-centric and enhance their market-relating, customer-relating and process thinking capabilities, hiring customer oriented people with collaborative and technological skills, and compensating employees on achieving CRM goals.

In the short time period of a decade after CRM came into being in its present form, it has already started having significant effects on employees' customer orientation, and cross-functional cooperation and collaboration. Evidences can be found in companies who have been successful in implementing CRM, such as Harrah's Entertainment, Royal Bank of Canada (RBC), and the SBC Communications, the massive telecom carrier. These companies are well on their way to move past discrete and formal initiatives, to weave customer focus into informal values and daily behavior of all employees. They are 
coordinating key activities across vertical and horizontal boundaries. Technology has helped. It has facilitated companies to communicate customer information across functions and manage customer knowledge better. CRM technology has vastly improved in functionalities and integration capabilities. Databases have become more integrated and analytics have become more sophisticated. Customer information can be filtered in from all corners of the organization and then analyzed to get a complete picture of each of them. This has enhanced understanding of customers allowing companies to target profitable customers and making management of customer loyalty more effective. CRM technology has thus facilitated and strengthened cooperation across functions and made customer segmentation and profiling more of a cross-functional process. At the same time this is happening only in a small handful of companies. Largely, understanding and implementing CRM is still done in a piecemeal manner and this has to change if companies have to realize the full benefits from CRM. The secret lies in a holistic understanding of customer relationship management and in resulting capabilities (arising partly out this superior understanding) allowing integration and alignment of processes, people, technology, metrics and compensation, organization wide under an umbrella of customer centricity. Collaborative processes across and up and down the organization form the foundation for successful CRM implementation. This along with open knowledge management and performance measurement processes should result in collaborative and informed resource allocation towards coordinated cross-functional customer interactions. These finely tuned interactions and communications lead to improved customer learning and with further analysis help to come up with more customized offerings. This dynamic reinforcing cycle of experimentation and learning, 
overtime should result in superior processes leading to strong profitable customer relationships and a hard to imitate competitive advantage. 


\section{LIST OF REFERENCES}

Abbott, Julie, Merlin Stone, and Francis Buttle (2001), "Customer Relationship Management Practice-A Qualitative Study," Journal of Database Management, 9 (1), 24-34.

Achrol, David S. (1997), "Changes in the Theory of Interorganizational Relations in Marketing: Toward a Network Paradigm," Academy of Marketing Science Journal, 25 (1), 56-71.

Adenbajo, D. (2003), "Classifying and selecting e-CRM applications: An analysis-based proposal," Management Decision, 41 (6), 570- 577.

Ang, S. and Endeshaw, A. (1997), "Legal Case Analysis in IS Research: Failures in Employing and Outsourcing for IT Professionals," in Information Systems and Qualitative Research, A.S. Lee, J. Liebenau, and J.I. DeGross, eds. London: Chapman \& Hall, 497-523.

Applegate, L. (1994), "Managing in an Information Age: Transforming the Organisation for the 1990s," in Transforming Organisations with Information Technology, Baskerville, R.S. Smithson, O. Ngwenyama, and J. DeGross, eds. Amsterdam: Elsevier Science, 15-94.

Badgett, Melody, Steve Ballou, and Steve LaValle (2004), "Doing CRM Right: What it Takes to be Successful with CRM-Executive Summary View," CRM Global Study, IBM Consulting Services.

Bailor, Coreen, Colin Beasty, Alexandra DeFelice, and Marshall Lager (2005), "The 2005 Market Leaders. Part 1," www. destinationcrm.com/articles, (October 01).

Barth, Brad, (2004), "Double Down: CRM is the Cornerstone of it at Harrah's Entertainment, and New CIO Tim Stanley is Eyeing an even Bigger Payoff with Version 2.0 of its Total Rewards Loyalty Program," Fairchild's Executive Technology, 6 (3), 38.

Battista, Paul and Darcy Verhun (2000), "Customer Relationship Management: The Promise and the Reality," CMA Management, 74 (4), 34-37.

Bernstein, Corrine (2005), "Tim Stanley: Harrah's Placing Its Bets on Operational CRM," Fairchild's Executive Technology, 6 (10), 36.

Berry, L.L. (1983), "Relationship marketing", in Emerging Perspectives of Services Marketing, L.L. Berry, G.L. Shostak, and G.D. Upch, eds. Chicago, IL: American Marketing Association, 25-38. 
., Lewis P. Carbone, and Stephen H. Haeckel (2002), "Managing the Total Customer Experience," MIT Sloan Management Review, 43 (3), 85-89.

Binggelli, Urs, Sanjay Gupta, and Carlos De Pommes (2002), "CRM in the Air," The McKinsey Quarterly, 3, 6-11.

Blattberg, R.C. and J. Deighton (1991), "Interactive marketing: exploiting the age of addressability," Sloan Management Review, (Fall), 5-14.

(1996), "Manage Marketing by the Customer Equity

Test," Harvard Business Review, (July-August), 136-144.

Bligh, Phil, Doug Turk (2004), "Cashing In on Customer Loyalty," Customer Relationship Management, 8 (6), 48-52.

Boles, James S., Barry J. Babin, Thomas G. Brashear, and Charles Brooks (2001), “An Examination of the Relationships between retail work environments, Salespersons Selling Orientation-Customer Orientation and Job Performance," Journal of Marketing Theory and Practice, 9 (3), 1-13.

Bose, R. (2002), "Customer Relationship Management: Key Components for IT Success," Industrial Management and Data Systems, 102 (2), 89-97.

Boynton, A. (1993), "Achieving Dynamic Stability through Information Technology," California Management Review, 35 (2), 58-78.

Brady, Mairead, Mike Saren, and Nikos Tzokas (2002), "The Assimilation of IT into Marketing Practice," Irish Marketing, 15 (2), 17-29.

Brendler, William F. (2001), "8 Critical Factors that Make or Break CRM," Target Marketing, 24 (4), 57-62.

Brown, Tom J., John C. Mowen, D. Todd Donavan, and Jane W. Licata (2002), "The Customer Orientation of Service Workers: Personality Trait Effects on Self and Supervisor Performance Ratings," Journal of Marketing Research, 39 (1), 110120.

Bush, Alan J., Jarvis B. Moore, and Rich Moore (2005), "Understanding the Salesforce Automation Outcomes," Industrial Marketing Management, 34, 369-377.

Buttle, F. (1996), Relationship Marketing: Theory and Practice. London: Paul Chapman.

Campbell, Alexandra (2003), “Creating Customer Knowledge Competence: Managing Customer Relationship Management Programs Strategically,” Industrial Marketing Management, 32, 375-383. 
Campbell, Scott (2001), “CRM Saviors,” CRN, 944, 30-34.

Cao, Yong and Thomas S. Gruca (2005), "Reducing Adverse Selection Through Customer Relationship Management," Journal of Marketing, 69 (October), 219229.

Cespedes, Frank V. and Smith H. Jeff (1993), "Database Marketing: New Rules for Policy and Practice," Sloan Management Review, 34 (4), 7-22.

Chen, Injazz J. and Karen Popovich (2003), "Understanding Customer Relationship Management (CRM): People, Process and Technology," Business Process Management Journal, 9, 5, 672-688.

Cherkassky, Irene (2005), "Better Access to Customer Data Fuels VIP Business," Target Marketing, 28 (3), 21.

Cholewka, Kathleen (2000), “Tiered CRM: Serving Pip-squeaks to VIP's,” Sales \& Marketing Management, (April), 25-26.

(2001), “CRM: Lose the Hype and Strategize," Sales \& Marketing Management, (June), 27-28.

Chonko, Lawrence B., Eli Jones, A. Roberts, and Alan Dubinsky (2002), "The Role of Environmental Turbulence, Readiness for Change, and Salesperson Learning in the Success of Sales Force Change," Journal of Personal Selling and Sales Management, 4 (fall), 227-245.

Christopher, M., A. Payne, and D. Ballantyne (1991), Relationship Marketing. Oxford: Butterworth-Heinemann.

Colgate, Mark R. and Peter J. Danaher (2000), "Implementing a Customer Relationship Strategy: The Asymmetric Impact of Poor Versus Excellent Execution," Academy of Marketing Science Journal, 28 (3), 375-387.

Colletti, Jerome A. and Lawrence B. Chonko (1997), "Change Management Initiatives: Moving Sales Organizations from Obsolescence to High Performance," The Journal of Personal Selling and Sales Management, 17 (2), 1-30.

CRM Guru (2003), "What is CRM?," http:// www.crmguru.com/content/answers/whatiscrm.html

Crosby, Lawrence A. and Sheree L. Johnson (2002), "CRM and Management," Marketing Management, 11 (1), 10-11. 
Cross, Rob, Wayne Baker, and Andrew Parker (2003), "What Creates energy in Organizations," MIT Sloan Management Review, 44 (4), 51-56.

Croteau, A. M. and P. Li (2003), "Critical success factors of CRM technological Initiatives," Canadian Journal of the Administrative Sciences, 20 (1), 21-34.

Davenport, T. H. and M. C. Beers (1995), "Managing Information about Processes," Journal of Management Information Systems, 12, 57-80.

Davids, Merly (1999), "How to Avoid the 10 Biggest Mistakes in CRM," The Journal of Business Strategy, 20 (6), 22-26.

Davies, L. and G. Mitchell (1994), "The Dual Nature of the Impact of IT on organizational Transformation,"," in Transforming Organisations with Information Technology, Baskerville, R.S. Smithson, O. Ngwenyama, and J. DeGross, eds. Amsterdam: Elsevier Science, 243-262.

Davidson, E.J. (1997), "Examining Project History Narratives: An Analytic Approach" in Information Systems and Qualitative Research, A.S. Lee, J. Liebenau, and J.I. DeGross, eds. London: Chapman \& Hall, 123-148.

Day, George S. (1994), “The Capabilities of Market-Driven Organizations," Journal of Marketing, 58 (October), 37-52.

. (1999), The Market Driven Organization. New York: The Free Press.

. (2000a), "Managing Market Relationships," Journal of the Academy of Marketing Science, 28 (1), 24-30.

. (2000b), “The Market-Driven Organization,” Direct Marketing, 62 (9), 32-

37.

. (2000c), “The Market-Driven Organization,” Direct Marketing, 62 (10), 20-24.

. (2003), "Creating a Superior Customer-Relating Capability," MIT Sloan Management Review, (Spring), 77-82.

and Christopher Van den Bulte (2002), "Superiority in customer relationship management: Consequences for competitive advantage and performance," MSI Report, 02-123.

Deck, S. (2003), “What is CRM?," http://www.cio.com/research/crm/edit/crmabc.html. 
Destination CRM (2002), "What is CRM?,"

http://www.destinationcrm.com/articles/default.asp?ArticleID = 1747

Dibb, Sally and Maureen Meadows (2004), "Relationship Marketing and CRM: A

Financial Services Case Study," Journal of Strategic Marketing,

$12,111-125$.

Dickson, Peter R. (2003), “The Pigeon Breeders' Cup: A Selection On Selection Theory of Economic Evolution," Journal of Evolutionary Economics, 13, 259-280.

., Gary Hunter, Walfried Lassar, Paul Root, and Samit Chakravorti (2005), "CRM Organization," Working Paper of the Department of Marketing, Florida International University.

Dickie, Jim (2003), “Key Factors for Optimizing CRM Project Success," in Defying the Limits: The CRM Project, 4, San Francisco: Montgomery Research Inc., 59-62.

Douzou, S. and J. Legare (1994), "Network-Based Information Systems, Professional Culture, and Organisation dynamics: A Multiple Case Study in the Health Care Sector," ," in Transforming Organisations with Information Technology, Baskerville, R.S. Smithson, O. Ngwenyama, and J. DeGross, eds. Amsterdam: Elsevier Science, 263-276.

Fairhurst, P. (2001), “E-CRM,” Journal of Database Marketing, 8 (2), 137- 142.

Fleischer, Joe, Warren S. Hersch, and Lee Hollman (2001), "Embodying CRM," Call Center Magazine, 14 (9), 50-62.

Fletcher, Keith and Linda Peters (1996), "Issues in Customer Information Management," Journal of the Market Research Society, 38 (2), 145-161.

Foss, B. and M. Stone (2001), Successful Customer Relationship Marketing. London: Kogan Page.

Frantz, Bryan and Gordon McDougall (2004), "Assessing the Potential of Customer Relationship Management: Clarifying the Decision," Service Marketing Quarterly, 26 (1), 1-17.

Freeland, John G. (2004), “The Innovator's Advantage: A Customer Relationship Management Perspective," Accenture Consulting White Paper.

(2001). "CRM's New Frontier: Revitalizing Sales, Service, and Marketing,' in Defying the Limits: The CRM Project, 2, San Francisco: Montgomery Research Inc., 10-16. 
Galbreath, J. and T. Rogers (1999), "Customer relationship leadership: A leadership and motivation model for the twenty-first century business," The TQM Magazine, 11 (3), 161- 171.

Gefen, D. and C.M. Ridings (2002), "Implementation team responsiveness and user evaluation of customer relationship management: A quasi experimental design study of social exchange theory," Journal of Management Information Systems, 19 (1), 47-69.

Gordon, Ian (2002), “Best Practices: Customer Relationship Management,” Ivey Business Journal Online, (November/December), 1.

Grant, R. M. (1991), “The Resource-based Theory of Competitive Advantage: Implication for Strategy Formulation," California Management Review, 33 (3), 114-135.

(1998), Contemporary Strategy Analysis ( $3^{\text {rd }}$ ed.). Malden: Blackwell.

Grant, Alan W.H. and Leonard A. Schlesinger (1995), "Realize Your Customer's Full Profit Potential," Harvard Business Review, (September-October), 59-72.

Greenberg, P. (2001), CRM at the Speed of Light. Berkeley: McGraw Hill.

Gregory, Marianne A. (2004), "Keys to Successful Performance Management," Business Intelligence Journal, 9 (1), 41-48.

Gronroos, C. (2000), Service management and marketing: A customer relationship management approach (2nd ed.). West Sussex: Wiley.

Gulati, Ranjay and James B. Oldroyd (2005), "The Quest for Customer Focus,” Harvard Business Review, (April), 92-101.

Gustafsson, Anders, Michael D. Johnson, and Inger Roos (2005), "The Effects of Customer Satisfaction, Relationship Commitment Dimensions, and Triggers on Customer Retention,” Journal of Marketing, 69 (October), 210-218.

Haeckel, S.H. and R.H. Nolan (1993), "Managing by Fire," Harvard Business Review, (September-October), 22-32.

Han, Jin K., Namwoon Kim , Rajendra K Srivastava (1998), "Market Orientation and Organizational Performance: Is Innovation a Missing Link," Journal of Marketing, 62 (4), 30-46.

Hasan, M. (2003), "Ensure success of CRM with a change in mindset," Marketing Management, 37 (8), 16. 
Hansen, Morten T. and Nitin Nohria (2004), "How to Build Collaborative Advantage," MIT Sloan Management Review, 46 (1), 22-30.

Hartline, Michael D., James G. Maxham III, and Daryl O McKee (2000), "Corridors of Influence in the Dissemination of Strategy to Customer Contact Service Employees," Journal of Marketing, 64 (2), 35-50.

Hoffman, Douglas K. and Thomas N. Ingram (1992), "Service Provider Job Performance and Customer-Oriented Performance," Journal of Services Marketing, 6 (2), 6879.

Holland, Christopher P. and Pete Naude (2004), "The Metamorphosis of Marketing into an Information-Handling Problem," The Journal of Business and Industrial Marketing, 19 (3), 167-180.

Homburg, Christian, John P. Workman Jr., and Ove Jensen (2000), "Fundamental Changes in Marketing Organization: The Movement Toward a Customer-Focused Organizational Structure," Academy of Marketing Science Journal, 28 (4), 459478.

Hopkins, William S., Carter J.Lusher, and Britton Manasco (1999), "Can Technology Strengthen Customer Loyalty?," Sales \& Marketing Management, (September), S4.

Jabali, Terry (2003), "Relationship Dynamics: The Savior of CRM," Intelligent Enterprise, 6 (16), 31-35.

Jarratt, Denise (2004), “Conceptualizing a Relationship Management Capability," Marketing Theory, 4 (4), 287-309.

Jayachandran, Satish, Subhash Sharma, Peter Kaufman, and Pushkala Raman (2005), "The Role of Relational Information Processes and Technology Use in Customer Relationship Management," Journal of Marketing, 69 (October), 177-192.

Kale, Sudhir H. (2004), "CRM Failure and the Seven Deadly Sins," Marketing Management, (September/October), 42-46.

Kapanen, Robert (2004), "Customer Relationship Management and Service Delivery," Int. J. Services Technology and Management, 5 (1), 42-55.

Kavanagh, Shayne (2003), "Planning for CRM Success," Government Finance Review, (August), 39-45.

Kaydo, Chad (1999),'Friend or Foe?," Sales and Marketing Management, (March), 4345. 
Kennedy, Karen Norman, Jerry R. Goolsby, and Eric J. Arnould (2003), "Implementing a Customer Orientation: Extension of Theory and Application," Journal of Marketing, 67 (October), 67-81.

Kim, J., E. Suh, and H. Hwang (2003), "A model for evaluating the effectiveness of CRM using the balanced scorecard," Journal of Interactive Marketing, 17 (Spring), 5-19.

Kohli, R., F. Piontek, T. Ellington, T. VanOsdol, M. Shepard, and G. Brazel (2001), "Managing Customer Relationships Through E-business Decision Support Applications: A Case of Hospital-Physician Collaboration," Decision Support Systems, 32 (2), 171-187.

Kracklauer, A., O. Passenheim, and D. Seifert (2001), "Mutual Customer Approach: How Industry and Trade are Executing Collaborative Customer Relationship Management," International Journal of Retail and Distribution Management, 29 (12), 515-519.

Krippendorf, Klaus (1980), Content analysis : an introduction to its methodology. Beverly Hills: Sage Publications.

Kumar, Suresh (2004), “Missing in Action! CRM's Failure is not Intrinsic to it but Lies in its Deployment. The Concept is not about Technology, it's about Service: CRM Lies in Ensuring Good Customer Care," Business Line, (January 15), 1-3.

Kumar, V. and Denish Shah (2004), "Building and Sustaining Profitable Customer Loyalty for the $21^{\text {st }}$ Century," Journal of Retailing, 80, 317-330.

Langerak, Fred and Peter C. Verhoef (2003), "Strategically Embedding CRM," Business Strategy Review, 14 (3), 73-80.

Light, Ben (2003), "CRM Packaged Software: A Study of Organizational Experiences," Business Process Management Journal, 9 (5), 603-616.

Lorge, Sarah (1998), "Teaching Support People to Sell," Sales and Marketing Management, (July), 78.

Majchrzak, Ann and Qianwei Wang (1996), "Breaking the Functional Mind-Set in Process Organizations," Harvard Business Review, (September-October), 93-99.

McGovern, Todd and Joseph Panaro (2004), “The Human Side of Customer Relationship Management," Benefits Quarterly, 20 (3), 26-33. 
Mithas, Sunil, M.S.Krishnan, and Claes Fornell (2005), "Why do Customer Relationship Management Applications Affect Customer Satisfaction," Journal of Marketing, 69 (October), 201-209.

Mohamed, Mirghani, Michael Stankosky, and Arthur Murray (2004), “Applying Knowledge Management Principles to Enhance Cross-Functional Performance," Journal of Knowledge Management, 8 (3), 127-142.

Morgan, Amy J. and Scott A. Inks (2001), "Technology and the Salesforce: Increasing Acceptance of Salesforce Automation," Industrial Marketing Management, 30 (5), 463

Narver, John C. and Stanley F. Slater (1990), "The Effect of a Market Orientation on Business Profitability," Journal of Marketing, 54 (4), 20-36.

Naude, P. and C.P. Holland (1996), "Business-to-Business Marketing," in Relationship Marketing: Theory and Practice, F.Buttle, eds. London: Paul Chapman, 40-54.

O'Halloran, Patrick J. and Patrick Mosher (2003), "Marketing: Underrated, Undervalued and Unimportant," in Defying the Limits: The CRM Project, 4, San Francisco: Montgomery Research Inc., 74-78.

Olsen, Ellen (2001), “CRM: Go Deep," Sales and Marketing Management, (July), 23-24. Pantazopoulos, A., (2003), "What's really CRM," http://www.crm2day.com/what is_crm/

Paas, Leonard and Tom Kuijlen (2001), "Towards a General Definition of Customer Relationship Management," Journal of Database Management, 9 (1), 51-60.

Park, C.H. and Y.G. Kim (2003), “A Framework of Dynamic CRM: Linking Marketing with Information Strategy,” Business Process Management Journal, 9 (5), 652671.

Payne, Adrian and Pennie Frow (2005), "A Strategic Framework for Customer Relationship Management," Journal of Marketing, 69 (October), 167-176.

(2004), "The Role of Multichannel Integration in Customer Relationship Management," Industrial Marketing Management, 33, 527-538.

Peck, H., A. Payne, M. Christopher, and M. Clark (1999), Relationship Marketing: Strategy and Implementation. Oxford: Butterworth-Heinemann.

Peppers, D. and Rogers, M. (1993), The One-to-One Future: Building Relationships One Customer at a Time. Garden City, NY: Doubleday. 
, M. Rogers, and B. Dorf (1999), "Is your company ready for one-to-one marketing?," Harvard Business Review, 77 (1), 101-119.

Peters, Linda (1997), "IT Enabled Marketing: A Framework for Value Creation in Customer Relationships," Journal of Marketing Practice, 3 (4), 213-228.

Petersen, Glen S. (2004), "CRM Success and Best Practices: A Wake up Call," www.technology-evaluation.com/ResearchHighlights/crm, $\left(\right.$ October $21^{\text {st }}, 22^{\text {nd }}$ ).

Phillips, D. (1998), "The Social Construction of a Secure, Anonymous Electronic Payment System: Frame Alignment and Mobilization Around Ecash," Journal of Information Technology Special Issue on Interpretive Research in Information Systems, 13 (4), 273-284.

Pitta, Dennis A. (1998), "Marketing One-to-One and its Dependence on Knowledge Discovery in Databases," Journal of Consumer Marketing, 15 (5), 468-482.

Plakoyiannaki, E. and N. Tzokas (2002), "Customer relationship management: A capabilities portfolio perspective," Journal of Database Marketing, 9 (3), 228237.

Plouffe, Christopher R., Brian C. Williams, and Thomas W. Leigh (2004), "Who's on First? Stakeholder Differences in Customer Relationship Management and the Elusive Notion of "Shared Understanding"," Journal of Personal Selling and Sales Management, 24 (4), 323-338.

Porter, M.E. (1984), Competitive Advantage. New York: The Free Press.

Pries, Christina and Merlin Stone (2004), "Managing CRM Implementation with Consultants-CRM or Change Management," Journal of Change Management, 4 (4), 351-370.

Reinartz, Werner J. and V. Kumar (2000), "On the Profitability of Long-Life Customers in a Noncontractual Setting: An Empirical Investigation and Implications for Marketing," Journal of Marketing, 64 (October), 17-35.

Harvard Business Review, (July), 86-94.

(2002), "The Mismanagement of Customer Loyalty," (2003), "The Impact of Customer Relationship Characteristics on Profitable Lifetime Duration," Journal of Marketing, 64 (January), 77- 99. 
, M. Krafft, and W.D. Hoyer (2004), "The Customer Relationship Management Process: Its Measurement and Impact on Performance," Journal of Marketing Research, 41 (August), 293-305.

, Jacquelyn S. Thomas, and V. Kumar (2005), "Balancing Acquisition and Retention Resources to Maximize Customer Profitability," Journal of Marketing, 69 (January), 63-79.

Rigby, Darrell. K., F.F. Reichheld, and P. Schefter (2002), "Avoid the four perils of CRM," Harvard Business Review, 80 (February), 101- 109. . and Dianne Ledingham (2004), "CRM Done Right," Harvard Business Review, (November), 118-129.

Ryals, Lynette (2005), "Making Customer Relationship Management Work: The Measurement and Profitable Management of Customer Relationships," Journal of Marketing, 69 (October), 252-261.

Salesboom (2005), "History of CRM: From Ancient Clay Tablets, to on demand hosted CRM solutions of today," www.salesboom.com/company/history of crm.html.

Sawhney, Mohanbir and Jeff Zabin (2002), "Managing and Measuring Relational Equity in the Network Economy," Academy of Marketing Science Journal, 30 (4), 313332.

Sheth, Jagdish N., D. Garden, and D. Garrett (1988) Marketing Theory: Evolution and Evaluation. New York, NY: John Wiley. . (2002), "The Future of Relationship Marketing," The Journal of Services Marketing, 16 (7), 590-593.

Seybold, Patricia B. (2001), "Get Inside the Lives of your Customers," Harvard Business Review, (May), 81-89.

Shoemaker, M. E. (2001), “A framework for examining IT-enabled market relationships," Journal of Personal Selling and Sales Management, 21 (2), 177185 .

Shultz, Don E. (2000), “Learn to Differentiate CRM's two faces," Marketing News, 34 (Nov 20), 11-11.

Siebel (2001), "Why CRM? The Business Case for Customer Relationship Management," Siebel Systems white paper, November, 1-18. 
Siebel (2002), “CRM Integration across Marketing, Sales and Service," Siebel Systems white paper, December, 1-25.

Siguaw, Judy A., Gene Brown, and Robert E II Widing (1994), "The Influence of the Marketing Orientation of the Firm on Salesforce Behavior and Attitudes," Journal of Marketing Research, 31 (1), 106-117.

Sims (2005), "Today in CRM History," blog.tmcnet.com/telecom-crm/ archives/2005/04/18/today-in-crm-history.asp, (April 18).

Sowalskie, Rodney (2001), "The Five CRM Essentials for Insurance," National Underwriter (Life and Health/Financial Services Edition), (July 9), 24 -27.

Srivastava, R. K., T.A. Shervani, and L. Fahey (1999), "Marketing, business processes, and shareholder value: An organizationally embedded view of marketing activities and the discipline of marketing," Journal of Marketing (Special Issue), $63,168-179$.

Swift, Ronald S. (2003), “ The Rules Have Changed,” Teradata Magazine, 1Q 35-39.

Tan, X., D.C. Yen, and X. Fang (2002), "Internet integrated customer relationship management," Journal of Computer Information Systems, 77-86.

Thomas, Jaccquelyn S. and Ursula Y. Sullivan (2005), "Managing Marketing Communications with Multichannel Customers," Journal of Marketing, 69 (October), 239-251.

Thompson, Bob (2005), "The Loyalty Connection: Secrets to Customer Retention and Increased Profits," (March), www.crmguru.com.

Tuzovic, Sven and Manfred Bruhn (2005), "Integrating Customer Orientation, Employee Compensation and Performance: A Conceptual Framework,” Int. J. Business Performance Management, 7 (3), 255-274.

Vandenbosch, Mark and Niraj Dawar (2002), "Beyond Better Products: Capturing Value in Customer Interactions," MIT Sloan Management Review, 43 (4), 34-42.

Vandermerwe, Sandra (2000), "How Increasing Value to Customers Improves Business Results," MIT Sloan Management Review, 42 (1), 27-37.

Venkatesan, Rajkumar and V. Kumar. (2004), "A Customer Lifetime Value Framework for Customer Selection and Resource Allocation Strategy," Journal of Marketing, 68 (October), 106-125. 
Verhoef, P. C. and B. Donkers (2001), "Predicting customer potential value: An application in the insurance industry," Decision Support Systems, 32 (2), 189199.

Verity, J.W. (1995), “The Networked Corporation,” Business Week, (26 June), 45-55.

Weber, Robert P. (1990), Basic Content Analysis. Newbury Park, CA: Sage Publications.

Wehmeyer, Kai (2005), “Aligning IT and Marketing-The Impact of Database Marketing and CRM," Database Marketing and Customer Strategy Management, 12 (3), 243-256.

Williams Michael R. (1998), "The Influence of Salespersons' Customer Orientation on Buyer-Seller Relationship Development," The Journal of Business and Industrial Marketing, 13 (3), 271-287.

Winer, Russell S. (2001), "A Framework of Customer Relationship Management," California Management Review, 43 (4), 89-105.

Xeveloankis, Evangelos (2005), "Developing Retention Strategies Based on Customer Profitability in Telecommunications," Database Marketing and Customer Strategy Management, 12 (3), 226-242.

Yim, Frederick Hong-kit, Rolph E. Anderson, and Srinivasan Swaminathan (2004), "Customer Relationship Management: Its Dimensions and Effect on Customer Outcomes," 24 (4), 263-278.

Yu, Larry (2001), "Successful Customer Relationship Management," MIT Sloan Management Review, 42 (4), 18-19.

Zablah, Alex R., Danny N. Bellenger, and Wesley J. Johnston (2004), “An Evaluation of Divergent Perspectives on Customer Relationship Management: Towards a Common Understanding of an Emerging Phenomenon," Industrial Marketing Management, 33, 475-489.

Zeithmal, Valerie A., Roland Rust, and Katherine N. Lemon (2001), "The Customer Pyramid: Creating and Serving Profitable Customers," California Management Review, 43 (4), 119-142. 


\title{
APPENDIX I
}

\author{
HTTP://CRM.FIU.EDU
}

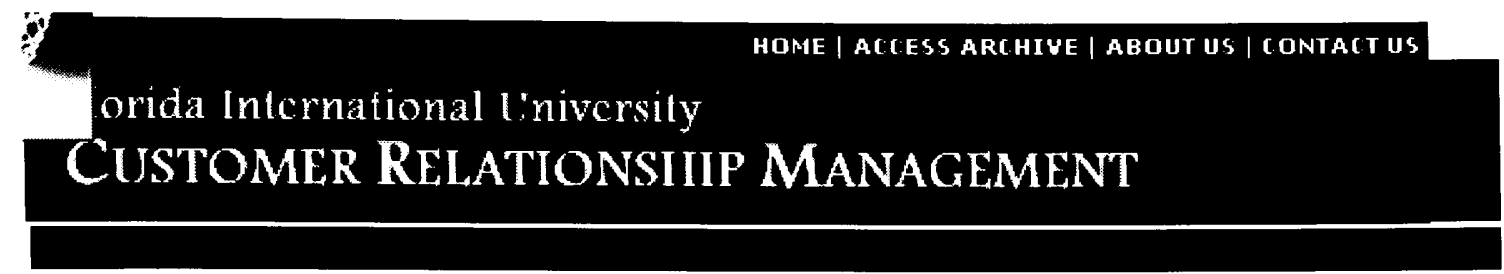

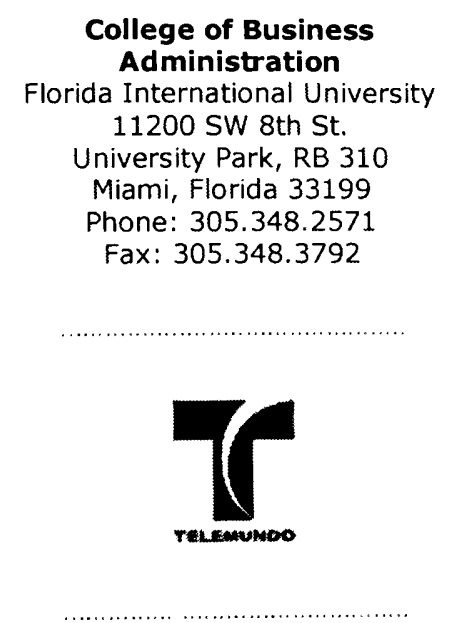

\section{CRM Links}

- Home

- Access Archive

- About Us

- Contactus

\section{Welcome to the FIU Collaborative} Customer Relationship Management (CRM) Strategy Research Archive. This archive is a joint collaboration effort by a number of marketing scholars at College of Business Administration.

This archive contains a comprehensive database of academic and industry research examining the effect of CRM on US industries. To learn more about the archive, how to access research abstracts, and how to submit new research, , click here.

- Access Archive

- About Us

- Contact Us

Home I Access Archive I About Us I Contact Us

Copyright $\odot 2004$ FIU College of Business Administration Phone: 305.348.2571 | Fax: 305.348.3792 


\section{APPENDIX II}

\section{ARTICLE ABSTRACT SAMPLES}

\section{$\underline{\text { CRM Done Right }}$}

Darrell K.Rigby and Dianne Ledingham

Harvard Business Review, November 2004, 118-129.

\section{Abstract}

The authors describe how investment.in CRM dropped by $40 \%$ between 2000 and 2003 according to Gartner research but is increasing again. Why? It is because firms are taking "a pragmatic, disciplined approach to CRM, launching highly focused projects that are relatively narrow in their scope and modest in their goals. Rather than use CRM to transform entire businesses, they've directed their investment toward solving clearly defined problems within the customer relationship cycle - the series of activities that runs from initial segmenting and targeting of customers all the way through to wooing them back for more." (p. 118). The success of the initial focused project is used as a springboard for the next CRM project. The authors then describe several case studies:

Wanting to be the premier supply-chain supplier of aircraft parts Aviall greatly improved its order-entry from 11 screens and 50 steps to one screen and 10 steps. This and improvement in salesforce and call center coordination tripled the number of sales calls and the customer base grew by $33 \%$.

Kimberly-Clark greatly improved its retailer promotions by developing a real-time analysis of a promotion's effect on sales and profits... and discovered that some of its promotions were twice as profitable as others. 
Ingersoll-Rand used CRM technology to enable sales-people to sit down with customers and design a golf-cart order, immediately supplying a price quote and delivery date.

Molex used its CRM system to better manage its order pipe-line which was a mess. Brother had a problem with product returns at $5 \%$. By reorganizing its call-centers around product expertise with standard responses to common problems. Returns were reduced by one third and the new CRM system is providing valuable information to product development about problems and suggested solutions and to the teams developing the product instruction brochures.

Experience common across all these successful companies and which the authors also stress is that just as it is vital to consider "strategic" CRM process targets without consideration of which "....the organization will be hard-pressed to summon the vigor necessary to tackle entrenched business processes or retool its organizational structure and garner expected returns.", it is equally important to have a relatively narrow focus in the beginning so that employees will become familiar with the system ".... without being overwhelmed, deliver quick wins and help garner broader management and line support down the road."

The advantage of a narrowly focused CRM initiative lies in that it opens up additional opportunities for important business refinements. "And all that business refinements taken together can amount to a broad CRM application that extends across the company." Brother International's initial CRM effort in call centers enhanced its marketing and outreach campaigns and later enhanced its product development and 
quality control processes. Molex's order pipeline enhancement led to improvements in budgeting, procurement and supply chain management.

The authors point out that all processes do not need to be controlled with a realtime system's control process: “A hotel manager certainly needs real-time data on the availability of rooms but not on the customer's opinion of the carpets and drapes." (p. 122). In short, the CRM system and information requirements should be designed around management decision-making needs: "and the keys to successful implementation are also becoming familiar: strong executive and business-unit leadership, careful strategic planning, clear performance measures, and a coordinated program that combines organizational and process changes with the application of new technology." (p. 129) Abstracter comments:

This is an important applied paper that points out that a common sense, problem solving approach needs to be taken with the implementation of CRM. It points out the high complexity and cost of implementing CRM organization wide This underscores firms' limited capability to change and that the change should be a step by step process, building on each previous project. . Interesting and instructive as the stories of the companies and their actions (process changes, technology installations and training)are it would have been still more so to learn how senior leadership cultivated a customer oriented culture. Another concern which the authors do not address is the integration of systems scattered around the organization which is important for having the 360 degree view about the customer. If technology is installed to correct only the pain points how does this integrate with the other systems when additional opportunities come up for important business refinement in other parts of the organization. 
Peter Dickson \& Samit Chakravorti

\section{$\underline{\text { CRM Integration across Marketing, Sales and Service }}$}

Siebel eBusiness, December 2002

Abstract

“Today's organizations increasingly seek to drive corporate performance by maximizing the value of their customer relationships. Beyond technology, however, many companies fail to appreciate the importance of developing specific, well-defined, and integrated business processes focused on the customer."

"When revising CRM processes, it is critical to note that these processes span across marketing, sales, and service functions affecting employees, partners, and customers at all points of interaction in the relationship cycle.” For example, CRM requires changes in employee relationship management through selecting and hiring new Analytical CRM skills, training new skills and aligning rewards to measured CRM performance. Similarly partner management programs need to be adapted to CRM systems' control and management. In short, higher-level employee and partner management processes need to be revamped and realigned.

Siebel the lays out how CRM changes across:

\section{Marketing processes}

Analytic CRM: "Customer and transaction analysis empowers users to leverage all existing data across the organization, provides real-time reporting and insight into all customer and business activities, and is integrated into all other customer-facing processes to varying degrees. This process focuses on providing key constituents in an 
organization with a comprehensive view of customer behavior, preferences, and trends, typically extracted from disparate sources such as operational, analytical, and legacy systems." (p. 11)

Customer segmentation: An effective segmentation process is one that uses customer profiling, customer profitability analysis, churn/retention analysis, and behavior analysis. Armed with intelligence about who customers are, what they want, how they want to interact, and how valuable they are, companies can prioritize marketing decisions, budgets and initiatives that will yield the highest return on investment." (p. 9) What is described is a far more informed and indepth segmentation process that actually becomes a superior resource allocation process to increase product development, marketing, sales and customer service return on investment. Another advantage of the new segmentation process is that it is shared by everyone and becomes a day-to-day working consensus understanding of customer groups. This has to increase shared understanding and coordination of effort in-itself.

Campaign management: Closed loop feedback and learning is used to understand why and how results vary from goals, develop new campaigns and keep tracking and learning. "The key is to get the right content to the right person at the right time through all groups that interact with customers....When creating new content, companies should have processes in place to ensure that all new messages fit with the overall corporate messaging strategy and that these new documents go through the appropriate approval channels before being released to the public. Without this release process, companies run the risk of sending mixed messages and inaccurate branding to the marketplace, causing 
confusion and lost revenue opportunities." (p. 11). In short, CRM adds further systems control to the firm's integrated marketing communication processes.

\section{$\underline{\text { Sales processes }}$}

Sales management: The discipline and direction of capturing and using relevant information during sales calls improves personal selling processes such as initiating the relationship process, qualifying process and identification of supporters and key decision maker processes.

Sales forecasting: By knowing when deals are likely to be closed provide by CRM senior management can look much better down the pipeline and manage inventory and production.

Account management: "Once a dialogue has been established with a company, it is critical to establish an institutional repository of all account interactions (activity management), so that a company maintains the knowledge about an account vs. having that information reside only in the minds of particular account team members. This approach yields tremendous benefit to an organization by simplifying changes to account team structure, allowing new account team members to get up to speed quickly and avoiding lost institutional knowledge about an account if key mebers of an account team leave the company." (p. 13)

Order management: By integrating ordering processes through the web, call centers and the field the order process becomes more automated, tracked and controlled. By having the customer purchase behavior in the CRM data-base, it also becomes more transparent. 


\section{$\underline{\text { Customer Service Processes }}$}

Customer service is able to use CRM to prioritize service, understand the history of customer service problems and also add on site information to the data-base about questions, opportunities and cross-selling leads. Satisfaction needs to be tracked through surveys and "compensation for customer-facing employees should be tied directly to future customer satisfaction scores." (p. 19)

Success factors Associated with Implementing Process Change

1. Powerful and influential supporters champion the project.

2. Identify key reasons for implementing change such as solving a problem or pursuing an opportunity.

3. Senior management need to develop a blueprint and track progress.

4. Understand the process change pessimism dip.

5. Provide regular, open communication about progress to keep the initiative front and center in employees' minds and make them feel part of the change process by encouraging questions, concerns and suggestions.

6. Provide coaching and training

7. Align incentives to the desired behavior and make sure management walks the talk.

8. Measure the change from baseline performance and establish interim goals to avoid the change effort straying off course.

Abstracter comments:

This is an excellent summary of Siebel's "learnings" about how marketing, sales and service processes must change to get the most out of CRM. It does not actually talk 
about the integration of Marketing, Sales and Service organizationally but rather about how the intra-function processes of marketing, sales and service should change. Has interesting insights into how segmentation does not just become deeper and more fact based but also a resource deployment process. Also CRM introduces new system's control into a firms integrated marketing communication, personal selling, forecasting and customer service. The section on implementation is a very sound, text book list of things to do when managing organization change. But it does not talk about how to realign existing people, organization and politics that can all frustrate change.

“Companies must not rework or revise processes piecemeal. Instead of revising customer-facing processes one by one, companies should analyze the interrelationships and dependencies between processes. Processes do not exist in isolation; therefore, ignoring how a process works in conjunction with other processes across the organization's ecosystem results in both inter- and intra-departmental bottlenecks, mismanaged handoffs between groups, misinformed participants across an organization, and even worse, completely uninformed participants." (p. 7)

This requires a lot of process thinking about how to fit build the new processes, business rules and workflow around technology, people, and teams. 
An Evaluation of Divergent Perspectives on Customer Relationship Management:

Towards a Common Understanding of an Emerging Phenomenon

Alex R. Zablah, Danny N. Bellenger \& Wesley J. Johnston

Industrial Marketing Management, 33 (2004), 475-489.

\begin{abstract}
In this article the authors have made a concerted effort to reconcile the divergent perspectives about CRM into a common conceptualization of the CRM process and put forth a generalized recipe for CRM success.
\end{abstract}

The article can be divided into three distinct segments. The first part conceptualizes what CRM essentially, stands for and integrates the different perspectives to come to a common definition. That is followed by the second part where the authors conceptualize the interlinked processes necessary to achieve the goal of CRM and finally in the third segment they lay down a framework for successful CRM implementation. CRM has been conceptualized as a process, strategy, philosophy, capability and last but not the least as technology. The authors take the process view, primarily because it includes the essences of the other perspectives in the form of input and output processes (resource allocation processes, continuous learning processes, technology processes) necessary to achieve the goals of a CRM process and thus defined CRM as an “... ongoing process that involves the development and leveraging of market intelligence for the purpose of building and maintaining a profit-maximizing portfolio of customer relationships."

The CRM process is concerned with the creation of market intelligence and utilizing such intelligence to achieve the objective of profit-maximizing portfolio of 
customer relationships. The corresponding two processes proposed by the authors are those of knowledge management and interaction management respectively. Knowledge management helps develop market intelligence and aids in segmentation of customers according to their relationship preferences and their value to the organization. This intelligence is then brought to bear selectively on interactions with customers to enhance buyer-seller relationships through mutual benefit.

Both these processes are dependent to a great extent on the technological and more critically on the human resources of the firm. Integrating data from various customer interactions, segmenting customers profitably, sharing intelligence, and utilizing that intelligence in maintaining quality and consistency of customer interactions across all touch points require cross-functional coordination and collaboration across marketing, sales and service as well as an organization wide customer orientated culture. Collaboration processes thus need to form a link between the knowledge management and interaction management processes for the CRM objective to be attained. Only senior management can instill such a culture.

In their proposed framework for CRM success the authors stress the importance of starting off with a CRM strategy stressing customer value, then defining processes and finally mapping capabilities on these processes and enhancing them on a continuous basis (learning and collaborative processes) to improve the productivity of customer relationship management through continuous learning and collaboration within processes, people and technology. 
Abstracters Comments

The article makes a contribution by aligning the divergent perspectives on CRM by giving a process definition of CRM with various input processes and output processes. The authors talk about knowledge management and interaction management processes as input processes. What they do not really talk about is the collaboration processes required to coordinate the people part of CRM. Successful implementation of knowledge management and interaction management will depend on a customer orientation of the people of the organization and coordination among them. So what is crucial to know is what activities an organization needs to engage in to collaborate better within itself. This can be successfully brought about only with senior management initiative.

Samit Chakravorti

The Market Driven Organization

George S. Day

Direct Marketing, Jan 2000, 62, 9 32-37 \& Feb 2000, 62, 10 20-23.

Abstract

In this article the author outlines six conditions that every successful marketdriven change management initiative will have to meet. These "..conditions will increase the odds of success of translating the concepts of the market-driven organization into reality." The author describes these conditions and the experiences of three companies' successful transformation into market-driven organizations. They are Owen Corning, Sears, Roebuck and Euro Tunnel. 
"In contrast with most other discussions of change, our focus is not on the leaders of the organization but on conditions that will enable their people to produce good results."

Through meeting these six conditions these three and other companies have been able to successfully overcome the obstacles to change programs appearing in the guise of absence of leadership, initiative burnout, stifling cultures, management turmoil, lack of urgency and poor implementation.

The six conditions are:

1. Demonstrate Leadership Commitment: Top leaders can signal their commitment with occasional direct interventions to help solve a customer's problems, spending time visiting customers and listening aggressively for their point of view and insisting on senior management doing the same, emphasizing customer and market issues and insisting on calibration of the performance of the business against the "best of breed".

“The CEO's of all three firms gave direction and meaning to the sense of urgency by setting aggressive targets for improvement. Martinez of Sears posed five new strategic priorities-core business growth, customer focus, cost reduction, responsiveness to local markets, and organizational and cultural renewal."

2. Understand the Need for Change: Companies have used two approaches to get deep understanding of the need for change to permeate the organization. 1) Expose employees to customer judgments about the product and service, and 2) solicit candid assessment by management about organizational effectiveness required to implement the change. 
"Sears established a customer task force that reviewed past survey data and conducted eighty focus groups to get direct feedback."

3. Mobilize Commitment: "Companies need to create an effective management team to mobilize commitment for change efforts. This team can be drawn together from mavericks inside the firm or-often more effective in a crisis situation-may include outsiders to bring fresh perspectives to the problem. Wherever it is drawn from the team must demonstrate the experience and credibility to gain the commitment of the entire organization."

"One of the main reasons Arthur Martinez was able to change Sears is that he changed most of the senior executive team, and most of the new appointees had no prior experience in retailing."

4. Shape the Vision: Strategic priorities need to have broad ownership and employee engagement for the change program to be successful. "An organization's members do best when there is a line-of-sight understanding between strategy for delivering superior customer value and their individual contributions." To help employees understand their proper role in the bigger picture Sears prepared learning maps which were discussed by teams of employees at "town hall meetings". In Eurotunnel about one third of the 3000 employees were involved in one of 87 cross-functional teams. "Many of the teams that addressed the needs of a customer segment included a customer such as a lorry owner." It is also advantageous to show early wins through grassroots hothouse experiments. They are less disruptive and will act as bottoms-up examples of success to follow. 
5. Align Structures, Systems and Incentives: The three most effective ways to institutionalize the change initiative are organizational and process redesign, systems support and incentives and rewards.

At Eurotunnel the company was reorganized around customers and processes. Customer facing groups are charged with creating credible superior value propositions for their segments like tourist travelers versus business travelers as well as lorry drivers and international trains.

"Crucial to an organizational redesign is "reengineering" the core value development and delivery processes and realigning them with supporting processes such as human resources.”

As far as incentives and rewards are concerned research unequivocally confirms that if change effort is to be taken seriously, the rewards and incentives have to be aligned. "Sears has taken the concept as far as any company by basing long-term executive compensation on nonfinancial as well as financial performance."

In order to properly focus on customers with the greatest life-time value it is important to have the complete picture of the customer. This calls for integration of legacy systems scattered throughout the organization.

6. Sustain the Change: Those responsible for change "..need to continuously create wins and disseminate these best practices, measure and assess progress (and assess the metrics used to measure), and keep attention focused on the process." "Companies need to find ways to turn episodic efforts at improvement into a discipline that is embedded in the culture." Development of early small wins, the 
dissemination of best practices and monitoring of performance against objectives need to be ongoing.

Such a change process does not happen over night and usually takes years. "The aim is to have a market-facing culture, distinctive capabilities for market sensing, marketrelating, and strategic thinking, and a configuration that can stay in alignment with an increasingly unpredictable market." .

Abstracter's comments:

An excellent article on Operational CRM that stresses the importance of change management to successful CRM implementation. The essence is to get employees coordinate and collaborate for the sake of the customers by demonstrating commitment, offering broad ownership of the initiative, re-engineering processes and restructuring the organization, integrating technology and aligning incentives with the core value proposition. This has to be ongoing so that the values and attitudes are institutionalized. Samit Chakravorti 


\section{SAMIT CHAKRAVORTI}

September 27, 1969

1993

1993-1998

$1999-2000$

2000

2000-2005
Born, Durgapur, India

B.S. Chemistry

Banaras Hindu University

Varanasi, India

Sales representative in India

Research Assistant

Department of Marketing

School of Management

State University of New York at Binghamton

Binghamton, New York

Masters in Business Administration

State University of New York at Binghamton

Binghamton, New York

Graduate Assistant

Department of Marketing

College of Business Administration

Florida International University

Miami, Florida

\section{PUBLICATIONS AND PRESENTATIONS}

Chakravorti, Samit, V. Daniels, and Walfried Lassar (2003), "Enhancing Inter-firm Performance through Internet Driven Management of Inter-organizational Knowledge and Resources," Proceedings of the 2003 Academy of Marketing Science Annual Conference.

Chakravorti, Samit (2005), “Internet Driven Sales Performance: An Investigation of the Effect of Internet Usage on Individual and Organizational Determinants of Sales Performance," Florida International University Scholarly Forum. 